Florida International University FIU Digital Commons

$11-5-2010$

\title{
Bilirubin: an Animal Pigment in the Zingiberales and Diverse Angiosperm Orders
}

Cary L. Pirone

Florida International University, carypirone@hotmail.com

DOI: $10.25148 /$ etd.FI10122201

Follow this and additional works at: https://digitalcommons.fiu.edu/etd

Part of the Biochemistry Commons, and the Botany Commons

\section{Recommended Citation}

Pirone, Cary L., "Bilirubin: an Animal Pigment in the Zingiberales and Diverse Angiosperm Orders" (2010). FIU Electronic Theses and Dissertations. 336.

https://digitalcommons.fiu.edu/etd/336

This work is brought to you for free and open access by the University Graduate School at FIU Digital Commons. It has been accepted for inclusion in FIU Electronic Theses and Dissertations by an authorized administrator of FIU Digital Commons. For more information, please contact dcc@fiu.edu. 


\section{FLORIDA INTERNATIONAL UNIVERSITY \\ Miami, Florida}

BILIRUBIN: AN ANIMAL PIGMENT IN THE ZINGIBERALES AND DIVERSE ANGIOSPERM ORDERS

A dissertation submitted in partial fulfillment of the

requirements for the degree of

DOCTOR OF PHILOSOPHY

in

BIOLOGY

by

Cary Lunsford Pirone 
To: Dean Kenneth G. Furton

College of Arts and Sciences

This dissertation, written by Cary Lunsford Pirone, and entitled Bilirubin: An Animal Pigment in the Zingiberales and Diverse Angiosperm Orders, having been approved in respect to style and intellectual content, is referred to you for judgment.

We have read this dissertation and recommend that it be approved.

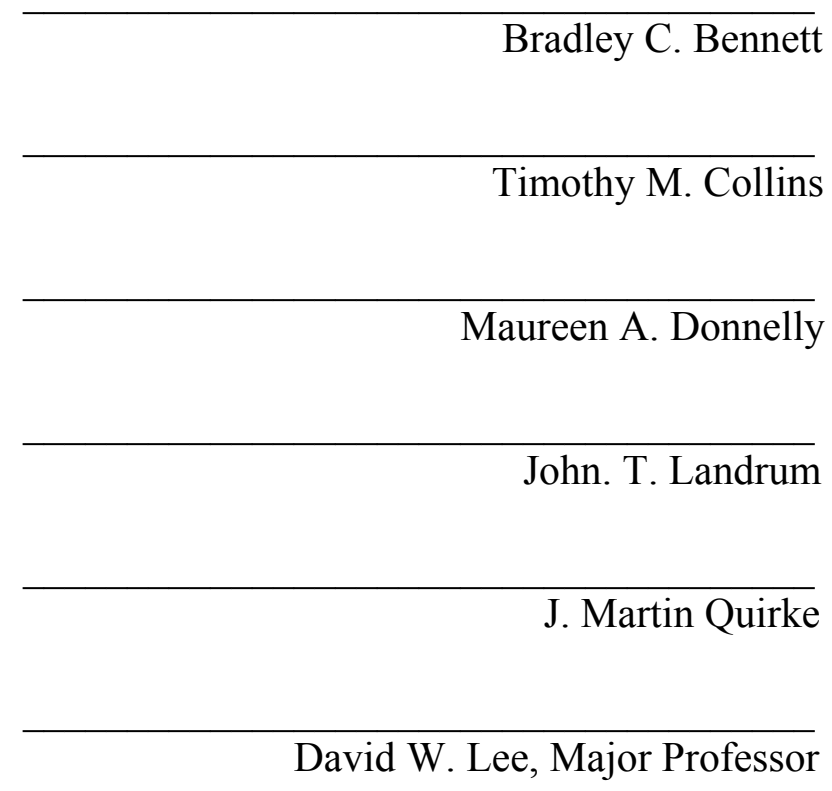

Date of Defense: November 5, 2010

The dissertation of Cary Lunsford Pirone is approved.

Dean Kenneth G. Furton

College of Arts and Sciences

Interim Dean Kevin O'Shea

University Graduate School

Florida International University, 2010 


\section{ACKNOWLEDGMENTS}

I am so appreciative of the network of friends, family, colleagues who have enabled me to complete my $\mathrm{PhD}$. I am grateful to my sister Miriam and niece Evelyn, whom I can not imagine living without, and to my Mom and Dad, whose love and support has never faltered.

I am grateful to my advisor, David Lee, who was always willing to listen and respond. Thank you for teaching me about the wonderful world of plant color, research, and life. I am also grateful to James Martin Quirke, who, regardless of my biology background, took countless hours in the lab to teach me chemistry and beyond with much patience and kindness. I would also like to thank Horacio Priestap, for his companionship in the lab and assistance with all things phytochemical, and Jodie Johnson, at UF, for his careful mass spectrometry analyses and discussions. Thanks to all of the above for being excellent collaborators on the bilirubin project.

I would also like to acknowledge the excellent teachers and committee members who have helped me along the way: Brad Bennett for his knowledge of ethnobotany and taxonomy, Jack Fisher and Jenny Richards for their insight regarding plant morphology, and Tim Collins, who has provided guidance in the field of phylogenetics. John Landrum shared his expertise in plant pigment chemistry, and Alvarro Velandia and Sylvia Smith generously provided space and training for my efforts to investigate the blue protein. Mo

Donnelly offered me encouragement and logistical support since my first day at FIU. Thanks also to Fernando Noriega and John Berry for making me feel welcome in their labs. Also, many thanks to everyone in the Biology office. 
I am also appreciative of the support I received through collaborators outside of FIU. Adam Green and Justin Ramsey at the University of Rochester provided lab space and advice for my phylogenetics work, as did John Kress and his lab at the Smithsonian Institute. Thanks.

Finally, my research would not have been possible without the many financial contributors: United States Environmental Protection Agency (EPA) -- Greater Research Opportunities (GRO) Graduate Fellowship, the Dissertation Year Fellowship (DYF) and the Doctoral Evidence Acquisition Fellowship (DEA) through FIU, the McBryde Science Program - National Tropical Botanical Garden, the RISE Biomedical Research Initiative (NIH), the Office of Research (OSRA) at FIU, and the Botanical Society of America (BSA) Travel Funds.

Chapters II, III, and IV have been published in the Journal of American Chemical Society, HortScience, and AoB Plants, respectively. Publishers have generously granted permission for the articles to be included as part of this dissertation. 


\title{
ABSTRACT OF THE DISSERTATION \\ BILIRUBIN: AN ANIMAL PIGMENT IN THE ZINGIBERALES AND DIVERSE \\ ANGIOSPERM ORDERS
}

\author{
by \\ Cary Lunsford Pirone \\ Florida International University, 2010 \\ Miami, Florida \\ Professor David W. Lee, Major Professor
}

Strelitziaceae is a tropical monocot family comprising three genera and seven species: Ravenala Adans and Phenkospermum Endl., which are monotypic, and five species of Strelitzia Aiton. All species produce woody capsular fruits that contain vibrantly colored arillate seeds. Arils of the Strelitzia species are orange, those of Phenakospermum are red, and those of Ravenala are blue. Unlike most plant pigments, which degrade after cell death, aril pigments in the family persist for decades. Chemical properties of the compounds are unusual, and do not match those of known pigment classes (carotenoids, flavonoids, betalains, and the chlorophylls). I isolated the orange pigment from the arils of Strelitzia nicolai, and performed HPLC-ESMS, UV-visible, ${ }^{1} \mathrm{H}$ NMR and ${ }^{13} \mathrm{C}$ NMR analyses to determine its chemical structure. These data indicated the pigment was bilirubin-IX, an orange-yellow tetrapyrrole previously known only in mammals and some other vertebrates as the breakdown product of heme. Although related tetrapyrroles are ubiquitous throughout the plant kingdom and include vital biosynthetic products such as chlorophyll and phytochromobilin, this is the first report of bilirubin in a plant, and 
evidence of an additional biosynthetic pathway producing orange coloration in flowers and fruits.

Given the unexpected presence of bilirubin, Iexamined the fruits and flowers of twelve additional angiosperm species in diverse orders for the presence of bilirubin using HPLC and LC-MS. Bilirubin was present in ten species from the orders Zingiberales, Arecales, and Myrtales, indicating its wide distribution in the plant kingdom. Bilirubin was present in low concentrations in all species except those within Strelitziaceae. It was present in particularly high concentrations in S. nicolai, S. reginae and P. guyannense, and is thus responsible for producing color in these species.

No studies have examined the evolutionary relationship among all species in the family. Thus, I also constructed a molecular phylogeny of the family. This information, combined with further studies on the distribution and synthesis of bilirubin in plants, will provide a basis for understanding the evolutionary history of this pigment in the plant kingdom. 


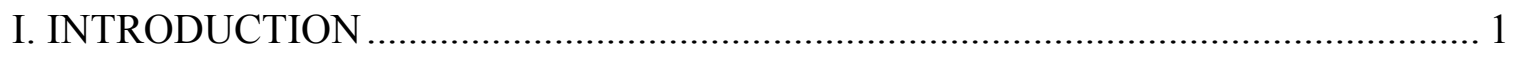

Major Pigment Pathways ............................................................................... 1

Minor Pigment Pathways ................................................................................. 3

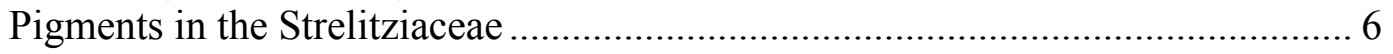

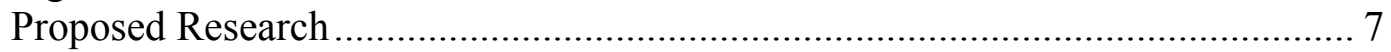

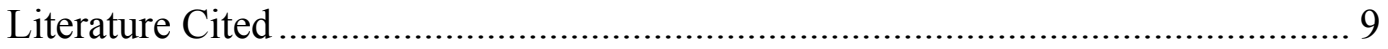

II. THE ANIMAL PIGMENT BILIRUBIN DISCOVERED IN PLANTS ……….......... 14

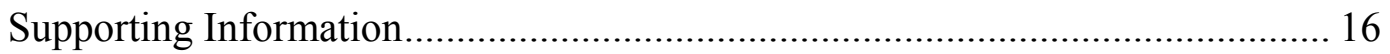

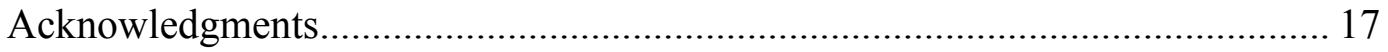

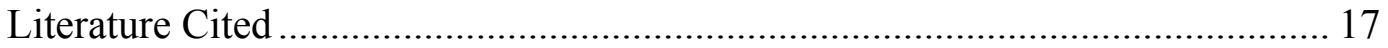

III. THE ANIMAL PIGMENT BILIRUBIN IDENTIFIED IN STRELITZIA REGINAE,

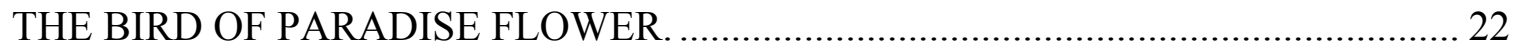

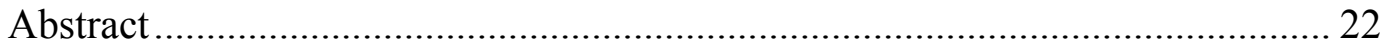

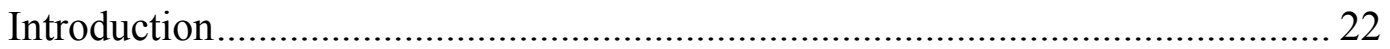

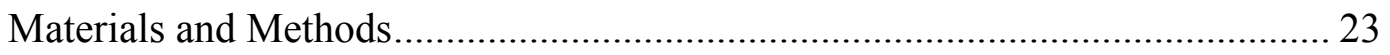

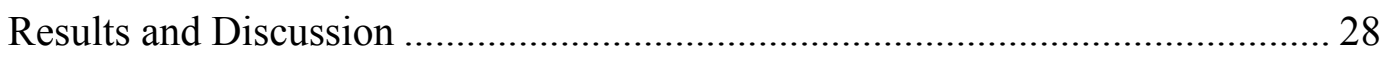

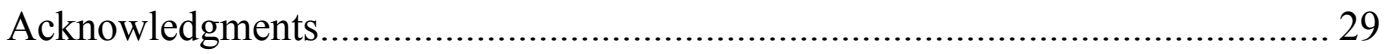

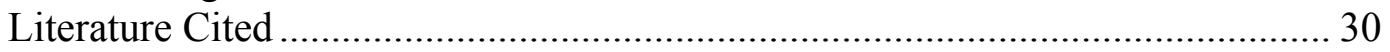

IV. BILIRUBIN PRESENT IN DIVERSE ANGIOSPERMS ……….......................... 38

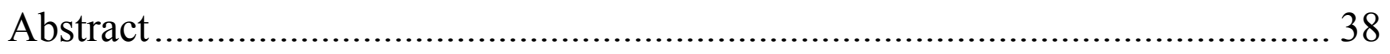

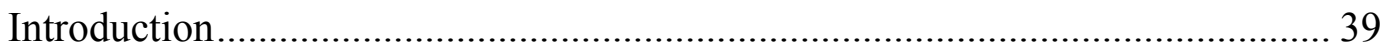

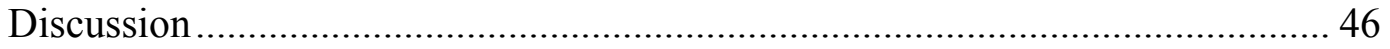

Acknowledgments.......................................................................................... 49

Literature Cited ........................................................................................ 49

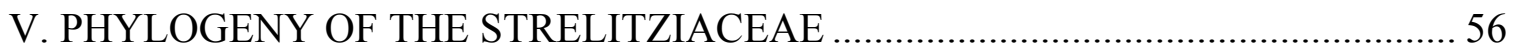

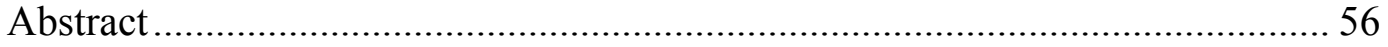

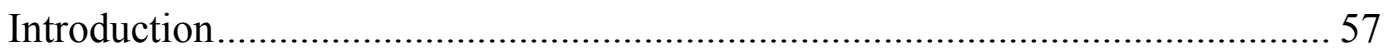

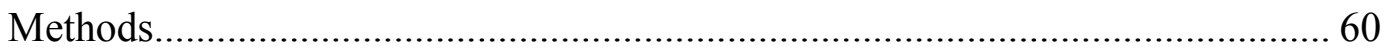

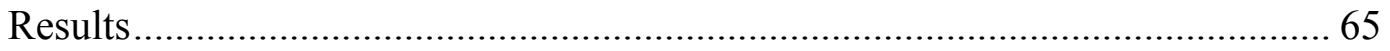

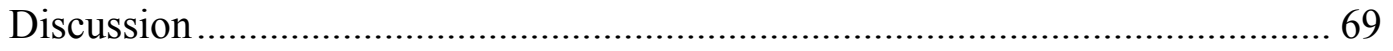

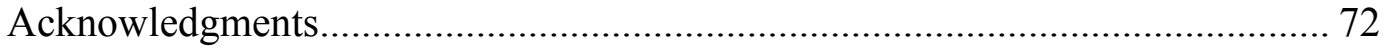

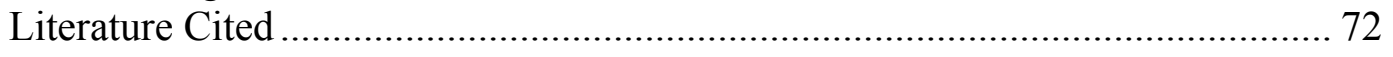




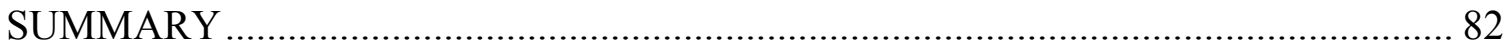

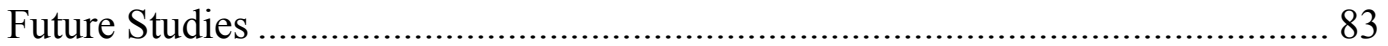

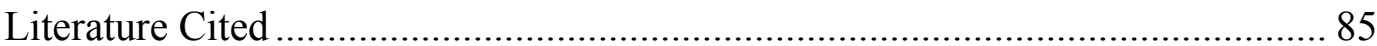

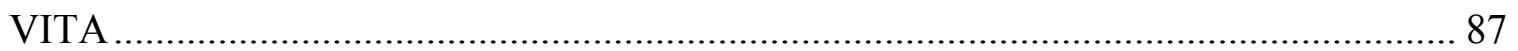




\section{LIST OF TABLES}

TABLE

PAGE

2.1. ${ }^{1} \mathrm{HNMR}$ values of bilirubin.............................................

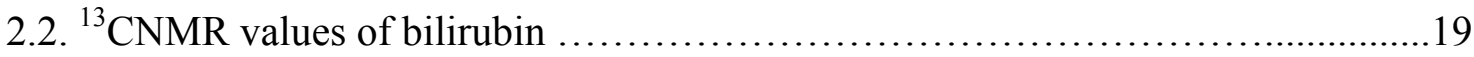

3.1. Concentration of bilirubin in S. reginae arils and sepals.................................... 31

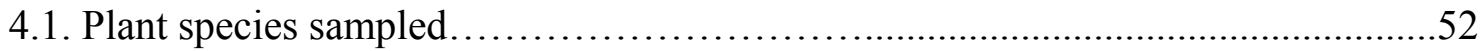

4.2. Bilirubin detection and concentration..........................................

5.1. Species sampled and taxonomic affiliations............................... 77

5.2. Data on individual regions............................................ 77 


\section{LIST OF FIGURES}

FIGURE

PAGE

1.1. Pigment structures from each of the four main classes, taken from Lee (2007)....12

1.2. Pigmented arils of species from three Strelitziaceae genera. From

left to right: $R$. madagascariensis, S. nicolai, $P$. guyannense. Seeds $\sim 4 \mathrm{~mm}$ in diameter.

2.1. Bilirubin-IX $\alpha$ demonstrating intramolecular H-bonding.

2.2. UV-VIS spectrum of bilirubin from S. nicolai (solvent system: 9:1 0.04

$\mathrm{mM}$ sodium acetate in methanol: $1 \%$ aqueous ammonium acetate)

3.1. Strelitzia reginae. A. Inflorescence of S. reginae photographed at Fairchild Tropical Botanic Garden. Inflorescence is $\sim 22 \mathrm{~cm}$ long. B. Mature and open capsule of $S$. reginae with arillate seeds exposed, capsules $\sim 5.5 \mathrm{~cm}$ across. Photographed in Del Mar, CA by Tom DeFanti. C. Arillate seeds of S. reginae, seeds $\sim 4 \mathrm{~mm}$ in diameter, photographed by Tom DeFanti. D. Aril fibers of S. reginae, in longitudinal view. Bilirubin is present in the crystalline granules attached to inner cell wall of these dead cells. Length of image $=300 \mu \mathrm{m}$. E. Paradermal view of epidermal cells of orange sepals of S. reginae. Bilirubin granules are not seen in these cells, the color produced primarily by carotenoids

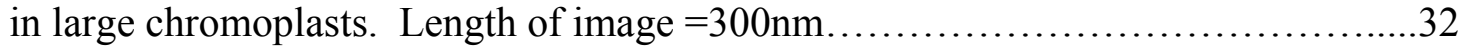

3.2. HPLC standard curve of bilirubinIX $\alpha$

3.3. HPLC chromatograms of (A) Bilirubin standard and (B) Aril extract of

S. reginae.

3.4. Bilirubin standard via (+)ESI-Zoom-MS and MS/MS: (A) Zoom-MS of molecular ion region; (B) product spectrum of $\mathrm{m} / \mathrm{z} 585$; (C) product spectrum of $\mathrm{m} / \mathrm{z} 583$.

3.5. Bilirubin in S. reginae aril via (+) ESI-MS and MS/MS: (A) Zoom-MS of molecular ion region; (B) product spectrum of $\mathrm{m} / \mathrm{z} 585$; (C) product spectrum of $\mathrm{m} / \mathrm{z} 583$.

3.6. Bilirubin in S. reginae sepal extract via (+) ESI-Zoom-MS and MS/MS:

(A) Zoom-MS of molecular ion region; (B) product spectrum of $\mathrm{m} / \mathrm{z} 585$;

(C) product spectrum of $\mathrm{m} / \mathrm{z} 5$. 
4.1. Phylogeny of the Zingiberales. Phylogenetic relationships of genera in the Zingiberales (figure adapted from Kress et al., 2001) with photographs of four species sampled in this study

4.2. Bilirubin production in Strelitzia nicolai during aril development Maturing arils of S. nicolai with increasing amounts of bilirubin. Seeds $\sim 4$. $\mathrm{mm}$ in diameter.

5.1. Figure 5.1. Strict consensus tree of all analysis types constructed using eleven chloroplast regions. Support values overlaid on nodes: MPBS (above branch, left), MLBS (above branch, right), and PP (below branch) .78

5.2. Strict consensus tree of all analysis types constructed using ETS and rpb2. Support values overlaid on nodes: MPBS (above branch, left), MLBS (above branch, right), and PP (below branch). "_“ indicates node not present.

5.3. Strict consensus tree of all analysis types using combined nuclear and chloroplast regions. Support values overlaid on nodes: MPBS (above branch, left), MLBS (above branch, right), and PP (below branch). “_“ indicates node not present.

5.4. One of the two most parsimonious trees resulting from the analysis of the combined nuclear and chloroplast regions. 


\section{INTRODUCTION}

Green plants are reliant on light for a multitude of physiological processes including photosynthesis and the regulation of growth and development. The capture and transmission of light energy by plants is achieved using compounds which absorb, transmit, and reflect a broad spectrum of light from the UV-B to far-red. Most of these compounds are pigments, that absorb light in the visible range and thus produce color. Multiple metabolic pathways produce pigments, yet colors observed among flowering plants can be attributed to only four pathways: the terpenoid (carotenoids), the phenylpropanoid (flavonoids), the tetrapyrrole (chlorophyll, phytochromobilin), and the indole (betalains) (Fig. 1.1.).

An unusual orange pigment exists in the arils of several species in the monocot family Strelitziaceae. The pigment is intense, durable, and exhibits chemical properties that differ from those of known plant pigments. The research presented here focuses on the characterization of the pigment, and examines its phylogenetic distribution among flowering plants.

\section{MAJOR PIGMENT PATHWAYS}

The carotenoids, flavonoids, and tetrapyrroles are ubiquitous among plants and responsible for the majority of angiosperm coloration. Carotenoids are yellow, orange and red pigments synthesized via the terpenoid pathway. The basic C-40 tetraterpene backbone can be linear or contain cyclic end groups, and, like all pigments, it undergoes modifications such as hydroxylation that cause shifts in wavelength absorption and thus color production (Goodwin and Britton, 1988). Carotenoids play an integral role in 
photosynthesis, they are synthesized in the chloroplasts of all photosynthetic organisms, and also accumulate in the plastids of flowers and fruits to produce color. Familiar examples include beta-carotene in carrot roots and sunflowers, lycopene in tomato fruits, and capsaxanthin in red peppers.

Anthocyanins are vacuolar pigments responsible for most magenta, red, and blue colors observed in vascular plants. Anthocyanins are a subclass of the flavonoids, and are thus phenolic compounds produced by the phenylpropanoid pathway. Other flavonoid subclasses include the yellow flavonols and the orange and red aurones and chalcones, which are less common than the anthocyanins (Harborne and Turner, 1984). Flavonoids have a 15-carbon base structure composed of two phenyl rings connected by a three carbon bridge that usually forms a third ring. Structural modifications such as glycosylations are common, and often shift the color of the molecule. Color is also altered by changes in the cellular environment, such as a shift in $\mathrm{pH}$, by self-association in planar stacks, association with other molecules, or by complexation with metal ions (Koes, 1994; Harborne and Williams, 2000). Anthocyanins are often produced in flowers and fruits like blueberries and grapes. Yet they also are produced in leaves and stems, visible as either a red flush or mixed with chlorophyll to produce bronze and brown colors (Lee and Collins, 2001). In addition to facilitating pollination and dispersal, anthocyanin functions include photoprotection and free radical scavenging (Davies, 2004).

Tetrapyrroles include the chlorophylls and phytochromobilin, the photoreceptor of the light sensing protein phytochrome. All tetrapyrroles are synthesized from eight molecules of $\delta$-aminolevulinc acid (ALA) and are composed of four nitrogenous rings. In the case of chlorophyll, the tetrapyrrole structure is cyclical, and includes a fifth 
isocylic ring and a long phytol chain. The linear tetrapyrrole phytochromobilin is built from the same precursors as chlorophyll and shares the early portion of its biosynthetic pathway. However, its biosynthetic route diverges from that of chlorophyll when the cyclic protoporphyrin-IX is cleaved to form biliverdin-IX, the phytochromobilin precursor (Tanaka at al., 2008). Although tetrapyrroles are of fundamental import for photosynthesis and respiration, they are not typically involved in the coloration of flowers or fruits.

\section{MINOR PIGMENT PATHWAYS}

Betalains are a nitrogenous group of water soluble compounds with an indole nucleus. They are subdivided into two groups, the red-violet betacyanins and the yelloworange betaxanthins (Lee, 2007). Both are conjugates of betalamic acid with cyclodihydroxyphenylalanine (cDOPA) glucoside and either an amino acid or an amine. Betalains are produced in all members of the Caryophyllales, with the exception of the Molluginaceae and the Caryophyllaceae, which produce anthocyanins (Strack et al., 2003). Although carotenoids and flavonoids are often produced within the same cells, production of betalains and anthocyanins appears to be mutually exclusive (Stafford, 1994). Betalain compounds contributes to color production in reproductive structures; the flowers of cacti, bougainvillea, and beets are colored by these compounds.

Quinones are widespread in the plant kingdom. The core structure is usually one, two, or three phenolic derived rings modified with carbonyl groups, but larger polycyclic structures also exist. These compounds can be derived from various biosynthetic pathways. Although broadly distributed, quinones do not usually contribute to the color of flowers and fruits for two reasons: they are usually found in roots and wood, and they 
are often colorless or weakly pigmented (Davies, 2004).

A rare group of pigments, the phenalenones, are typically yellow to red in color, and occur in Strelitziaceae and some related families (Opitz and Schneider, 2002). Although they are present in a variety of plant organs including fruits, phenalones are not known to significantly contribute to color. Structures of these compounds are diverse, and their biosynthetic pathways have not yet been completely resolved. Other rare pigments exist, but are excluded from this discussion because of the low frequency of occurrence. For comprehensive coverage of plant pigments and their metabolic pathways, see reviews by Davies (2004), Lee (2007), and Grotewold (2006).

\section{SYSTEMATICS OF STRELITZIACEAE}

Strelitziaceae, a small monocot family in the order Zingiberales, includes seven species: Ravenala madagascariensis Sonn., Phenkospermum guyannense (L.C. Rich.) Endl. ex Miq., Strelitzia reginae Banks ex Aiton, Strelitzia juncea Link, Strelitzia alba Skeels, Strelitzia nicolai Regel and Körn and Strelitzia caudata R. A. Dyer (APG: Stevens, 2001, Coates Palgrave and Coates Palgrave, 2002; Archer, 2003; Columbus et al., 2006). Like other Zingiberales, Strelitziaceae have an herbaceous habit, large petiolate leaves, and green, boat shaped bracts which subtend colorful inflorescences (Kress, 1990). Synapomorphies of the family include a tree-like growth form, three free sepals, two fused petals that enclose five (or six in Ravenala) stamens, and a woody loculicidal capsule (Kress, 1990) containing seeds with brightly colored arils. Three of the members, S. reginae, the bird of paradise flower, S. nicolai, the white bird of paradise tree, and R. madagascariensis, the travelers' palm, are widely cultivated as ornamentals. 
Although the monophyly of Ravenala madagascariensis and Phenakospermum guyannense is widely accepted, Strelitzia species have a convoluted taxonomic history. The International Plant Names Index (IPNI) lists 34 names of Strelitzia species which have been in use in the past, although today there are just five recognized species. $S$. reginae and S. nicolai have been recognized as distinct species throughout their taxonomic history (Wright, 1913). These species can be distinguished on the basis of many morphological traits, perhaps the most obvious difference is that S. nicolai is caulescent, having an elongated main shoot, while S. reginae is acaulescent. However, the features which distinguish S. nicolai, S. caudata, and S. alba from each other, and S. reginae from S. juncea are less obvious. S. alba, S. caudata, and S. nicolai, are differentiated only by sepal color, complexity of inflorescence, geographic locale, and habit (Wright, 1913; Dyer; 1945; Goldblatt and Manning, 2000; Coates Palgrave and Coates Palgrave, 2002). They have been classified as distinct species since 1945, when Dyer clarified species boundaries between S. nicolai and S. alba, and described $S$. caudata (Dyer, 1945). The morphological differences between S. juncea and S. reginae are also minor; the main distinguishing feature of these taxa is the reduced leaf blade of S. juncea (Moore and Hyypio, 1970). Although S. juncea was originally described as a species in 1821 by Link, it was reduced to a variety or cultivar of S. reginae (Moore and Hyypio, 1970), and then raised again to species status on the basis of developmental differences (Van der Venter, 1975, Dyer, 1975). Because of the minor morphological differences which guide the delineation of some of the Strelitzia taxa, molecular data could help clarify species delimitations. 
Several large scale phylogenetic studies have sampled a single species from each of the three genera, but results are ambiguous, and no studies have included all Strelitzia species. Ravenala madagascariensis was found to be basal to the sister taxa S. nicolai and P. guyannense in the combined three gene (atpB, rbcL, 18s rDNA) analyses of Soltis et al. (2000), Soltis et al. (2007), and Chase (2000), and also in the combined three gene (atpB, rbcL, 18s rDNA) plus morphological dataset of Kress (2001). Using a single gene dataset of ndhF, Givnish et al. (2006) found S. nicolai to be basal to R. madagascariensis and P. guyannense. Thus, although the Strelitziaceae has been confirmed as a monophyletic group, evolutionary relationships within the family remain unclear (Kress et al., 2001, Chase et al., 2000, Givnish 2006, Rudall et al., 1999, Soltis et al., 2000, Soltis 2007).

\section{PIGMENTS IN THE STRELITZIACEAE}

Members of Strelitziaceae produce woody tripartite loculicidal capsules, which dehisce at maturity to reveal brightly colored arillate seeds (Kress, 1990). The waxy, funicular arils of $R$. madagascariensis are blue, those of $P$. guyannense are orange-red, and those of the Strelitzia species are orange (Fig. 1.2). Remarkably, aril color remains unchanged years after cell death; arils with little or no change in color were observed in herbarium sheets up to 45 years old (personal observation; HUH, Sturrock \#93, 1963; and Natal $\# 50,000,1976)$. Previous studies of pigments from species within Strelitziaceae have focused on Strelitzia reginae. S. reginae has striking flowers composed of three vibrant orange sepals and three blue petals. At least nineteen carotenoids are present in the orange sepals (Simpson et al., 1975; Tappi and Menziani, 1955), and the anthocyanin delphinidin-3-rutinoside was found in the blue petals (Harborne, 1967). Phenalenones 
were documented in its roots (Holster and Schneider, 2000).

Preliminary studies indicated that the aril pigments of $S$. nicolai, $P$. guyannense, and R. madagascariensis showed unusual UV-Visible spectra and solubilities that did not match those of the $S$. reginae floral pigments, or any of the aforementioned major pigments. It was not possible to compare aril pigment properties to those of phenalenones because of the diversity of UV-Visible spectra and solubility of these compounds. Thus, the structure of these unusually durable visible pigments remains unknown.

\section{PROPOSED RESEARCH}

Given the unusual chemical properties of the persistent orange pigment in $S$. nicolai, it is of interest to determine whether the pigment is restricted to $S$. nicolai, or whether it present in other flowering plants. Thin layer chromatography of $P$. guyannense aril extracts yielded an orange band with an $\mathrm{R}_{\mathrm{f}}$ value identical to that of $S$. nicolai under several different solvent regimes, suggesting that the pigment is not limited to S. nicolai.

Using high performance liquid chromatography with UV detection (HPLC/UV) and HPLC/UV/electrospray ionization tandem mass spectrometry (HPLC/UV/ESIMS/MS), representatives from diverse flowering plant lineages were analyzed for the presence of the pigment. Since structurally related compounds are often found in closely related taxa (Harborne and Turner, 1984), sampling focused on species of phylogenetic proximity to $S$. nicolai within the family, including $P$. guyannense and $R$. madagascariensis. Other members of the Zingiberales were also sampled. Representatives from the "banana group", a basal clade of the Zingiberales including the 
Musaceae, Strelitziaceae, Heliconiaceae, Lowiaceae (Kress et. al., 2001) were sampled, with the exception of Orchidantha, the sole genus of Lowiaceae. Inclusion of this genus in the analysis is desirable due to its sister relationship with the Strelitziaceae (Kress et al., 2001, Chase et al., 2000, Givnish 2006, Rudall et al., 1999, Soltis et al., 2000, Soltis 2007), but Orchidantha is rare and thus difficult to obtain. Species from two of the more derived ginger families, Zingiberaceae, Costaceae, were also sampled. Outside of the Zingiberales, members of the basal dicot order Laurales, two monocot orders, the Arecales and the Pandanales, and the eudicot order Myrtales, a part of the Rosid clade (APG 9: Stevens, 2008) were also sampled to determine the breadth of the orange pigment distribution among angiosperms.

Consideration of these data in a better-resolved phylogenetic framework will provide a basis for understanding the evolutionary history of the orange pigment in plants. Phylogenies are available for the major angiosperm clades (APG 9: Stevens, 2008), yet no phylogeny of Strelitziaceae exists. The research presented here will therefore include a reconstruction of the phylogeny of the Strelitziaceae using eleven chloroplast regions, $r b c L$, matK -5'trnK, $p s b A$ - matk , psbB-psbH, Ycf6-trnC, the $r p L 16$ intron, rpoB-trnC, trnS-trnfM, trnY-trnE, rp132-trnL, rps16, and two nuclear regions, ETS and $r p b 2$.

Research Aims:

1. Identify the orange pigment in the arils of S. nicolai.

2. Identify the orange pigment in the arils and sepals of $S$. reginae, and compare this pigment with that of S. nicolai.

3. Determine the presence of the orange pigment in diverse angiosperm taxa. 
4. Reconstruct the phylogeny of the Strelitziaceae.

Chapters II, III, and IV have been published in the Journal of American Chemical

Society, HortScience, and AoB Plants, respectively. Chapter V will be submitted to

Systematic Botany.

\section{LITERATURE CITED}

Archer C. 2003. Strelitziaceae. p. 1106. In: Germishuizen, G. \& Meyer, N. L. (eds.).

Plants of southern Africa: an annotated checklist. Strelitzia National Botanical Institute of South Africa, Kirstenbosch.

Chase, M. W., D.E. Soltis, P. S., Soltis, P. J., Rudall, M. F., Fay, W. H., Hahn, S., Sullivan, J., Joseph, M., Movray, P. J., Kores, T. J., Givnish, K. J., Sytsma, and J.C. Pires. 2000. Higher-level systematics of the monocotyledons: An assessment of current knowledge and a new classification. p. 3-16. In: K. I. Wilson and D. A. Morrison (eds.). Monocots: Systematics and evolution. CSIRO, Melbourne.

Coates Palgrave, K. and Coates Palgrave, M. 2002. Strelitziaceae. p. 118-9. In: L. Martin (ed.). Trees of southern Africa. Struik Publishers, Cape Town.

Columbus, J. T., E. A., Friar, J. M., Porter, L. M. Prince, and M G. Simpson. 2006. Monocots: comparative biology and evolution. Rancho Santa Ana Botanical Garden, California.

Davies, K. 2004. Plant Pigments and their Manipulation. CRC Press, Boca Raton.

Dyer, R. A., 1945. The Flowering Plants of Africa. Pretoria, Van Schaik LTD.

Dyer, R. A., 1975. Notes on African plants: Strelitziaceae: The status of Strelitzia juncea. Bothalia 1: $519-520$.

Givnish, T.J., Pires, J.C., Graham, S.W., McPherson, M.A., Prince, L.M., Patterson, T.B., Rai, H.S., Roalson, E.H., Evans, T.M., Hahn, W.J., Millam, K.C., Meerow, A.W., Movray, M., Kores, P.J., O’Brien, H.E., Hall, J.C., Kress, W.J., and K.J. Systma. 2006. Phylogenetic relationships of monocots based on the highly informative plastid gene ndhF: evidence for widespread concerted convergence. Aliso 22: 28-51.

Goldblatt, P. and J. Manning. 2000. Cape plants: A conspectus of the Cape flora of South Africa. National Botanical Institute, Pretoria.

Goodwin T.W. and G. Britton. 1988. Distribution and analysis of carotenoids. In: T.W. Goodwin (ed.). Plant Pigments. Academic Press, San Diego, CA. 
Grotewold, E. 2006. Review on the genetics and biochemistry of flower pigments. Ann. Rev. Plant Biol. 57:761-80.

Harborne, J.B. 1967. Comparative biochemistry of the flavonoids. Academic Press, New York.

Harborne, J.B. and C. Williams. 2000. Advances in flavonoid research since 1992. Phytochemistry 55: 481-504.

Haborne, J.B. and B.L. Turner. 1984. Plant Chemosystematics. Academic Press, London.

Holster, D. and S. Schneider. 2000. Phenalenones from Strelitzia reginae. J. Nat. Prod. 63: 1027-1028.

Koes, R.E., W. Verweij, and F. Quattrocchio. 1994. The flavonoid biosynthetic pathway in plants: function and evolution. BioEssays 16: 123-132.

Kress, J.W. 1990. The phylogeny of the Zingiberales. Ann. MO. Bot. Gard. 77(4): 698721.

Kress, J.W., L.M., Prince, W.J., Hahn, and E. Zimmer. 2001. Unraveling the evolutionary radiation of the families of the Zingiberales using morphological and molecular evidence. Syst. Biol. 50(6): 926-944.

Lee, D.W. and T. Collins. 2001. Phylogenetic and ontogenetic influences on the distribution of anthocyanins and betacyanins in leaves of tropical plants. Int. J. Plant Sci. 162: 1141-1153.

Lee, D. W. 2007. Nature's Palette. The Science of Plant Colours. Chicago, University of Chicago Press.

Moore, H.E. and P. A. Hyypio. 1970. Some comments on Strelitzia (Strelitziaceae). Baileya 17: 64-74.

Opitz, S. and B. Schneider. 2002. Organ-specific analysis of phenylphenalenone-related compounds in Xiphidium caeruleum. Phytochem. 61: 819-825.

Rudall, P.J., D.W., Stevenson, and H.P. Linder. 1999. Structure and systematics of Hanguana, a monocotyledon of uncertain affinity. Aust. Syst. Bot. 12: 311-330.

Simpson, D.J., M.R., Baqar, and T.H. Lee. 1975. Ultrastructure and carotenoid composition of chromoplasts of the sepals of Strelitzia reginae Aiton during floral development. Ann. Bot. 39: 175-183. 
Soltis, D. E., P.S., Soltis, M.W., Chase, M.E., Mort, D.C., Albach, M.,Zanis, V., Savoleinen, W.H., Hahn, S.B., Hoot, M.F., Fay, M., Axtell, S.M., Swensen, L.M., Prince, W.J., Kress, K.C., Nixon, and J.S. Farris. 2000. Angiosperm phylogeny inferred from 18S rDNA, $r b c L$, and $a t p B$ sequences. Bot. J. Linn. Soc. 133: 381-461.

Soltis, D.E., M.A., Gitzendanner, and P. S. Soltis. 2007. A 567-taxon data set for angiosperms: the challenges posed by Bayesian analyses of large datasets. Int. J. Plant Sci. 168(2): 137-157.

Stafford, H.A. 1994. Anthocyanins and betalains: evolution of the mutually exclusive pathways. Plant Sci. 101: 91-98.

Strack, D., T. Vogt and W. Schliemann. 2003. Recent advances in betalain research. Phytochem. 62: 247-269.

Stevens, P. F. (2001 onwards). Angiosperm Phylogeny Website. Version 9, June 2008. http://www.mobot.org/MOBOT/research/APweb/.

Tanaka, Y., N., Sasaki, and A. Ohmiya. 2008. Biosynthesis of plant pigments: anthocyanins, betalains and carotenoids. Plant J. 54(4): 733-749.

Tappi, G. and E. Menziani. 1955. Sui carotenoidi di Strelitzia reginae. Gazz. Chim. Ital. 85: $720-724$.

Van der Venter, H.A., J.G.C, Small, and P.J. Robbertse. 1975. Notes on the distribution and comparative leaf morphology of the acaulescent species of Strelitzia Aiton. J. S. Afr. Bot. 41(1): 1-16.

Wright, C. H. 1913. Strelitzia Aiton. p. 316 - 319. In: W.T. Thiselton-Dyer (ed.). Flora capensis. Volume 5: 3. Lovell, Reeve and Co. LTD, London. 
<smiles>CCOC1=Cc2c(O)cc(O)cc2[O+]([O-])C=C1c1ccc(O)c(O)c1</smiles>

anthocyanin with sugar

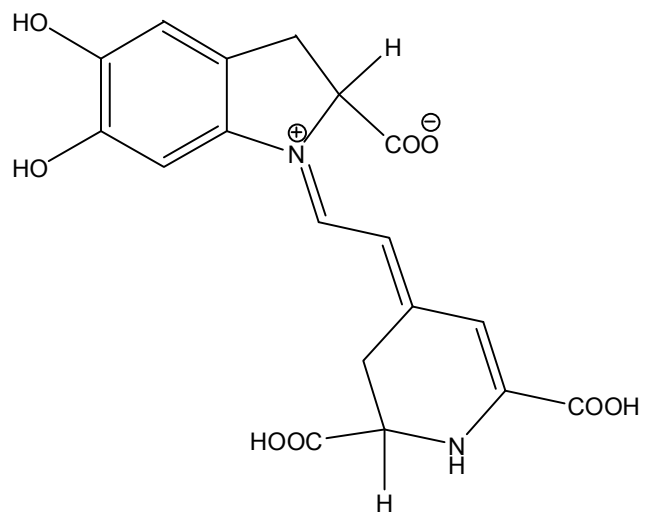

betanidin<smiles>CC1=C(/C=C/C(C)=C/C=C/C(C)=C/C=C/C=C(C)/C=C/C=C(C)/C=C/C2=C(C)CCCC2(C)C)C(C)(C)CCC1</smiles>

$\beta$-carotene

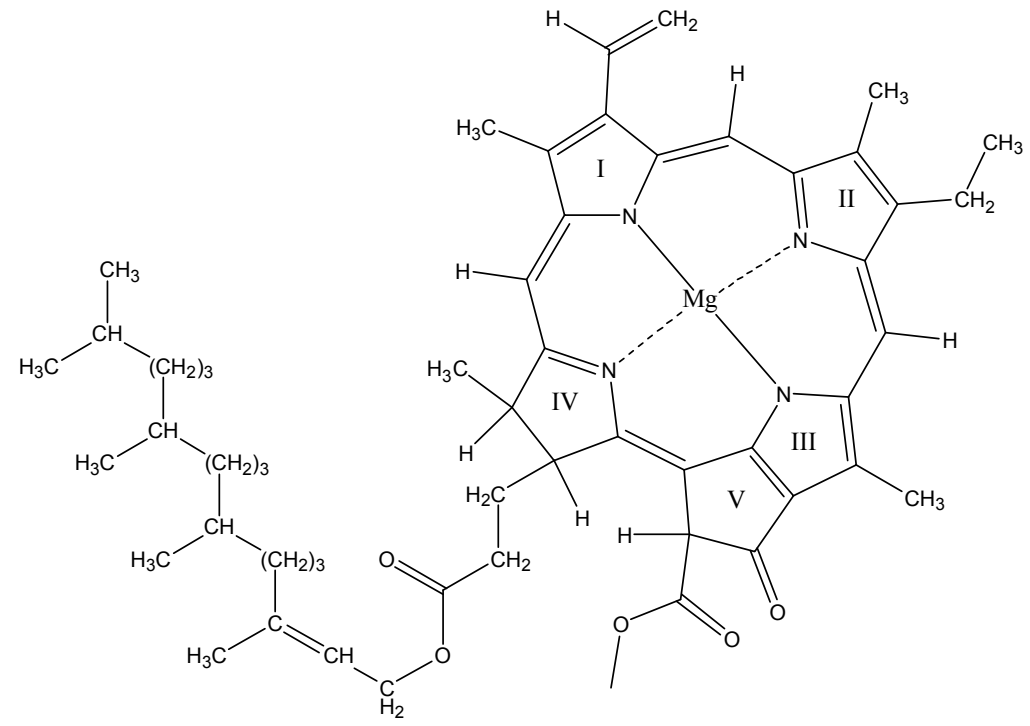

chlorophyll a

Figure 1.1. Pigment structures from each of the four main classes, taken from Lee (2007). 


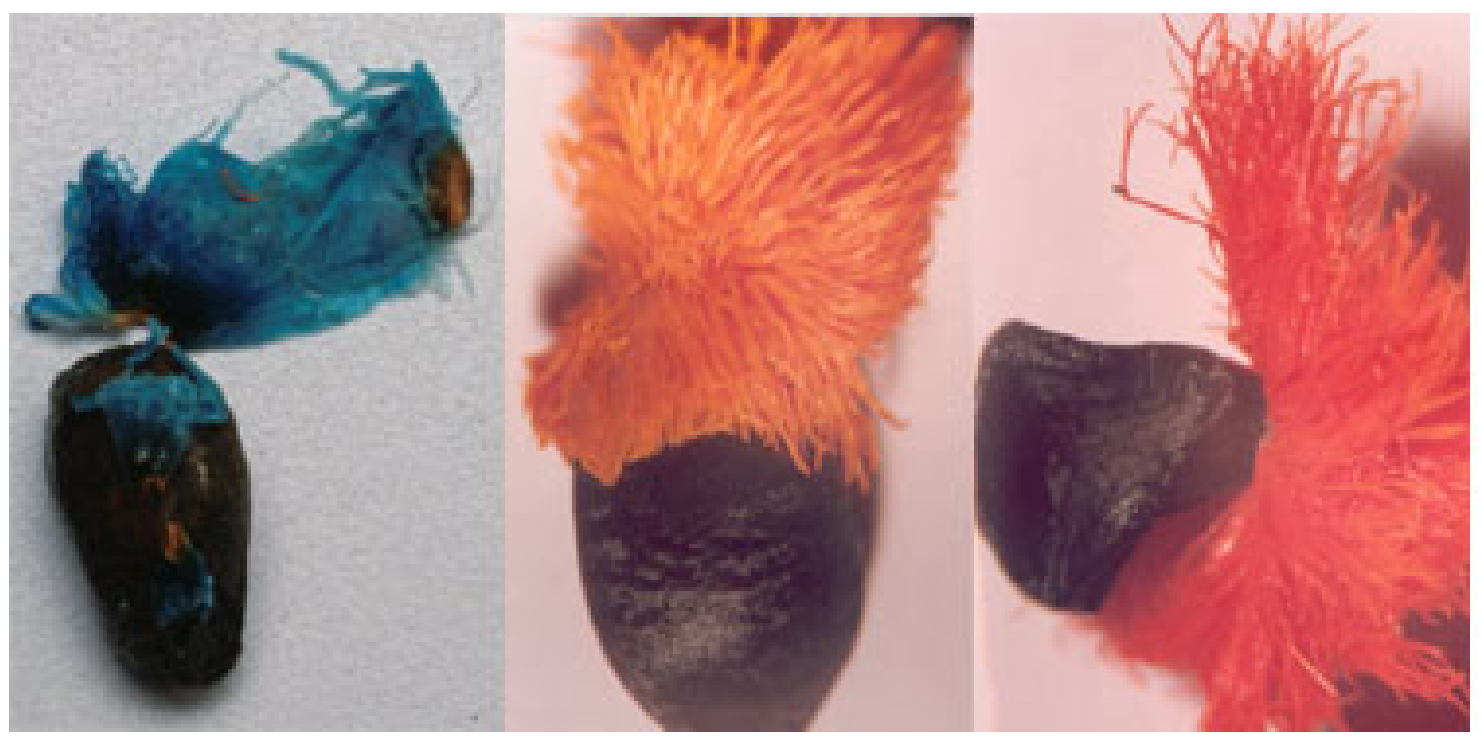

Figure. 1.2. Pigmented arils of species from three Strelitziaceae genera. From left to right: $R$. madagascariensis, $S$. nicolai, $P$. guyannense. Seeds $\sim 4 \mathrm{~mm}$ in diameter. 


\section{THE ANIMAL PIGMENT BILIRUBIN DISCOVERED IN PLANTS}

Reproduced with permission from Pirone, C. L., J.M.E., Quirke, H., Priestap, and D.W. Lee. 2009. Animal pigment bilirubin discovered in plants. J. Amer. Chem. Soc. 131 (8): 2830. Copyright 2009 American Chemical Society."

Cyclic tetrapyrroles occur throughout the plant kingdom and include vital biosynthetic products such as chlorophyll and heme. In plants, oxidative degradation of heme first forms biliverdin IX- $\alpha$ and subsequently phytochromobilin, the precursor of the phytochrome chromophore, an essential light sensing molecule (Tanaka and Tanaka, 2007). In animals, oxidative degradation of heme also leads to the formation of biliverdin-IX $\alpha$, but it is transformed into the yellow-orange pigment bilirubin-IX $\alpha$ (Fig. 2.1). Here, I present spectroscopic and chromatographic evidence that bilirubin is the major pigment of the orange aril of Strelitzia nicolai Regel \& Koern. (Strelitziaceae, order Zingiberales), the white bird of paradise tree. This is the first example of bilirubin in a plant (Willows et al., 2004), a finding which likely necessitates the revision of the plant tetrapyrrole pathway since there is currently no known mechanism of bilirubin production in the plant kingdom.

Strelitzia nicolai is native to South Africa and widely cultivated in the tropics. It produces woody capsular fruits that contain orange arillate seeds. Analytical highperformance liquid chromatography with UV detection (HPLC/UV) of the aril extract (Spivak and Yuey, 1986) revealed one major peak, which had a UV-visible spectrum with a maximum absorbance at $444 \mathrm{~nm}$. After purification using preparative scale $\mathrm{HPLC} / \mathrm{UV}$, the isolated pigment was analyzed by hydrogen nuclear magnetic resonance spectroscopy $\left({ }^{1} \mathrm{H} \mathrm{NMR}\right)$, and carbon NMR $\left({ }^{13} \mathrm{C}\right.$ NMR) (Brucker, $\left.400 \mathrm{MHz},\left(\mathrm{CD}_{3}\right)_{2} \mathrm{~S}=\mathrm{O}\right)$, 
and HPLC/UV/electrospray ionization tandem mass spectrometry (HPLC/UV/ESIMS/MS) (Thermo-Finnigan LCQ).

The ${ }^{1} \mathrm{H}$ NMR and ${ }^{13} \mathrm{C}$ NMR spectra of the isolated pigment matched published values of bilirubin (Kuenzle, 1970; Kaplan and Navon, 1980) (Tables 2.1 and 2.2). Identification was further supported by ${ }^{1} \mathrm{H}$ NMR analysis of bilirubin standard (Aldrich), which yielded a spectrum which matched that of the S. nicolai pigment (Figure 2.2). Both the positive ion electrospray mass spectrum and the product ion spectrum matched those of authentic bilirubin standard and previous published data (Lightner, 1982) (molecular ion, $\mathrm{m} / \mathrm{z} 585(\mathrm{M}+\mathrm{H})^{+}$, product ion $\left.\mathrm{m} / \mathrm{z} 299\right)$.

Given the unexpected discovery of bilirubin in plants, it was essential to confirm the identity of the pigment as bilirubin-IX $\alpha$, and not other isomers. Previous chromatographic studies have demonstrated that the ability of bilirubin-IX $\alpha$ to undergo intramolecular hydrogen bonding makes it significantly less polar than bilirubin-IX $\beta, \gamma$ or $\delta$ (Blanckeart et al., 1976; Bonnett et al., 1978). In my HPLC analyses, a single peak was observed when bilirubin-IX $\alpha$ standard was co-injected with the isolated pigment, thereby eliminating the possibility that the pigment was bilirubin-IX $\beta, \gamma$ or $\delta$.

Furthermore, the visible spectrum of bilirubin-IX $\alpha$ has an intense peak at $458 \mathrm{~nm}$ in dimethylsulfoxide (DMSO), which is approximately $50 \mathrm{~nm}$ longer than bilirubin-IX $\beta, \gamma$ or $\delta$ (Blanckeart et al., 1976). Other bilirubin isomers, including bilirubin-III $\alpha$ and bilirubin-XIII $\alpha$, were eliminated because their ${ }^{1} \mathrm{H}$ NMR spectra are substantially different (McDonagh et al., 1982).

The occurrence of bilirubin is not restricted to S. nicolai. Two other species in the Strelitziaceae, Phenakospermum guyannense Endl., and S. reginae Aiton, the bird of 
paradise, contain aril pigments which co-eluted with authentic bilirubin in HPLC and had similar UV-visible spectra. I am currently examining species in related families. This information, in combination with studies on the synthesis of bilirubin IX- $\alpha$ in S. nicolai, will provide the basis for a more thorough understanding of the evolutionary origin of this pigment in plants.

\section{SUPPORTING INFORMATION}

Isolation of Bilirubin from Plant Aril: Plant arils were removed from the seed and extracted with chloroform until the extracts were colorless. Aril lipids were isolated by re-dissolving the evaporated extract in dimethyl sulfoxide (DMSO) ( $3 \mathrm{~mL}$ per gram of extract) and extracting with hexane in a separatory funnel. The hexane layer was evaporated and the lipid residue stored for future study. The DMSO layer, which contained the pigment, was purified further by preparative HPLC using an XTerra MS $\mathbf{C}_{18}$ OBD column (5 $\mu \mathrm{m}, 50 \mathrm{~mm}, 19 \mathrm{~mm}$ i.d., Waters), and the binary solvent system developed by Spivak and Yuey (1986). The flow rate was $3 \mathrm{~mL}$ per minute. The bilirubin fraction, which eluted from 9 to 13 minutes, was collected from a series of runs, combined, diluted with HPLC grade water ( $1 \mathrm{~mL}$ eluate to $2.5 \mathrm{~mL}$ water), and passed through a Waters Sep-Pak C-18 cartridge. Bound pigments were washed with water to remove salts, then acetone, which was a co-solvent for water, and eluted with chloroform until eluates were colorless. The chloroform was evaporated under reduced pressure. Pigments were dried in a vacuum desiccator and stored at -80C. Analytical HPLC analyses were performed on a reversed phase ODS-A column $(5 \mu \mathrm{m}, 4.3 \times 150 \mathrm{~mm}$; Waters Corporation, Milford, MA, USA). The solvents and gradient were the same as those used for the preparative HPLC work. The flow rate was $1 \mathrm{~mL}$ per minute. 


\section{ACKNOWLEDGMENTS}

Co-authors on this paper are J. Martin E. Quirke, Horacio A. Priestap, and David Lee.

This research has been funded in part by the United States Environmental Protection

Agency (EPA) under the Greater Research Opportunities (GRO) Graduate Program, the

McBryde Science Program at the National Tropical Botanical Garden, and the RISE

Biomedical Research Initiative (NIH).

\section{LITERATURE CITED}

Blanckeart, N., K. P. M. Heirwegh, and F. Compernolle. 1976. Synthesis and separation by thin-layer chromatography of bilirubin-IX isomers. Biochem. J.155: 405-417.

Bonnett, R., J.E. Davies, M.B. Hursthouse, and G.M. Sheldrich. 1978. The structure of bilirubin. Proc. R. Soc. Lond. B.202: 249-268.

Kaplan D. and G. Navon. 1980. On the assignment of the carbon-13 NMR spectra of bilirubin. Org. Mag. Res. 13: 59-62.

Kuenzle C. Bilirubin conjugates of human bile. 1970. Biochem. J. 119: 395-409.

Lightner, D. A. 1982. Structure, photochemistry and organic chemistry of bilirubin. p. 75-123. In: Heirwegh, K. P. M. \& Brown, S. B. (eds.). Bilirubin. vol. 1, Chemistry. CRC Press, Boca Raton, FL.

McDonagh A.F., L. A Palma, and D.A. Lightner. 1982. Phototherapy for neonatal jaundice. Stereospecific and regioselective photoisomerization of bilirubin bound to human serum albumin and NMR characterization of intramolecularly cyclized photoproducts. J. Am. Chem. Soc.104: 6865-6867.

Spivak W. and W. Yuey. 1986. Application of a rapid and efficient h.p.l.c. method to measure bilirubin and its conjugates from native bile and in model bile systems.

Biochem. J. 234: 101-109.

Tanaka R. and A. Tanaka. 2007. Tetrapyrrole biosynthesis in higher plants. Ann. Rev. Plant. Biol. 58: 321-346.

Willows, R.D., A.Cuttriss, B. Pogson; K.E. Schwinn, K.M. Davies, J.P. Zryd, and L. Christinet. 2004. Chapters 2-7. In: Davies, K.M. (ed.). Plant Pigments and Their Manipulation. CRC Press, Boca Raton. 
Table 2.1. ${ }^{1}$ HNMR values of bilirubin

\begin{tabular}{|c|c|c|c|}
\hline Hydrogens & Bilirubin from $S$. nicolai & Multiplicity & Bilirubin Standard \\
\hline 2-CH3 & 1.94 & singlet & 1.92 \\
\hline 7-CH3 & 2.02 or 2.05 & singlet & 2.0 or 2.03 \\
\hline 13-CH3 & 2.05 or 2.02 & singlet & 2.03 or 2.0 \\
\hline $\begin{array}{l}17-\mathrm{CH} 3 \\
8 \& 12-\end{array}$ & 2.11 & singlet & 2.17 \\
\hline $\begin{array}{l}\mathrm{CH} 2 \mathrm{CH} 2 \mathrm{CO} 2 \mathrm{H} \\
8 \& 12-\end{array}$ & 2.46 & $\begin{array}{c}\text { triplet } \\
\text { triplet (partly }\end{array}$ & 2.43 \\
\hline $\mathrm{CH} 2 \mathrm{CH} 2 \mathrm{CO} 2 \mathrm{H}$ & 1.97 & obscured) & 1.94 \\
\hline $10 \mathrm{CH} 2$ & 4 & singlet & 3.99 \\
\hline $18-\mathrm{CH}=\mathrm{CH} 2 *$ & $\sim 5.30$ (centroid)* & ABX system & $\sim 5.31$ (centroid)* \\
\hline $18-\mathrm{CH}=\mathrm{CH} 2 *$ & $\sim 6.22$ (centroid)* & ABX system & $\sim 6.21$ (centroid)* \\
\hline $18-\mathrm{CH}=\mathrm{CH} 2 *$ & $\sim 6.6$ (centroid)* & ABX system & $\sim 6.59$ (centroid)* \\
\hline $3-\mathrm{CH}=\mathrm{CH} 2 *$ & $\sim 5.63$ (centroid)* & ABX system & $\sim 5.62$ (centroid)* \\
\hline $3-\mathrm{CH}=\mathrm{CH} 2 *$ & $\sim 5.66$ (centroid)* & $\mathrm{AB} X$ system & $\sim 5.66$ (centroid)* \\
\hline $3-\mathrm{CH}=\mathrm{CH} 2 *$ & $\sim 6.84$ (centroid)* & $\mathrm{AB} X$ system & $\sim 6.83$ (centroid)* \\
\hline $5-\mathrm{H}$ & 6.1 & singlet & 6.1 \\
\hline $15-\mathrm{H}$ & 6.1 & singlet & 6.1 \\
\hline 21-H & 10.1 & broad singlet & 10.04 \\
\hline $22-\mathrm{H}$ & 10.49 or 10.52 & broad singlet & 10.45 or 10.48 \\
\hline $23-\mathrm{H}$ & 10.52 or 10.49 & broad singlet & 10.48 or 10.45 \\
\hline $24-\mathrm{H}$ & 9.97 & broad singlet & 9.92 \\
\hline $\mathrm{COOH}$ & 12 & broad singlet & 11.9 \\
\hline
\end{tabular}


Table 2.2. ${ }^{13} \mathrm{CNMR}$ values of bilirubin

Carbons
C-1 C=O
C-2
C-3
C-4
C-5 methine
C-6
C-7
C-8
C-9
C-10
C-11
C-12
C-13
C-14
C-15 methine
C-16
C-17
C-18
C-19 C=O
C-2'
C-3'
C-3'”
C-7'
C-8'(C-12')
C-8''(C-12'”)
C-8'”'(C-12'”)
C-13'
C-17'
C-18' CH=CH2
C-18'' CH=CH2

$\begin{array}{cc}\begin{array}{c}\text { Bilirubin from } \boldsymbol{S} . \\ \text { nicolai }\end{array} & \begin{array}{c}\text { Published Bilirubin } \\ \text { Values }^{\mathbf{1 0}}\end{array} \\ 171.33 & 171.5 \\ 123.23 & 123.4 \\ 140.4 & 140.5 \\ 127.44 & 127.6 \\ 98.9 & 99.2 \\ 122.03 & 122.1 \\ 119.56 & 119.6 \\ 123.42 & 123.4 \\ 130.79 & 130.6 \\ 23.6 & 23.7 \\ 131.45 & 131.4 \\ 124.1 & 124.0 \\ 119.77 & 119.8 \\ 122.26 & 122.3 \\ 100.01 & 100.1 \\ 128.21 & 128.4 \\ 141.93 & 142.0 \\ 122.39 & 122.6 \\ 170.39 & 170.6 \\ 9.43 & 9.5 \\ 127.34 & 127.5 \\ 122.08 & 122.2 \\ 9.11 & 9.2 \\ 19.23 & 19.3 \\ 34.02,34.00 & 34.4 \\ 173.95 & 174.1 \\ 9.12 & 9.3 \\ 9.23 & 9.4 \\ 127.06 & 127.2 \\ 117.1 & 117.2 \\ & \\ & \end{array}$




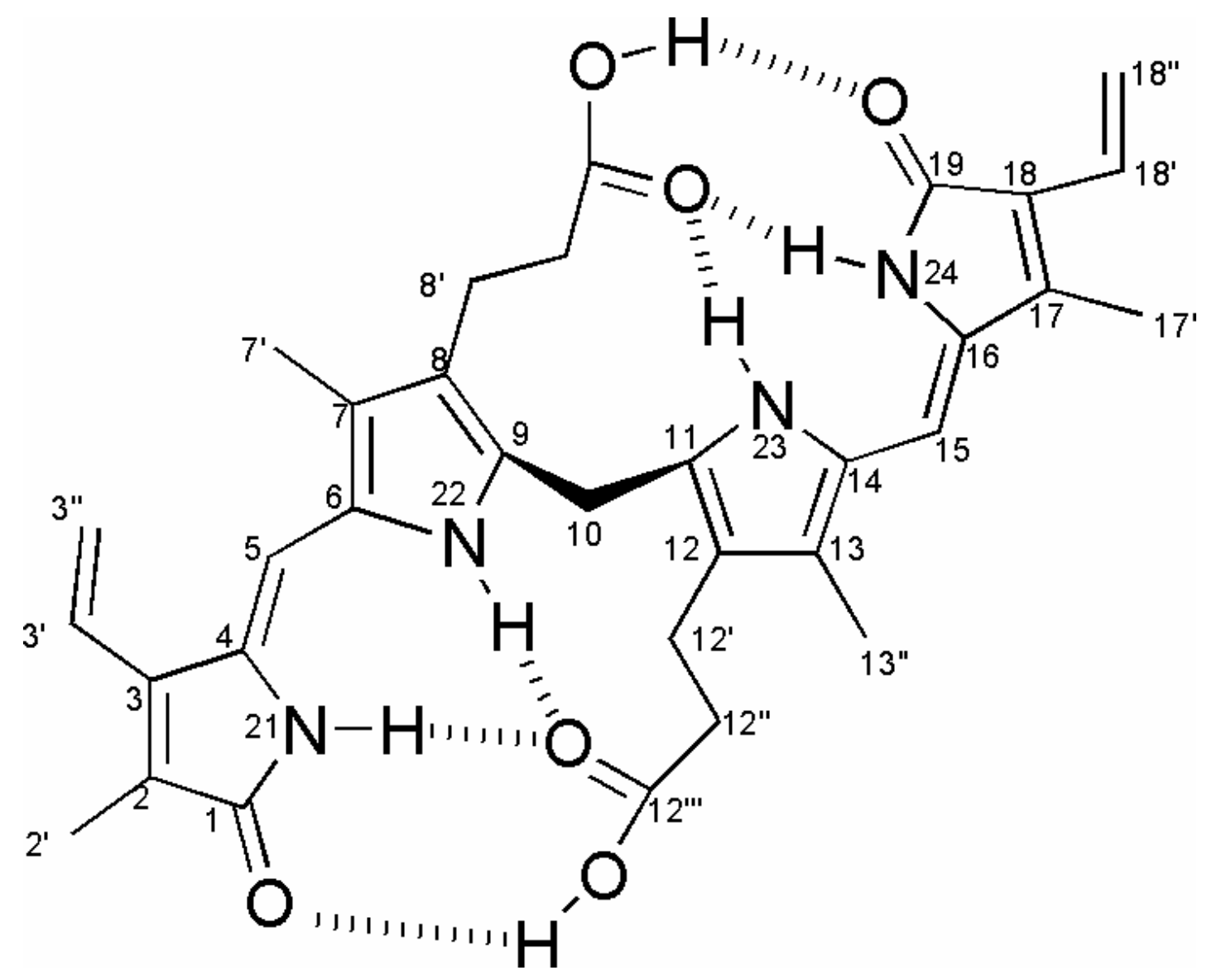

Fig. 2.1. Bilirubin-IX $\alpha$ demonstrating intramolecular H-bonding. 


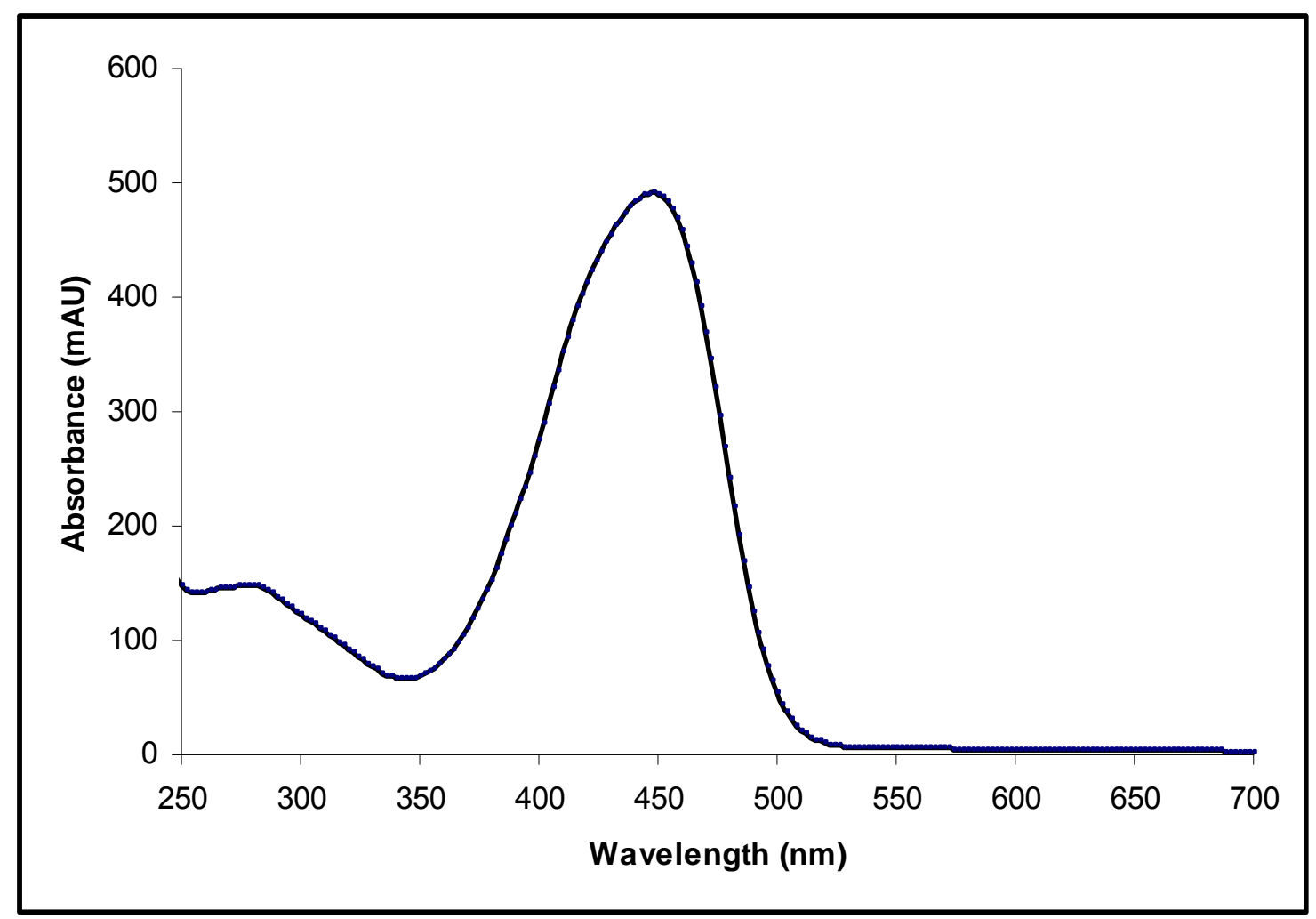

Figure 2.2. UV-VIS spectrum of bilirubin from S. nicolai (solvent system: 9:1 0.04 mM sodium acetate in methanol: 1\% aqueous ammonium acetate). 


\title{
III. THE ANIMAL PIGMENT BILIRUBIN IDENTIFIED IN STRELITZIA REGINAE, THE BIRD OF PARADISE FLOWER.
}

\begin{abstract}
Strelitzia reginae Aiton is an iconic plant known for its vibrant orange and blue inflorescences. Floral pigments include carotenoids and the anthocyanin delphinidin-3rutinoside. Strelitzia reginae has black seeds with vivid orange arils, yet the basis for the orange color is unknown. I recently discovered bilirubin in the arils of S. nicolai. Previously, this pigment was known only to exist in animals as a breakdown product of heme. Using high performance liquid chromatography with UV detection (HPLC/UV) and HPLC/UV/electrospray ionization tandem mass spectrometry (HPLC/UV/ESIMS/MS), I now show that bilirubin is the primary aril pigment of S. reginae, and is also present in low concentrations in its sepals (less than $44.0 \mathrm{ng} / \mathrm{g}$ ).

INTRODUCTION
\end{abstract}

Strelitzia reginae (family Strelitziaceae, order: Zingiberales), the Bird of Paradise Plant, is an herbaceous monocot native to South Africa but widely cultivated in warm temperate and tropical regions. Aside from the shape of its inflorescence, which resembles the head of a bird, S. reginae is also admired for its brilliant floral coloration. Each flower is composed of three vibrant orange sepals and three blue petals (Fig. 3.1A). At least nineteen carotenoids are present in the sepals (Simpson et al., 1975; Tappi and Menziani, 1955), and the anthocyanin delphinidin-3-rutinoside is found in the petals (Harborne, 1967). Anthocyanins are stored in the vacuole of petal cells (Kronsteadt and Walles, 1986), while carotenoids in mature sepal tissue are stored in spindle shaped chromoplasts 
(Simpson et al., 1975). Petal color is enhanced by papillar processes in the epidermis which refract light (Kronsteadt and Walles, 1986).

In contrast to the conspicuous flowers, the capsular fruit of $S$. reginae is pale and partially obscured by the bract during development. However, at maturity the capsule breaks open to reveal intensely colored orange arillate seeds (Fig. 3.1B-C). Remarkably, aril color remains unchanged years after cell death, a quality which likely contributes to the continued attraction of avian frugivores (Frost, 1980). We recently found the orange tetrapyrrole bilirubin to be the primary pigment in the arils of Strelitzia nicolai, a close relative of S. reginae (Pirone et al., 2009). Bilirubin was previously known in the animal kingdom where it is produced as a breakdown product of heme. Preliminary high performance liquid chromatography (HPLC) and ultraviolet-visible (UV) spectrometry analyses suggested that bilirubin is also present in the arils of S. reginae. I was therefore interested in whether this unusual pigment is indeed present in those arils, and whether it is also present in the flowers. I use HPLC/UV and HPLC/UV/electrospray ionizationtandem mass spectrometry (HPLC/UV/ESI-MS/MS) to investigate these questions. I also observe the aril cells using light microscopy to determine the location of pigment within the aril and sepal cells.

\section{MATERIALS AND METHODS}

Sepal tissue was collected from a single clonal plant at Fairchild Tropical Botanic Garden in Miami, FL. Aril tissue was obtained from two plants at Ellison Horticulture Pty. Ltd. in Allston, Australia. It was not possible to analyze aril and sepal tissue from the same individuals. Strelitzia reginae flowers in Miami, but does not set fruit. Bilirubin is known to decompose in heat, light, and oxygen. Preliminary analyses did not indicate 
that bilirubin is stable in sepal tissue, but they did suggest that bilirubin is stable in aril tissue for at least several months, likely a result of the high lipid content of the tissue. Therefore it was necessary to analyze fresh sepal tissue from local plants, but it was possible to analyze imported aril tissue.

For each sepal sample, $20.0 \mathrm{~g}$ of fresh tissue was ground in a blender with $100 \mathrm{~mL}$ methanol for two minutes, and was then filtered through a Buchner funnel. The residue was re-extracted with $50 \mathrm{~mL}$ of chloroform in a mortar and pestle, and this procedure was repeated until sepals were colorless. Methanol and chloroform extracts were pooled, and $100 \mathrm{~mL}$ of water was added. The mixture was left in a separatory funnel for five minutes, and then the (lower) chloroform layer was collected, filtered with a PTFE 0.2 $\mu \mathrm{m}$ filter, and divided into two equal aliquots. Each aliquot was dried to completion in a rotary evaporator at $30 \mathrm{C}$. For each aril sample, $0.05 \mathrm{~g}$ tissue from a single aril was ground by a mortar and pestle and extracted with chloroform repeatedly until the chloroform extracts were colorless. As above, the chloroform extract was filtered, divided into two equal aliquots, and dried on a rotovap. Sepal and aril tissue were sampled in duplicate. To determine the presence of bilirubin, one aliquot from each sample was analyzed via HPLC and the second aliquot was analyzed via HPLC/ESIMS/MS.

HPLC/UV: HPLC/UV analyses were performed on a Thermo-Finnigan SpectraSystem HPLC apparatus with a variable wavelength PDA detector (SMC1000, P4000, AS3000, UV6000LP; Thermo Electro Corporation, San Jose, CA, USA). Extract was redissolved in dimethyl sulfoxide (DMSO), partitioned with hexane to remove lipids, and chromatographed on a reverse phase ODS-A column ( $5 \mu \mathrm{m}, 4.3 \times 150 \mathrm{~mm}$; Waters 
Corporation, Milford, MA, USA). Mobile phase A was $0.1 \%$ formic acid in methanol, and mobile phase B was $0.1 \%$ formic acid in water. The HPLC gradient (at $1.0 \mathrm{~mL} / \mathrm{min}$ ) was started at $40 \% \mathrm{~A}$ and increased linearily to $95 \% \mathrm{~A}$ over $40 \mathrm{~min}$, then held constant at $95 \% \mathrm{~A}$ and $5 \% \mathrm{~B}$ for 10 minutes. Bilirubin was identified by comparing the retention time and UV-Visible spectra of S. reginae pigments with bilirubin standard (Sigma-Aldrich; St. Louis, MO, USA), which had a retention time of 42.9 min and a maximum absorbance at $444 \mathrm{~nm}$ in the HPLC solvent system described above. Bilirubin concentrations were determined by comparison with a standard curve $\left[\left(\mathrm{R}^{2}=.995\right)\right.$ estimated detection limit $=20 \mathrm{ng}$ injected on column] (Fig. 3.2). Preliminary analysis of sepal tissue showed compounds which eluted at retention times similar to that of bilirubin. The UV-Visible spectra of these compounds were similar to carotenoids. To avoid the possible overlap of the HPLC/UV spectra of these pigments with that of bilirubin, I treated sepals with diazomethane to convert bilirubin to its dimethyl ester, i.e. both carboxylic acids were converted to methyl esters $\left(\lambda_{\max }=453 \mathrm{~nm}\right.$ in HPLC solvents described above) (Kuenzle, 1973). Diazomethane was prepared from diazald according to the method of Vogel et al. (1989). Chloroform extracts of the sepals were treated with an excess of a solution of diazomethane in order to form the bilirubin dimethyl ester. The addition of the diazomethane was deemed to be complete when effervescence was no longer observed. The excess diazomethane was destroyed by the addition of a few drops of acetic acid. Although the diazomethane would also methylate any other carboxylic acid impurities in the extract, such ester byproducts did not interfere in any way with the observance of the bilirubin dimethyl ester peak in the HPLC analyses. Thus, it was unnecessary to carry out additional purification of the of the sepal 
extracts. The retention time of bilirubin dimethyl ester was $31.7 \mathrm{~min}$, thus enabling us to observe it without the interference of the other pigments. A standard curve for bilirubin dimethyl ester $\left[\left(\mathrm{R}^{2}=1\right)\right.$, estimated detection limit $=35.0 \mathrm{ng}$ injected on column $]$ was constructed by treating bilirubin standard with diazomethane. Identification of the peak at 31.7 minutes as bilirubin dimethyl ester was verified by comparison with bilirubin dimethyl ester standard (Frontier Scientific, Logan, UT, USA), which also eluted at 31.7 minutes. For samples in which bilirubin was detected via HPLC/ESI-MS/MS but not HPLC/UV, I assumed the mass of bilirubin to be less than the estimated detection limit of bilirubin or bilirubin treated with diazomethane. Standard deviation values were not calculated because of the low sample size of two. Instead, concentration values for both samples of aril and sepal tissue are presented in Table 3.1.

HPLC/UVESI-MS/MS: The plant extract was redissolved in dimethyl sulfoxide (DMSO) (Certified ACS; Fisher Scientific) and analyzed via reverse phase C8 HPLC/UV/ESIMS/MS utilizing both positive and negative electrospray ionization ( (+) and (-) ESI) and a number of different MSn scans. The HPLC/UV analyses were performed with an Agilent Technologies HPLC with binary pumps (1100 series; Santa Clara, CA, USA), a Symmetry C8 HPLC column (5 $\mu$ m, 2.1 x 150 mm; Waters Corporation, Milford, MA, USA) and an Agilent UV-Visible detector (G1314A). The mobile phase A was $0.2 \%$ acetic acid (glacial, biochemical grade (99.8\%); ACROS organics, Morris Plains, NJ, USA) in $\mathrm{H}_{2} \mathrm{O}$ (HPLC grade, Honeywell Burdick \& Jackson, Muskegon, MI, USA) and mobile phase B was $0.2 \%$ acetic acid in acetonitrile (LC-MS grade, Honeywell Burdick \& Jackson). The HPLC gradient (at $0.2 \mathrm{~mL} / \mathrm{min}$ ) was started at $20 \% \mathrm{~B}$ at time 0 and increased linearily to $85 \%$ B over 30 min and then increased linearly to $100 \% \mathrm{~B}$ over 15 
min. The column was held at $100 \%$ B until monitoring of the UV/MS signal showed no further elution of peaks. For some extracts this was more than $150 \mathrm{~min}$. The UV-Vis response was monitored at $450 \mathrm{~nm}$ for bilirubin, which eluted at approximately $39 \mathrm{~min}$.

All mass spectrometry data were obtained with a Finnigan MAT (San Jose, CA, USA) LCQ classic quadrupole ion trap mass spectrometer equipped with an electrospray ionization source (ESI). The ESI was operated with a nitrogen sheath and auxiliary gas flows of 65 and 5, respectively (unitless, software parameter) with a spray voltage of 3.3 $\mathrm{kVand}$ a heated capillary temperature of $250 \mathrm{C}$. The heated capillary voltage was $+15 \mathrm{~V}$ and $-22 \mathrm{~V}$ for $(+)$ and (-)ESI, respectively, while the tube lens was operated at $0 \mathrm{~V}$ for both ESI polarities. Collision-induced dissociation (CID) was conducted with a parent ion isolation of $3 \mathrm{u}, \mathrm{CID}$ energy of $37.5 \%$, qCID of 0.25 and CID time of $30 \mathrm{~ms}$.

With (+)ESI, bilirubin produced an m/z $585[\mathrm{M}+\mathrm{H}]+$ ion and an $\mathrm{m} / \mathrm{z} 583$ ion because of oxidation during ionization. The $\mathrm{m} / \mathrm{z} 585$ and $\mathrm{m} / \mathrm{z} 583$ ions underwent collision induced tandem mass spectrometry (CID-MS/MS) to form m/z 299, and 297 ions, respectively, as major product ions. With (-)ESI-MS, bilirubin produced m/z 583 $[\mathrm{M}-\mathrm{H}]-$ and $\mathrm{m} / \mathrm{z} 581$ ions which were dissociated to form $\mathrm{m} / \mathrm{z} 285$ and 537 major product ions, respectively. Bilirubin was identified in the plant extracts by matching of retention time and $(+)$ and (-)ESI-MS and -MS/MS spectra with those of an authentic bilirubin standard.

The DMSO solvent blanks were analyzed before and after analyses of each extract and after analyses of bilirubin standards to check for carryover of bilirubin. These DMSO blanks were repeated if significant levels of bilirubin were carried over. 
Microscopy: Sepal and aril tissues were observed in a Leica Model DME brightfield compound microscope with a 40X objective and photographed using a Nikon CoolPix 4500 camera (2272 x 1704 pixels). Tissues were sectioned by hand and mounted in water.

\section{RESULTS AND DISCUSSION}

Bilirubin was present in both the aril and sepal extracts of S. reginae. Each HPLC/UV analysis of the aril extracts showed a single peak with retention time and UV-Visible spectrum which matched those of the bilirubin standard (Fig. 3.3). Bilirubin identification was confirmed by HPLC/ESI-MS/MS (Figs. 3.4-3.5). Bilirubin was also identified in sepal samples via HPLC/ESI-MS/MS (Fig. 3.6), but was not detected via HPLC/UV, even after treatment with diazomethane. The concentration of bilirubin in the sepals was less than $44.0 \mathrm{ng} / \mathrm{g}$ of fresh tissue $(\mathrm{n}=2)$, while the average concentration in the aril was $17.4 \mathrm{mg} / \mathrm{g}$ fresh tissue $(\mathrm{n}=2)$ (see Table 3.1 for concentration values of all samples).

The low sample size was adequate for ensuring the detection of bilirubin in S. reginae, as false positives may have occurred via contamination of the sample or the equipment, but not by chance alone. Contamination was avoided by the washing of glassware multiple times (soap and water, acetone, chloroform), the use of disposable vials when possible, and changing gloves after the analysis of each sample. Blank(s) were run between all chromatographic procedures to avoid the carryover of bilirubin between samples and ensure a flat baseline.

In the arils, bilirubin is not only present in high concentration, but it is also the primary pigment, and is thus responsible for color production. In contrast, it is likely that the low 
concentration of bilirubin in the sepals preclude it from contributing significantly to color. Furthermore, high concentrations of sepal carotenoids (Simpson et al., 1975; Tappi and Menziani, 1955) likely mask low levels of bilirubin. Whether bilirubin serves a function other than color production in S. reginae remains unclear. In mature aril tissue, bilirubin was present as granular bodies irregularly distributed throughout the cell (Fig. 3.1D). In mature sepal tissue, I observed elongate structures (Fig. 3.1E) which were previously identified as containing carotenoids (Simpson et al., 1975). I saw no evidence of pigment bodies which might contain bilirubin. This study provides new insight into color production in an iconic tropical plant. It also demonstrates the first example of bilirubin in a flower, and verifies the presence of bilirubin in a plant species other than S. nicolai. Coupled with further research on the function, distribution, and synthesis of bilirubin in plants, this information may be of use for practical applications such as the manipulation of color through breeding and genetics.

\section{ACKNOWLEDGMENTS}

Jodie V. Johnson, J. Martin E. Quirke, Horacio A. Priestap, and David W. Lee are coauthors on this paper. I thank the National Institute of Health (NIH) and the Center for Ethnobiology and Natural Products (CeNAP) at FIU and for lab facilities, K. G. Furton for his generous support of H.A. Priestap, T. DeFanti for his images, and C. Husby and D. Ellison for aril material. This research was funded by the United States Environmental Protection Agency (EPA) under the Greater Research Opportunities (GRO) Graduate Program and the Office of Research (OSRA) at FIU. Funding for the 
Finnigan MAT LCQ Classic was provided by NSF CHE 9613678. I thank Waters Corporation for the donation of the C8 HPLC column.

\section{LITERATURE CITED}

Frost, P. G. H. 1980. Fruit - frugivore interactions in a South African coastal dune forest. Proc. Internat. Ornith. Congress: 1179-1184.

Harborne, J.B. 1967. Comparative biochemistry of the flavonoids. Academic Press, New York.

Kronsteadt, E.C. and B. Walles. 1986. Anatomy of the Strelitzia reginae flower (Strelitziaceae). Nordic J. Bot. 6: 307-320.

Kuenzle, C.C, M.H., Weibel, and R.R. Pelloni. 1973. The reaction of bilirubin with diazomethane. Biochem. J. 133: 357-368.

Pirone, C. L., J.M.E., Quirke, H., Priestap, and D.W. Lee. 2009. Animal pigment bilirubin discovered in plants. J. Amer. Chem. Soc. 131 (8): 2830.

Simpson, D.J., M.R., Baqar, and T.H. Lee. 1975. Ultrastructure and carotenoid composition of chromoplasts of the sepals of Strelitzia reginae Aiton during floral development. Ann. Bot. 39: 175-183.

Tappi, G. and E. Menziani. 1955. Sui carotenoidi di Strelitzia reginae. Gazz. Chim. Ital. 85: $720-724$.

Vogel, A.I., B.S., Furnis, A.J., Hannaford, P.W.G. Smith, and A.R. Tatchell. 1989. Textbook of Practical Organic Chemistry. Pearson Prentice Hall, Harlow. 
Table 3.1. Concentration of bilirubin in S. reginae arils and sepals.

\begin{tabular}{|l|l|l|}
\hline Sample & Aril & Sepal \\
\hline 1 & $21.97 \mathrm{mg} / \mathrm{g}$ & $<44 \mathrm{ng} / \mathrm{g}$ \\
\hline 2 & $12.82 \mathrm{mg} / \mathrm{g}$ & $<44 \mathrm{ng} / \mathrm{g}$ \\
\hline
\end{tabular}



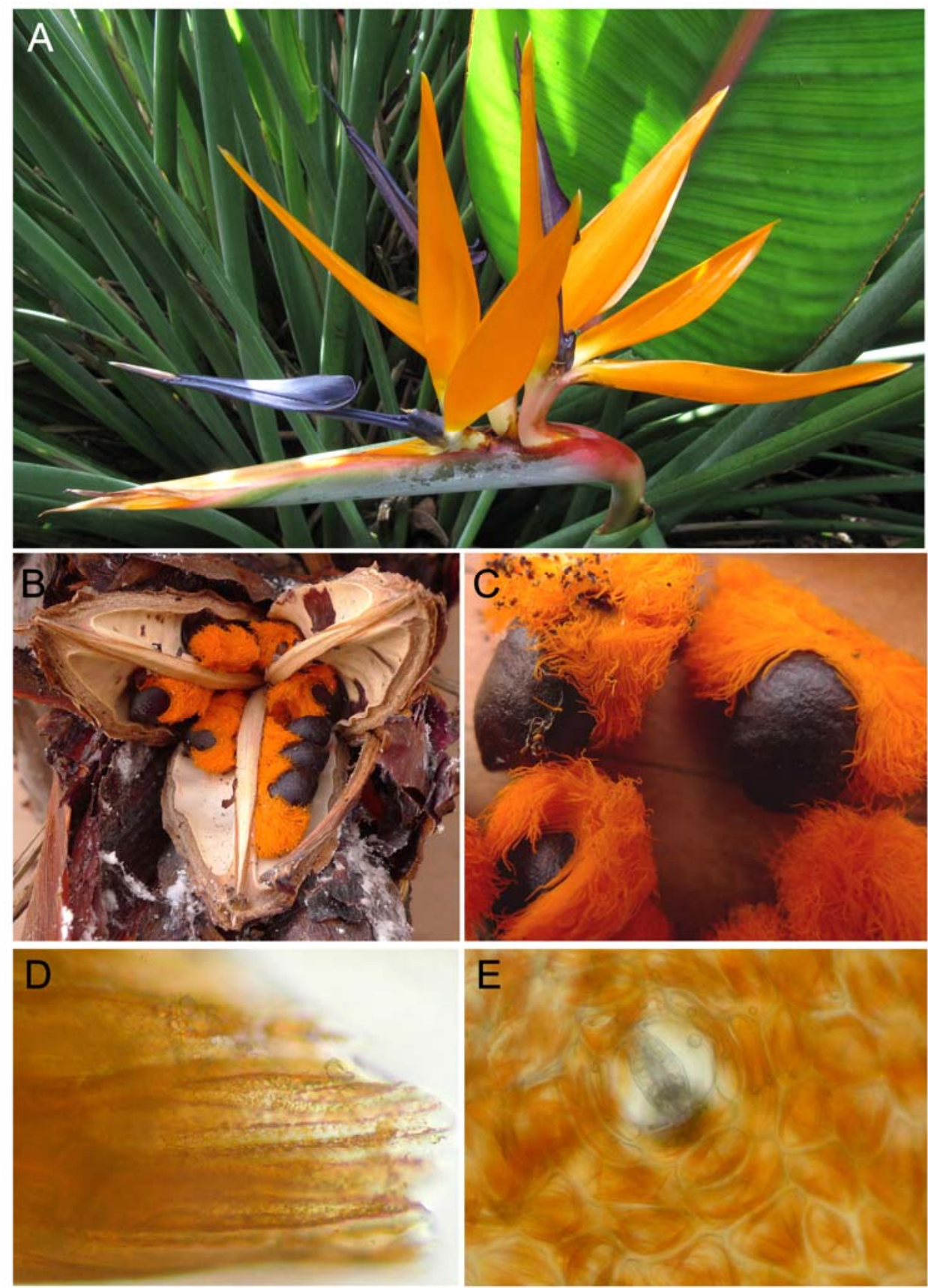

Figure 3.1. Strelitzia reginae. A. Inflorescence of $S$. reginae photographed at Fairchild Tropical Botanic Garden. Inflorescence is $\sim 22 \mathrm{~cm}$ long. B. Mature and open capsule of $S$. reginae with arillate seeds exposed, capsules $\sim 5.5 \mathrm{~cm}$ across. Photographed in Del Mar, CA by Tom DeFanti. C. Arillate seeds of S. reginae, seeds $\sim 4 \mathrm{~mm}$ in diameter, photographed by Tom DeFanti. D. Aril fibers of S. reginae, in longitudinal view. Bilirubin is present in the crystalline granules attached to inner cell wall of these dead cells. Length of image $=300 \mu \mathrm{m}$. E. Paradermal view of epidermal cells of orange sepals of S. reginae. Bilirubin granules are not seen in these cells, the color produced primarily by carotenoids in large chromoplasts. Length of image $=300 \mathrm{~nm}$. 


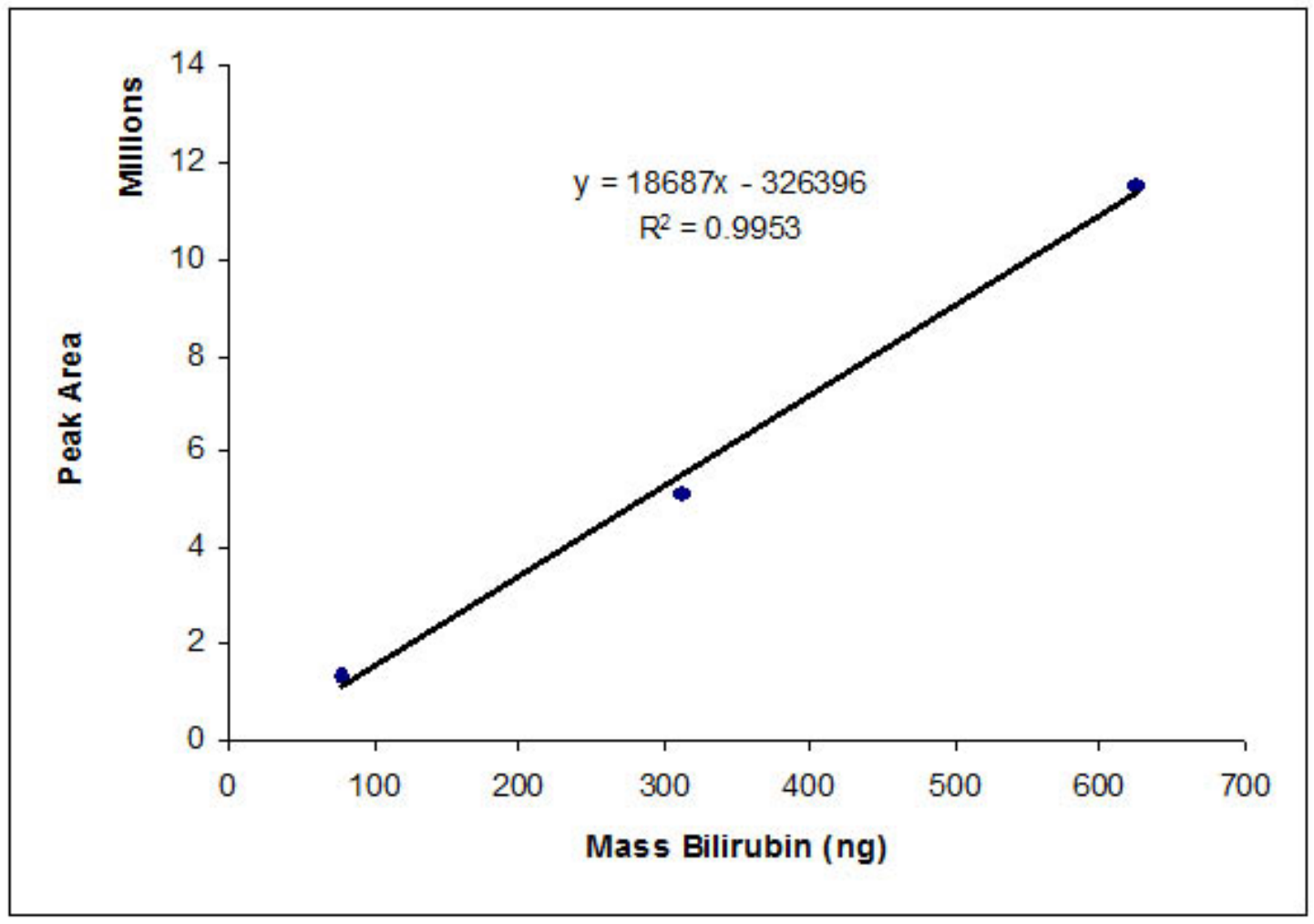

Figure. 3.2. HPLC standard curve of bilirubin-IX $\alpha$. 

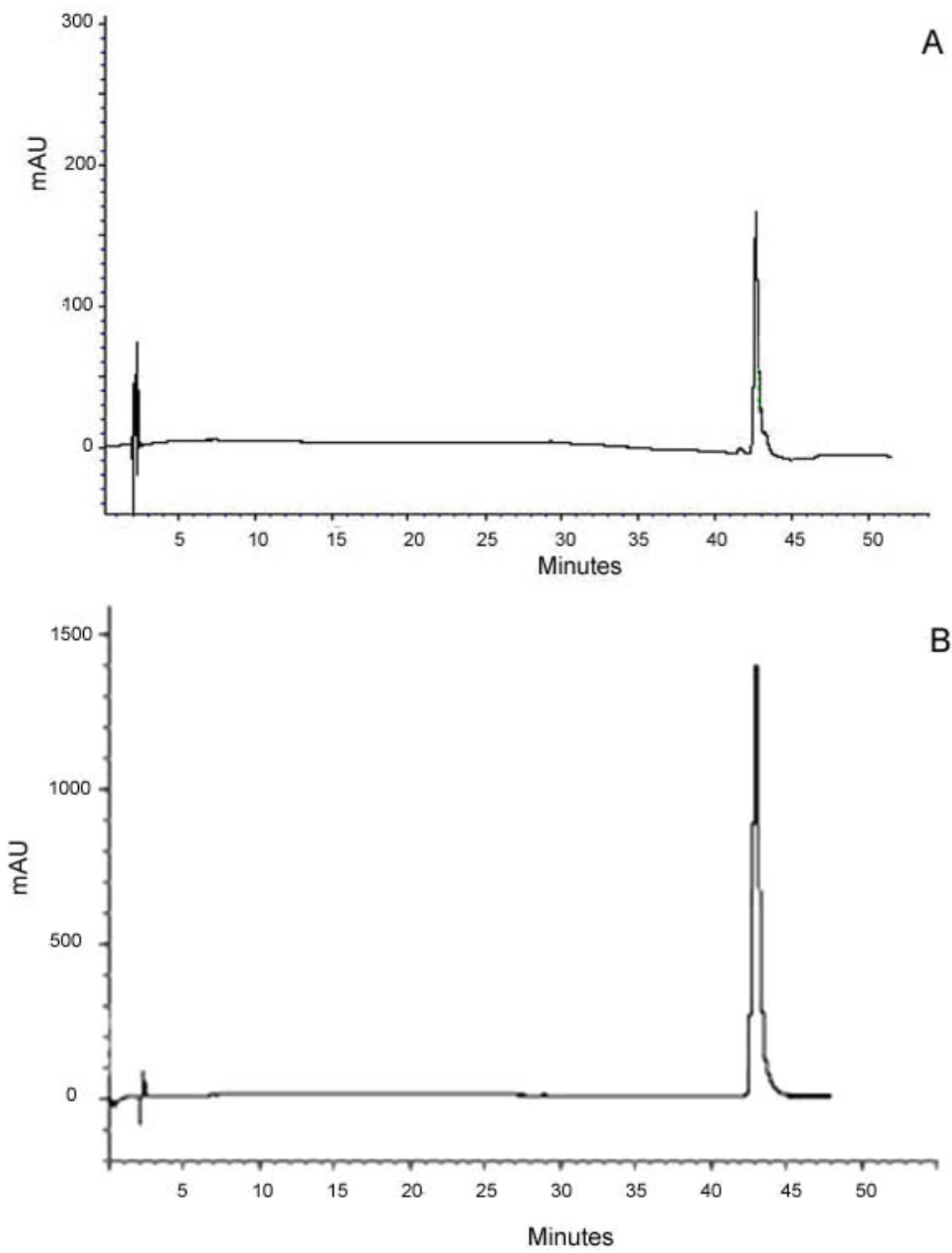

Figure. 3.3. HPLC chromatograms of (A) Bilirubin standard and (B) Aril extract of $S$. reginae. 

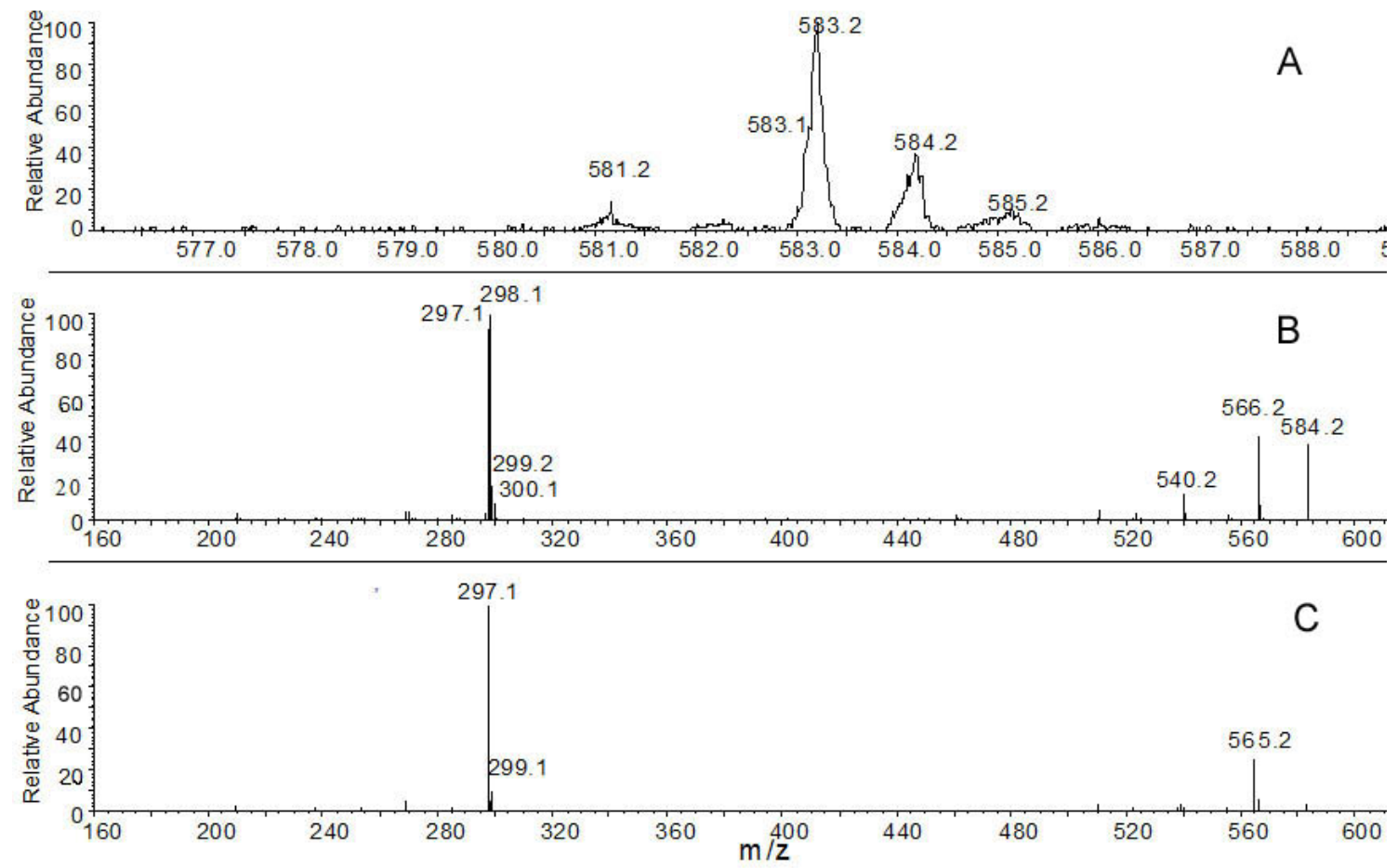

Figure. 3.4. Bilirubin standard via (+)ESI-Zoom-MS and MS/MS: (A) Zoom-MS of molecular ion region; (B) product spectrum of $\mathrm{m} / \mathrm{z} 585$; (C) product spectrum of $\mathrm{m} / \mathrm{z} 583$. 

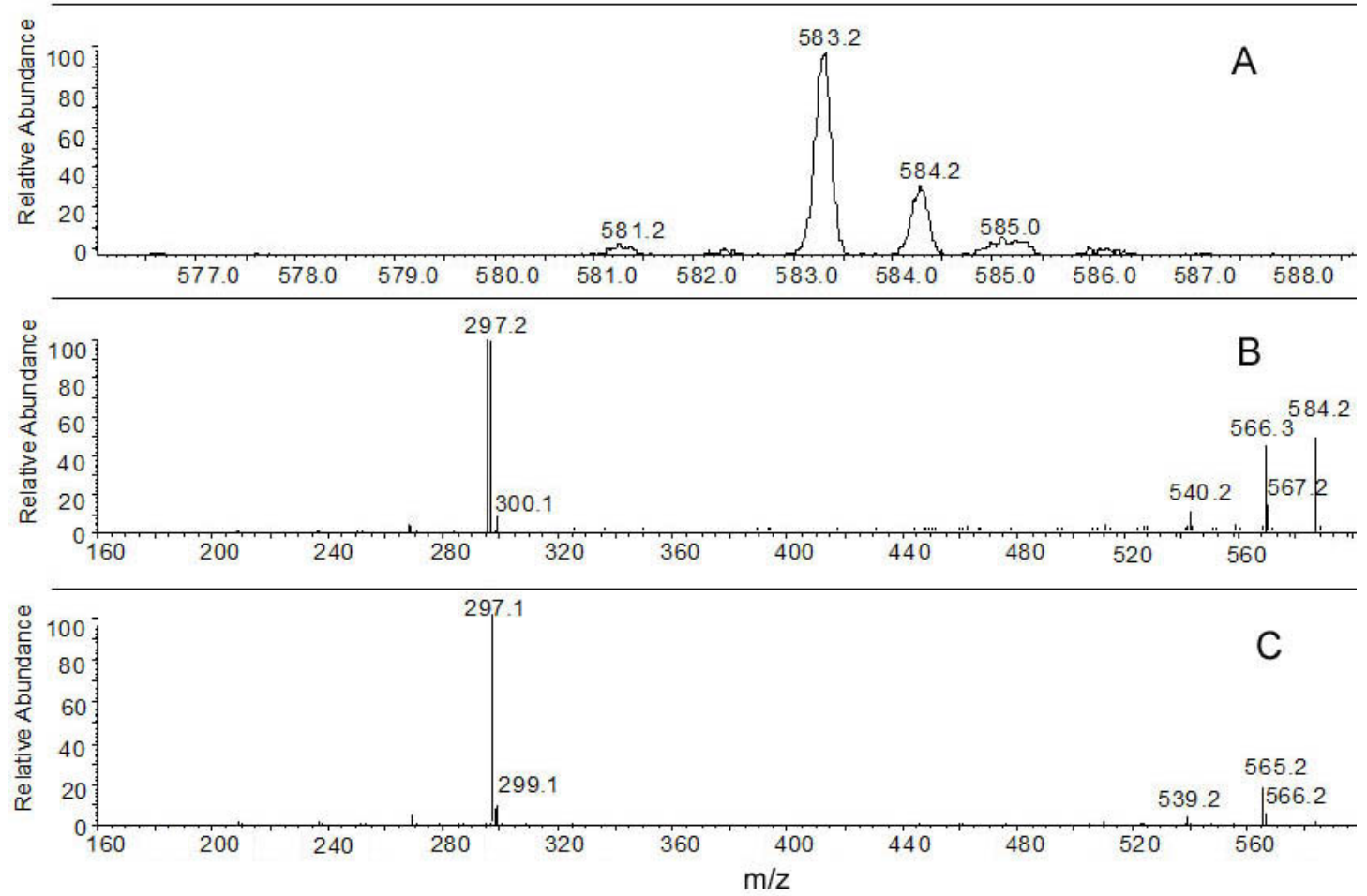

Figure. 3.5. Bilirubin in S. reginae aril via (+) ESI-MS and MS/MS: (A) Zoom-MS of molecular ion region; (B) product spectrum of $\mathrm{m} / \mathrm{z} 585$; (C) product spectrum of $\mathrm{m} / \mathrm{z} 583$. 

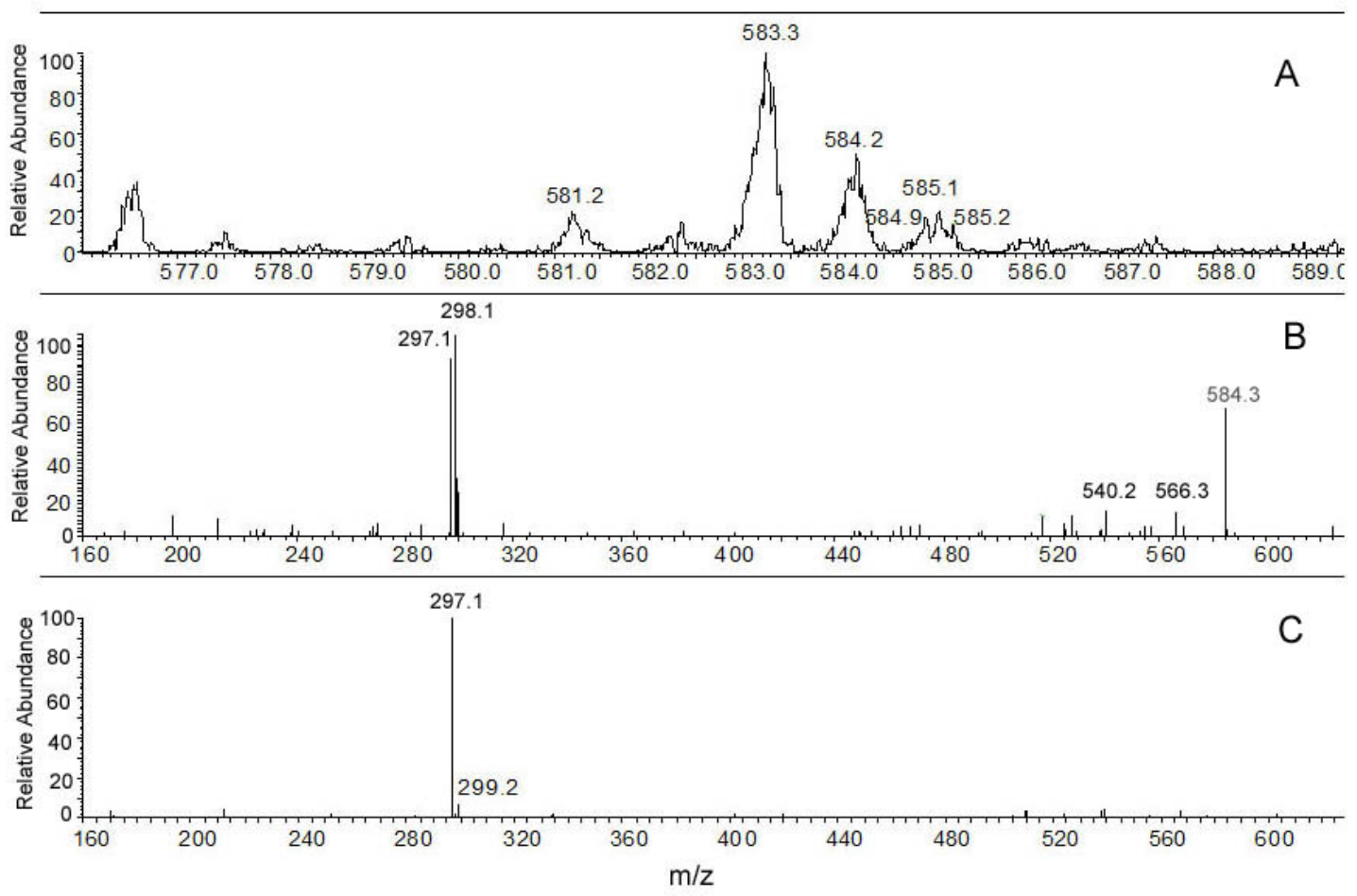

Figure. 3.6. Bilirubin in S. reginae sepal extract via (+) ESI-Zoom-MS and MS/MS: (A) Zoom-MS of molecular ion region; (B) product spectrum of $\mathrm{m} / \mathrm{z} 585$;

(C) product spectrum of $\mathrm{m} / \mathrm{z} 5$. 


\title{
IV. BILIRUBIN PRESENT IN DIVERSE ANGIOSPERMS
}

\author{
ABSTRACT \\ Bilirubin is an orange-yellow tetrapyrrole produced from the breakdown of heme by \\ mammals and some other vertebrates. Plants, algae, and cyanobacteria synthesize \\ molecules similar to bilirubin, including the protein-bound bilins and phytochromobilin \\ which harvest or sense light. Recently, I discovered bilirubin in the arils of Strelitzia \\ nicolai, the white bird of paradise tree, which was the first example of this molecule in a \\ plant. Subsequently, I identified bilirubin in both the arils and flowers of Strelitzia \\ reginae, the bird of paradise flower. In the arils of both species, bilirubin is present as the \\ primary pigment, and thus functions to produce color. Previously, no tetrapyrroles were \\ known to generate display color in plants. I was therefore interested in determining \\ whether bilirubin occurs in other plants, and whether it contributes to color in other \\ species. In this paper, I use high performance liquid chromatography with UV detection \\ (HPLC/UV) and HPLC/UV/electrospray ionization tandem mass spectrometry \\ (HPLC/UV/ESI-MS/MS) to search for bilirubin in ten species across diverse angiosperm \\ lineages. Bilirubin was present in eight species from the orders Zingiberales, Arecales, \\ and Myrtales, but only contributed to color in Strelitziaceae species. The wide \\ distribution of bilirubin in angiosperms indicates the need to reassess some metabolic \\ details of an important and universal biosynthetic pathway in plants, and further explore \\ its evolutionary history and function. Although color production was limited to the \\ Strelitziaceae in this study, further sampling may indicate otherwise.
}




\section{INTRODUCTION}

Tetrapyrroles occur throughout the plant kingdom; this class of molecules includes vital biosynthetic products such as chlorophyll and heme. In plants, the degradation of heme forms first biliverdin IX- $\alpha$, and subsequently phytochromobilin, the precursor of the phytochrome chromophore, an essential light-sensing molecule (Tanaka et al., 2007). In mammals and some vertebrates, biliverdin-IX $\alpha$ is also formed from the degradation of heme, but it is transformed into the yellow-orange pigment bilirubin-IX $\alpha$. I have identified bilirubin-IX $\alpha$ (henceforth referred to as bilirubin) as the major pigment in the orange arils of Strelitzia nicolai, the white bird of paradise tree (Pirone et al., 2009). Although ubiquitous in animals, this is the first example of bilirubin in a plant. Subsequently, I have discovered this pigment in the sepals and arils of S. reginae, the bird of paradise flower, indicating the pigment is not unique to S. nicolai (Pirone et al., 2010).

In S. nicolai and S. reginae, bilirubin is a novel biosynthetic source of display color. Most plant pigments are derived from one of three metabolic pathways: terpenoid (carotenoids), phenylpropanoid (flavonoids), or indole (betalains) (Davies, 2004; Grotewold, 2006; Lee, 2007). Betalain synthesis is restricted to families in the order Caryophyllales, while carotenoids and flavonoids (including anthocyanins) are pervasive in the plant kingdom (Harborne, 1967; Goodwin, 1988). A rare group of pigments, the phenalenones, has been documented in several species in the Strelitziaceae and related families (Davies, 2004). However, to my knowledge, neither the phenalenones nor other rare pigments play a significant role in color production. Bilirubin is thus the first product of an additional biosynthetic route, the tetrapyrrole pathway, to produce conspicuous color in a plant reproductive structure. Chlorophylls, which are also 
synthesized via the tetrapyrrole pathway, primarily produce color in foliage, thus forming a green background upon which the contrasting colors of flowers and fruits are displayed. While chlorophylls occasionally produce color in reproductive structures, these are fairly inconspicuous.

Given the presence of bilirubin in Strelitzia, it is interesting to determine if the pigment is produced by other taxa within the Strelitziaceae, in families closely allied to the Strelitziaceae (as in the Zingiberales), as well as throughout other angiosperms. Preliminary high performance liquid chromatography (HPLC/UV) analyses of aril extracts of an additional species in the Strelitziaceae, Phenakospermum guyannense, showed a pigment with a retention time and UV-Visible spectra which matched those of bilirubin. Here, I use HPLC/UV and HPLC/UV/electrospray ionization-tandem mass spectrometry (HPLC/UV/ESI-MS/MS) to confirm the presence of bilirubin in $P$. guyannense and investigate the presence of bilirubin in the mature fruits from nine additional species and the flowers of a single additional species. Six species are within the order Zingiberales, and four are from diverse angiosperm orders (Table 4.1). I discuss our findings within a phylogenetic and biochemical context, and comment on a possible ecological role for bilirubin as a color signal to attract animal dispersers and pollinators.

\section{MATERIALS AND METHODS}

Plant material was collected from Fairchild Tropical Botanic Garden in Miami, FL except aril tissue from Strelitzia reginae, which was obtained from Ellison Horticulture Pty. Ltd. in Allstonville, New South Wales, Australia, and P. guyannense, which was collected by John Kress in the Demerara-Mahaica region of Guyana, South America. Tissue for each sample and its replicate were composed of tissue from one or multiple inflorescences or 
infructescences from a single, sometimes clonal, individual. For the names and taxonomic affiliations of species sampled, see Table 4.1. The replicate aril samples of $P$. guyannense came from different individuals. For each sample (except aril samples), 20.0 $\mathrm{g}$ of fresh tissue was ground in a blender with $100 \mathrm{~mL}$ methanol for two minutes, and was then filtered through a Buchner funnel. The residue was re-extracted with chloroform in a mortar and pestle. Methanol and chloroform extracts were pooled, and $100 \mathrm{~mL}$ of water was added. The mixture was left in a separatory funnel for five minutes, and then the (lower) chloroform layer was collected, filtered with a polytetrafluoroethelene (PTFE) $0.2 \mu \mathrm{m}$ filter, and divided into two equal aliquots. Each aliquot was dried to completion in a rotary evaporator at $30^{\circ} \mathrm{C}$. For each aril sample, $0.05 \mathrm{~g}$ tissue from a single aril was ground by a mortar and pestle and extracted with chloroform repeatedly until the chloroform extracts were colorless. As above, the chloroform extract was filtered, divided into two equal aliquots, and dried on a rotary evaporator. All tissues were sampled in duplicate. To determine the presence of bilirubin, one aliquot from each sample was analyzed via HPLC and the second aliquot was analyzed via HPLC/ESIMS/MS.

HPLC/UV: The HPLC/UV analyses were performed on a Thermo-Finnigan SpectraSystem HPLC apparatus with a variable wavelength photodiode array (PDA) detector (SMC1000, P4000, AS3000, UV6000LP; Thermo Electro Corporation, San Jose, CA, USA). Each extract was redissolved in dimethyl sulfoxide DMSO, partitioned with hexane to remove lipids, and chromatographed on a reverse phase ODS-A column ( $5 \mu \mathrm{m}$, $4.3 \times 150 \mathrm{~mm}$; Waters Corporation, Milford, MA, USA). The mobile phase A was $0.1 \%$ formic acid in methanol, and mobile phase B was $0.1 \%$ formic acid in water. The HPLC 
gradient (at $1.0 \mathrm{~mL} / \mathrm{min}$ ) was started at $40 \% \mathrm{~A}$ and increased linearily to $95 \%$ A over 40 min, then held constant at 95\% A and 5\% B for 10 minutes. Bilirubin was identified by comparing the retention time and UV-Visible spectra of sample pigments with bilirubin standard (Sigma-Aldrich; St. Louis, MO, USA), which had a retention time of $42.9 \mathrm{~min}$ and a maximum absorbance at $444 \mathrm{~nm}$ in the above HPLC solvent system. Bilirubin concentrations were determined by comparison with a standard curve $\left[\left(\mathrm{R}^{2}=.995\right)\right.$ estimated detection limit $=20 \mathrm{ng}$ injected on column]. Preliminary analysis of some plant extracts showed compounds which eluted at retention times similar to that of bilirubin. The UV-Visible (ultraviolet-visible) spectra of these compounds were similar to carotenoids. To avoid the possible overlap of the HPLC/UV spectra of these pigments with that of bilirubin, I treated non-arillate samples (Table 4.2) with diazomethane to convert bilirubin to its dimethyl ester, i.e., both carboxylic acids were converted to methyl esters ( $\lambda_{\max }=453 \mathrm{~nm}$ in HPLC solvents described above) (Kuenzle, 1973). Diazomethane was prepared from diazald according to Vogel et al. (1989). Chloroform extracts of the sepals were treated with an excess of a solution of diazomethane in order to form the bilirubin dimethyl ester. The addition of the diazomethane was deemed to be complete when effervescence was no longer observed. The excess diazomethane was destroyed by the addition of a few drops of acetic acid. Although the diazomethane would also methylate any other carboxylic acid impurities in the extract, such ester byproducts did not interfere in any way with the observance of the bilirubin dimethyl ester peak in the HPLC analyses. Thus, it was unnecessary to carry out additional purification of the sepal extracts. With the HPLC/UV conditions described above, the retention time of bilirubin dimethyl ester was 31.7 min, thus making it possible to 
observe the compound without interference from other pigments. A standard curve for bilirubin dimethyl ester $\left[\left(\mathrm{R}^{2}=1\right)\right.$, estimated detection limit $=35.0 \mathrm{ng}$ injected on column $]$ was constructed by treating bilirubin standard with diazomethane. Identification of the peak at 31.7 minutes as bilirubin dimethyl ester was verified by comparison with bilirubin dimethyl ester standard (Frontier Scientific, Logan, UT, USA), which also eluted at 31.7 minutes. For samples in which bilirubin was detected via HPLC/ESIMS/MS but not HPLC/UV, I assumed the mass of bilirubin to be less than the estimated detection limit of bilirubin or bilirubin treated with diazomethane. Standard deviation values were not calculated owing to the low sample size. Instead, concentration values for the replicate samples of each plant are presented in Table 4.2.

HPLC/UVESI-MS/MS: The plant extract was redissolved in DMSO (Certified ACS; Fisher Scientific) and analyzed via reverse phase C8 HPLC/UV/ESI-MS/MS utilizing both positive and negative ESI and a number of different MSn scans. HPLC/UV was performed with an Agilent Technologies HPLC with binary pumps (1100 series; Santa Clara, CA, USA), a Symmetry C8 HPLC column ( $5 \mu \mathrm{m}, 2.1$ x $150 \mathrm{~mm}$; Waters Corporation, Milford, MA, USA) and an Agilent UV-Visible detector (G1314A). The mobile phase A was $0.2 \%$ acetic acid (glacial, biochemical grade (99.8\%); ACROS organics, Morris Plains, NJ, USA) in $\mathrm{H}_{2} \mathrm{O}$ (HPLC grade, Honeywell Burdick \& Jackson, Muskegon, MI, USA) and mobile phase B was $0.2 \%$ acetic acid in acetonitrile (LC-MS grade, Honeywell Burdick \& Jackson). The HPLC gradient (at $0.2 \mathrm{~mL} / \mathrm{min}$ ) was started at $20 \% \mathrm{~B}$ at time 0 and increased linearily to $85 \% \mathrm{~B}$ over $30 \mathrm{~min}$ and then increased linearly to $100 \%$ B over $15 \mathrm{~min}$. The column was held at $100 \% \mathrm{~B}$ until monitoring of the ultraviolet-visible and mass spectrometry (UV/MS) signal showed no further elution of 
peaks. For some extracts this was more than $150 \mathrm{~min}$. The UV-Visible response was monitored at $450 \mathrm{~nm}$ for bilirubin, which eluted at approximately $39 \mathrm{~min}$.

All mass spectrometry data were obtained with a Finnigan MAT (San Jose, CA, USA) LCQ classic quadrupole ion trap mass spectrometer equipped with an electrospray ionization source (ESI). The ESI was operated with a nitrogen sheath and auxiliary gas flows of 65 and 5, respectively with a spray voltage of $3.3 \mathrm{kV}$ and a heated capillary temperature of $250 \mathrm{C}$. The heated capillary voltage was $+15 \mathrm{~V}$ and $-22 \mathrm{~V}$ for $(+)$ and ()ESI, respectively, while the tube lens was operated at $0 \mathrm{~V}$ for both ESI polarities. Collision-induced dissociation (CID) was conducted with a parent ion isolation of $3 \mathrm{u}$, CID energy of $37.5 \%$, qCID of 0.25 and CID time of $30 \mathrm{~ms}$.

With $(+)$ ESI, bilirubin produced an $\mathrm{m} / \mathrm{z} 585[\mathrm{M}+\mathrm{H}]+$ ion and an $\mathrm{m} / \mathrm{z} 583$ ion because of oxidation during ionization. The $\mathrm{m} / \mathrm{z} 585$ and m/z 583 ions underwent collision induced dissociation tandem mass spectrometry (CID-MS/MS) to form m/z 299, and 297 ions, respectively, as major product ions. With (-)ESI-MS, bilirubin produced $\mathrm{m} / \mathrm{z} 583$ [M-H]- and m/z 581 ions which were dissociated to form m/z 285 and 537 major product ions, respectively. Bilirubin was identified in the plant extracts by matching of retention time and (+) and (-) ESI-MS and -MS/MS spectra with those of the authentic bilirubin standard.

False positives that could result from contamination during handling and analyses were avoided by the washing of glassware multiple times (soap and water, acetone, chloroform), the use of disposable vials when possible, and changing gloves after the preparation of each sample. Dimethyl sulfoxide (DMSO) solvent blanks were analyzed before and after analyses of each extract and after analyses of bilirubin standards to check 
for carryover of bilirubin. The DMSO blanks were repeated if significant levels of bilirubin were carried over to subsequent runs.

\section{RESULTS}

Bilirubin was present in eight of the ten species tested: Musa balbisiana Colla, Heliconia collinsiana Griggs, Costus lucanusianus J. Braun \& K. Schum, Ravenala madagascariensis Sonn., Phenakopsermum guyannense (L.C. Rich.) Endl. ex Miq., Hedychium coronarium J. Koenig, Gastrococos crispa (Kunth) H.E.Moore, and Eugenia luschnathiana Klotzch ex O.Berg (Table 4.2). Bilirubin was present in the fruits (including aril and peel) of all species except Costus lucanusianus, where it was present in the flowers (fruits were unavailable for sampling). In Ravenala madagascariensis and Phenakospermum guyannense, HPLC/UV analysis of the aril extracts showed a single peak with retention time and UV-Visible spectrum which matched those of the bilirubin standard. Bilirubin identification was confirmed by HPLC/ESI-MS/MS. Bilirubin was also identified in Musa balbisiana, Heliconia collinsiana, Costus lucanusianus, Hedychium coronarium, Gastrococos crispa, and Eugenia luschnathiana via HPLC/ESIMS/MS, but was not detected via HPLC/UV, even after treatment with diazomethane. In Heliconia collinsiana and Eugenia luschnathiana, bilirubin was detected in only one of the two replicate samples, while in all other species bilirubin was detected in both replicates. The concentration of bilirubin was highly variable among species. Concentrations ranged from less than $44 \mathrm{ng} / \mathrm{g}$ of fresh tissue ( $\mathrm{n}=2$ ) to $3.73 \mathrm{mg} / \mathrm{g}$ of fresh tissue $(\mathrm{n}=2)($ Table 4.2). 


\section{DISCUSSION}

I initially discovered bilirubin in S. nicolai (family: Strelitziaceae, order: Zingiberales), and also in the arils and sepals of S. reginae. Since similar secondary metabolites are sometimes expected to be found within members of a clade, I concentrated most of our sampling within the Strelitziaceae and the Zingiberales. Kress et al. (2001) divided the order into two major clades, the basal "banana group" which includes Musaceae, Strelitziaceae, Heliconiaceae, and Lowiaceae, and the more derived "ginger group", which includes the four remaining families (Fig. 4.1). Although resolution of intrafamilial relationships varies among studies, the ginger clade families are generally well resolved (Rudall et al., 1999; Chase et al., 2000; Givnish, 2006), and there is high support for the position of Lowiaceae as sister to Strelitziaceae (Rudall et al., 1997; Chase et al., 2000; Soltis et al., 2000; Givnish et al., 2006; Soltis et al., 2007). We sampled species from each banana group family, except from the Lowiaceae. This monotypic family consists of fifteen rare species within Orchidantha, and we were not able to obtain enough material for analyses. I selected Musa balbisiana (Musaceae), one of the wild progenitors of most cultivated bananas (Heslop-Harrison and Schwarzacher, 2007), Heliconia collinsiana (Heliconiaceae), and representatives from each of the two Strelitziaceae genera not previously analyzed for bilirubin content, Phenakospermum guyannense and Ravenala madagascariensis. I also sampled species from two of the most derived families in the order, Costus lucanusianus (Costaceae) and Hedychium coronarium (Zingiberaceae) (Kress, 2001). I mainly sampled orange fruits to maximize the potential chances of finding bilirubin, but we also included the blue arils of Ravenala 
madagascariensis, the yellow fruits of Heliconia collinsiana, and the multi-colored flowers of Costus lucanusianus.

To determine whether bilirubin is present in plants outside of the Zingiberales, I sampled species from the basal dicot order Laurales, two monocot orders, the Arecales and the Pandanales, and the eudicot order Myrtales, which is part of the Rosid clade. Selection of species within those orders (Table 4.1) was based on tissue availability and fruit color. The detection of bilirubin in Gastrococos crispa (family: Arecaceae, order: Arecales) and Eugenia luschnathiana (family: Myrtaceae, order: Myrtales), indicates that bilirubin is not restricted to Zingiberales and may be broadly distributed throughout the plant kingdom. However, the lack of detection of bilirubin in avocado, Persea americana Mill. (family: Lauraceae, order: Laurales) and Pandanus odorifer (Forssk.) Kuntze (family: Pandanaceae, order: Pandanales) suggests that bilirubin is not universal in plants at levels detectable by mass spectrometry.

The high concentration of bilirubin in the arils of $P$. guyannense indicates its role in color production. Previous studies indicated bilirubin is also responsible for color production in two other Strelitziaceae species, S. nicolai and S. reginae. Since brightly colored fruit displays often serve as signals to attract dispersers (van der Pijl, 1982), it is likely that in these species, bilirubin contributes to the attraction of avian frugivores which feed upon the arils (Frost, 1980; Kress, personal communication). Whether bilirubin plays an additional role beyond color production in plants remains to be determined. Bilirubin may function as a potent antioxidant in plants as it does in humans (Stocker, 1987), or serve a different physiological function. Bilirubin may also be a mere metabolic waste product. 
The detection of bilirubin in only one replicate of $H$. collinsiana and $E$. luschnathiana likely indicates that bilirubin biosynthesis is not constant, but is instead variable and influenced by factors which are currently unknown. For example, I observed the accumulation of bilirubin in aril cells during the development of S. nicolai (personal observation), with a maximum quantity present in mature tissue (Fig. 4.2), suggesting that bilirubin production may be influenced by development. The lack of bilirubin at the time of sampling may also be a function of variable production, and thus may not indicate an absence of bilirubin biosynthesis in the species.

The biochemical pathway that produces bilirubin in plants remains unknown. In animals, biliverdin-IX $\alpha$ is reduced by an nicotinamide adenine dinucleotide phosphate $(\mathrm{NAD}(\mathrm{P}) \mathrm{H})$ dependent biliverdin-IX $\alpha$ reductase (BR) to form bilirubin-IX $\alpha$ (Maines and Trakshel, 1993). Conversely, in plants, biliverdin-IX $\alpha$ is converted to a structural isomer of bilirubin, 3Z-phytochromobilin, the precursor of the phytochrome chromophore (Tanaka and Tanaka, 2007), by a ferredoxin-dependent bilin reductase, phytochromobilin synthase (Terry et al., 1995; Kohchi et al., 2001). In cyanobacteria and some algae, biliverdin-IX $\alpha$ is also reduced by ferredoxin-dependent enzymes, the bilin reductases, to form the phycobilin chromophores (Beale, 1993; Frankenburg et al., 2001). A BR enzyme was identified and cloned in the cyanobacterium Synechocystis (Schluchter and Glazer, 1997), and BR enzymes have also been found in a variety of other bacteria. Whether bilirubin IX- $\alpha$ in plants is formed by the reduction of biliverdin IX- $\alpha$ by a BR enzyme or via some other means remains to be determined.

Bilirubin was present in eight species from three diverse angiosperm orders, and contributed to aril color in species within the Strelitziaceae. Further sampling of bilirubin 
in plants, both across species, under variable conditions, and across different time scales, will be necessary to gain a comprehensive understanding of the distribution of bilirubin in plants, and to determine whether color production is limited to the Strelitziaceae.

These studies, combined with work on the biosynthesis of bilirubin in plants, will provide a more comprehensive understanding of the evolution of this unusual molecule in the plant kingdom.

\section{ACKNOWLEDGMENTS}

Jodie V. Johnson, J. Martin E. Quirke, Horacio A. Priestap, and David Lee are co-authors on this paper. ${ }^{\mathrm{I}}$ thank the Center for Ethnobiology and Natural Products (CeNAP) at FIU for lab facilities, K. G. Furton for his generous support of H.A. Priestap, and J. Kress for Phenakospermum material.

\section{LITERATURE CITED}

Beale, S. I. 1993. Biosynthesis of phycobilins. Chem. Rev. 93: 785-802.

Frankenberg, N., K. Mukougawa, T. Kohchi, and J. C. Lagarias. 2001. Functional Genomic analysis of the HY2 Family of ferredoxin-dependent bilin reductases from oxygenic photosynthetic organisms. Plant Cell 13: 965-978.

Chase, M. W., D.E. Soltis, P. S. Soltis, P. J. Rudall, M. F. Fay, W. H. Hahn, S. Sullivan, J. Joseph, M. Movray, P. J. Kores, T. J. Givnish, K. J. Sytsma, and J.C. Pires. 2000. Higher-level systematics of the monocotyledons: An assessment of current knowledge and a new classification. p. 3-16. In: K. I. Wilson and D. A. Morrison (eds.). Monocots: Systematics and evolution. CSIRO, Melbourne.

Davies, K. 2004. An introduction to plant pigments in biology and commerce. In: Davies, K (ed.). Plant pigments and their manipulation. p. 1-22. CRC Press, Boca Raton.

Frost, P. G. H. 1980. Fruit - frugivore interactions in a South African coastal dune forest. In: R. Noring, ed. Acta $17^{\text {th }}$ Congressus Internationalis Ornithologici. Berlin: Deutsche Ornithologen-Gesellschaft, 1179-1184.

Givnish, T.J., J.C. Pires, S.W. Graham, M.A. McPherson, L.M. Prince, T.B. Patterson, H.S. Rai, E.H. Roalson, T.M. Evans, W.J. Hahn, K.C. Millam, A.W. Meerow, M. 
Movray, P.J. Kores, H.E. O’Brien, J.C. Hall, W.J. Kress, and K.J. Systma. 2006. Phylogenetic relationships of monocots based on the highly informative plastid gene ndhF: evidence for widespread concerted convergence. Aliso 22: 28-51.

Grotewold, E. 2006. The genetics and biochemistry of floral pigments. Ann. Rev. Plant Biol. 57:761-780.

Goodwin, T.W. and G. Britton. 1988. Distribution and analysis of carotenoids. p.61-84. In: Goodwin, T.W. (ed.). Plant Pigments. Academic Press, London.

Harborne, J.B. 1967. Comparative Biochemistry of the Flavonoids. Academic Press, London.

Heslop-Harrison, J.S. and T. Schwarzacher. 2007. Domestication, genomics, and the future of banana. Ann. Bot. 100: 1073-1084.

Kohchi, T., K. Mukougawa, N. Frankenberg, M. Masuda, A.Yokota, and J.C. Lagarias. 2001. The Arabidopsis HY2 gene encodes phytochromobilin synthase, a ferredoxindependent biliverdin reductase. Plant Cell 13: 425-436.

Kress, J.W., L.M. Prince, W.J. Hahn, and E. Zimmer. 2001. Unraveling the evolutionary radiation of the families of the Zingiberales using morphological and molecular evidence. Sys. Biol. 50: 926-944.

Kuenzle, C.C., M.H. Weibel, and R.R. Pelloni. 1973. The reaction of bilirubin with diazomethane. Biochem. J. 133: 357-368.

Lee, D. 2007. Nature's Palette. The Science of Plant Colours. University of Chicago Press, Chicago.

Maines, M.D. and G.M. Trakshel. 1993. Purification and characterization of human biliverdin reductase. Arch. Biochem. Biophys. 300: 320-326.

Pirone, C. L., J.M.E. Quirke, H. Priestap, and D.W. Lee. 2009. Animal pigment bilirubin discovered in plants. J. Am. Chem. Soc 131: 2830.

Pirone, C. L., J.M.E. Quirke, H. Priestap, and D.W. Lee. 2010. The animal pigment bilirubin identified in Strelitzia reginae, the bird of paradise flower. Hort. Sci. 45: 1411 1415.

Rudall, P.J., D.W.Stevenson, and H.P. Linder. 1999. Structure and systematics of Hanguana, a monocotyledon of uncertain affinity. Aust. Sys. Bot. 12: 311-330.

Soltis, D. E., P.S. Soltis, M.W. Chase, M.E. Mort, D.C. Albach, M. Zanis, 
V. Savoleinen, W.H. Hahn, S.B. Hoot, M.F. Fay, M. Axtell, S.M. Swensen, L.M. Prince, W.J. Kress, K.C. Nixon, and J.S. Farris. 2000. Angiosperm phylogeny inferred from 18S rDNA, rbcL, and atpB sequences. Bot. J. Linn. Soc. 133: 381-461.

Schluchter, W.M. and A.N. Glazer. 1997. Characterization of cyanobacterial biliverdin reductase. J. Biol. Chem. 272: 13562-13569.

Soltis, D.E., M.A. Gitzendanner, and P. S. Soltis. 2007. A 567-taxon data set for angiosperms: the challenges posed by Bayesian analyses of large datasets. Int. J. Plant Sci.168:137-157.

Stocker, R., Y., A. F. Yamamoto, A. N. McDonagh, A.N. Glazer, and B.N. Ames. 1987. Bilirubin is an antioxidant of possible physiologic importance. Science 235: 1043-1046.

Tanaka R. and A. Tanaka. 2007. Tetrapyrrole biosynthesis in higher plants. Ann. Rev. Plant Biol. 58: 321-346.

Terry, M. J., M.T. McDowell, and C. Lagarias. 1995. (3Z)- and (3E)-Phytochromobilin are intermediates in the biosynthesis of the phytochrome chromophore. J. Biol. Chem. 270: 11111-11119.

Van der Pijl, L. 1982. Principles of dispersal in higher plants, $3^{\text {rd }}$ ed. Springer, Berlin. 
Table 4.1. Plant species sampled. All plants were collected from Fairchild Tropical Botanic Garden, except Persea americana, which was collected from the Kampong, a branch of the National Tropical Botanic Garden.

Species
Musa balbisiana Colla
Heliconia collinsiana Griggs
Costus lucanusianus
J. Braun \& K. Schum
Ravenala madagascariensis Sonn.
Phenakopsermum guyannense
(L.C. Rich.) Endl. ex Miq.
Hedychium coronarium J. Koenig
Gastrococos crispa (Kunth)
H.E.Moore
Pandanus odorifer ( Forssk.)
Kuntze
Persea americana Mill.
Eugenia luschnathiana
Klotzch ex O.Berg

$\begin{array}{cccc}\begin{array}{c}\text { Accession } \\ \text { Number } \\ 6222 \mathrm{~B}\end{array} & \text { Family } & \begin{array}{c}\text { Order } \\ \text { Musaceae }\end{array} & \begin{array}{c}\text { Zingiberales } \\ \text { Organ } \\ \text { peel }\end{array} \\ \text { 58523 A } & \text { Heliconiaceae } & \text { Zingiberales } & \text { fruit } \\ \text { 95815 A } & \text { Costaceae } & \text { Zingiberales } & \text { flower } \\ \text { P.1395 H } & \text { Strelitziaceae } & \text { Zingiberales } & \text { aril } \\ \text { N/A } & \text { Strelitziaceae } & \text { Zingiberales } & \text { aril } \\ \text { 78-333 } & \text { Zingiberaceae } & \text { Zingiberales } & \text { aril } \\ \text { 661025A } & \text { Arecaceae } & \text { Arecales } & \text { fruit } \\ \text { 68222A } & \text { Pandanaceae } & \text { Pandanales } & \text { fruit } \\ \text { 20052309 } & \text { Lauraceae } & \text { Laurales } & \text { fruit } \\ \text { X.3-48B } & \text { Myrtaceae } & \text { Myrtales } & \text { fruit }\end{array}$


Table 4.2. Bilirubin detection and concentration.

\begin{tabular}{|c|c|c|c|c|c|c|}
\hline Species & $\begin{array}{c}\text { BR } \\
\text { detection } \\
\text { via diazo- } \\
\text { methane } \\
\text { derivative }\end{array}$ & $\begin{array}{c}\text { BR } \\
\text { detection } \\
\text { via } \\
\text { HPLC-UV }\end{array}$ & $\begin{array}{c}\text { BR } \\
\text { detection } \\
\text { via } \\
\text { HPLC- } \\
\text { MS/MS }\end{array}$ & $\begin{array}{c}\text { BR } \\
\text { conc. } \\
\text { Sample } \\
1\end{array}$ & $\begin{array}{c}\text { BR } \\
\text { conc. } \\
\text { Sample } \\
2\end{array}$ & $\begin{array}{c}\text { Mean } \\
\text { BR } \\
\text { conc. } \\
(n=2)\end{array}$ \\
\hline & & & & $<44$ & & \\
\hline Musa balbisiana & $\mathrm{n}$ & $\mathrm{n}$ & y & $\mathrm{ng} / \mathrm{g}$ & $<44 \mathrm{ng} / \mathrm{g}$ & - \\
\hline $\begin{array}{l}\text { Heliconia } \\
\text { collinsiana }\end{array}$ & $\mathrm{n}$ & $\mathrm{n}$ & $\mathrm{y}$ & - & $<44 \mathrm{ng} / \mathrm{g}$ & - \\
\hline $\begin{array}{l}\text { Costus } \\
\text { lucanusianus }\end{array}$ & $\mathrm{n}$ & $\mathrm{n}$ & $y$ & $\begin{array}{l}<44 \\
\mathrm{ng} / \mathrm{g}\end{array}$ & $<44 \mathrm{ng} / \mathrm{g}$ & - \\
\hline $\begin{array}{l}\text { Ravenala } \\
\text { madagascariensis }\end{array}$ & $\mathrm{n} / \mathrm{a}$ & y & $y$ & $\begin{array}{l}0.001 \\
\mathrm{mg} / \mathrm{g}\end{array}$ & $\begin{array}{l}0.001 \\
\mathrm{mg} / \mathrm{g}\end{array}$ & $\begin{array}{l}0.001 \\
\mathrm{mg} / \mathrm{g}\end{array}$ \\
\hline $\begin{array}{l}\text { Phenakopsermum } \\
\text { guyannense }\end{array}$ & $\mathrm{n} / \mathrm{a}$ & y & $y$ & $\begin{array}{l}3.041 \\
\mathrm{mg} / \mathrm{g}\end{array}$ & $\begin{array}{l}5.787 \\
\mathrm{mg} / \mathrm{g}\end{array}$ & $\begin{array}{l}3.725 \\
\mathrm{mg} / \mathrm{g}\end{array}$ \\
\hline $\begin{array}{l}\text { Hedychium } \\
\text { coronarium }\end{array}$ & $\mathrm{n}$ & $\mathrm{n}$ & $y$ & $\begin{array}{l}<44 \\
\mathrm{ng} / \mathrm{g}\end{array}$ & $<44 \mathrm{ng} / \mathrm{g}$ & - \\
\hline $\begin{array}{l}\text { Gastrococos } \\
\text { crispa }\end{array}$ & $n$ & $\mathrm{n}$ & y & $\begin{array}{l}<44 \\
\mathrm{ng} / \mathrm{g}\end{array}$ & $<44 \mathrm{ng} / \mathrm{g}$ & - \\
\hline $\begin{array}{l}\text { Pandanus } \\
\text { odorifer }\end{array}$ & $\mathrm{n}$ & $\mathrm{n}$ & $\mathrm{n}$ & - & - & - \\
\hline Persea americana & $\mathrm{n}$ & $\mathrm{n}$ & $\mathrm{n}$ & - & - & - \\
\hline $\begin{array}{l}\text { Eugenia } \\
\text { luschnathiana }\end{array}$ & $\mathrm{n}$ & $\mathrm{n}$ & $y$ & $\begin{array}{l}<44 \\
\mathrm{ng} / \mathrm{g}\end{array}$ & - & - \\
\hline
\end{tabular}



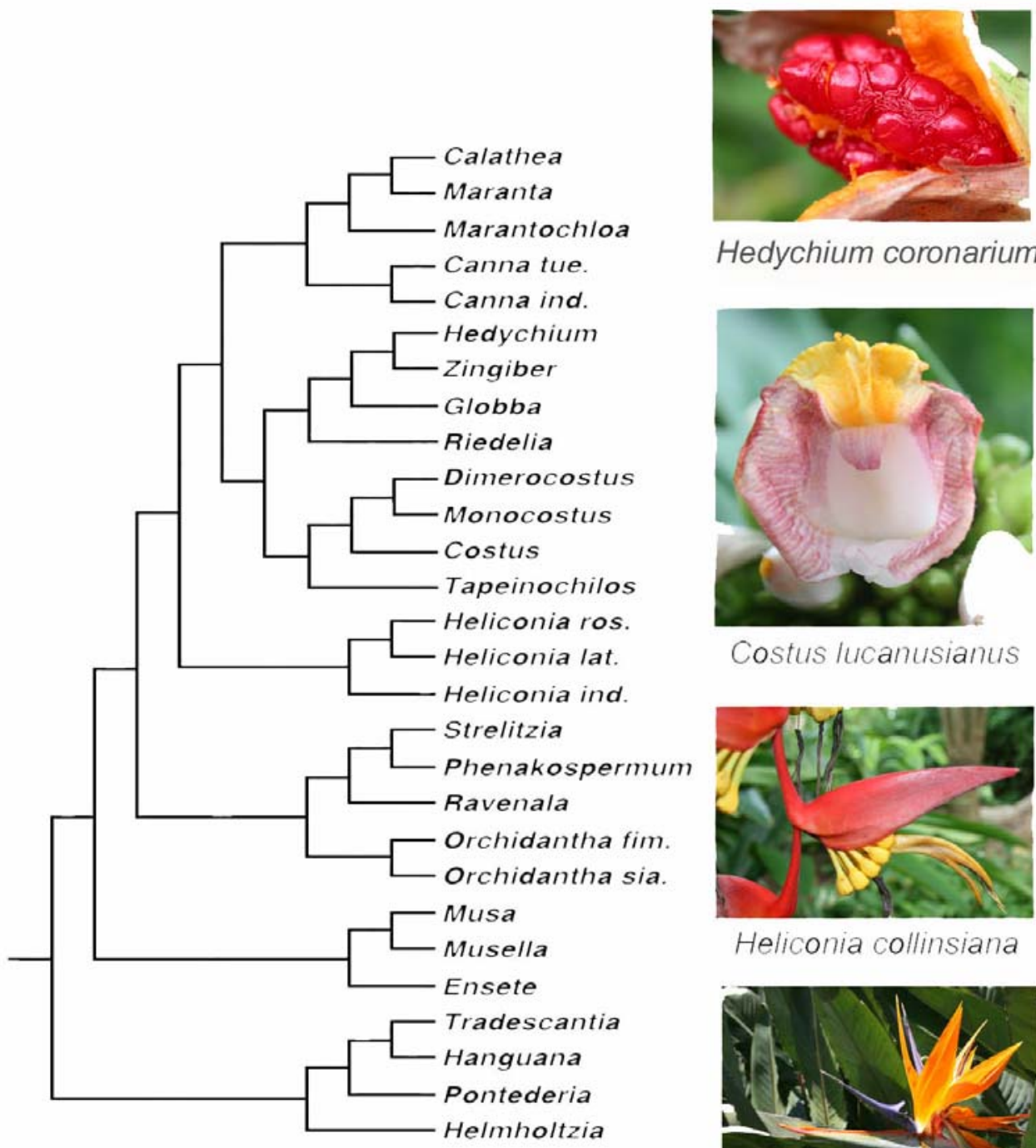

Hedychium coronarium

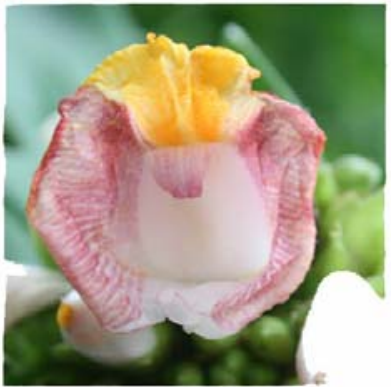

Costus lucanusianus

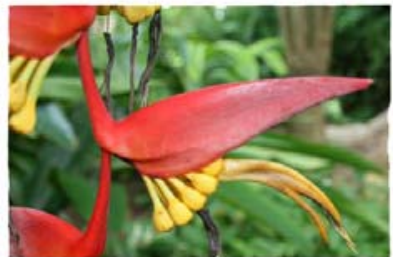

Heliconia collinsiana

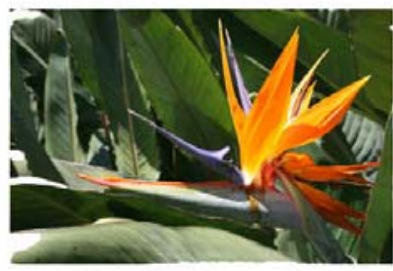

Strelitzia reginae

Figure 4.1. Phylogeny of the Zingiberales. Phylogenetic relationships of genera in the Zingiberales (figure adapted from Kress et al., 2001) with photographs of four species sampled in this study. 


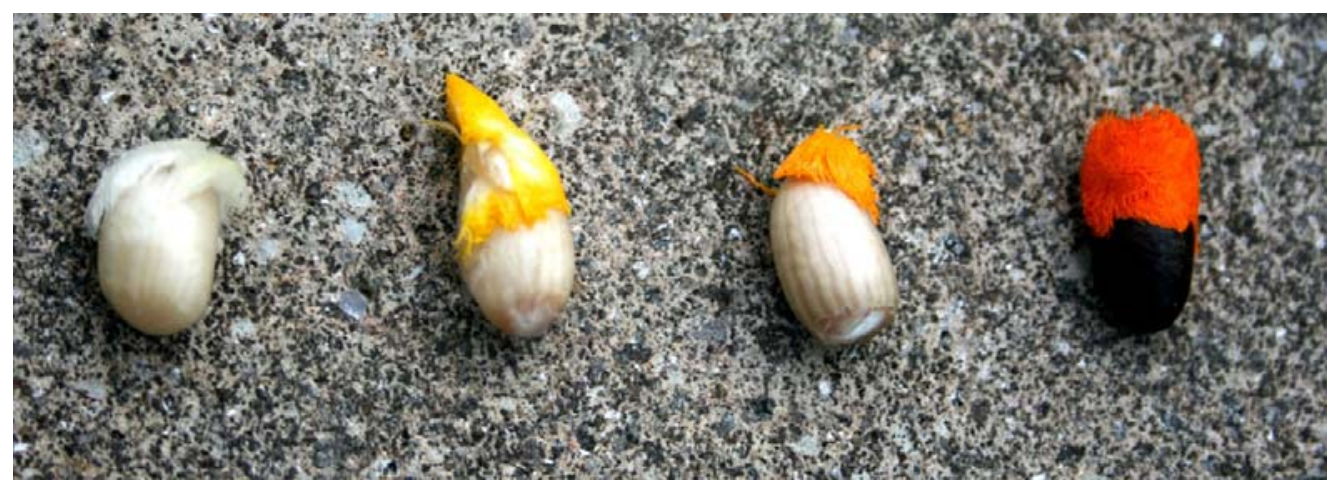

Figure 4.2. Bilirubin production in Strelitzia nicolai during aril development. Maturing arils of $S$. nicolai with increasing amounts of bilirubin. Seeds $\sim 4 \mathrm{~mm}$ in diameter. 


\section{PHYLOGENY OF THE STRELITZIACEAE}

\section{ABSTRACT}

Strelitziaceae, a small monocot family in the order Zingiberales, consists of seven species: Ravenala madagascariensis Sonn., Phenkospermum guyannense (L.C. Rich.) Endl. ex Miq., Strelitzia reginae Banks ex Aiton, Strelitzia juncea Link, Strelitzia alba Skeels, Strelitzia nicolai Regel and Koern and Strelitzia caudata R. A. Dyer. Two of the members, S. reginae, the bird of paradise flower, and $R$. madagascariensis, the travelers' palm, are widely cultivated as ornamentals. Despite this horticultural importance, and despite the close relationship of the Strelitziaceae with well known families including the bananas (Musaceae) and the gingers (Zingiberaceae), evolutionary relationships among the seven taxa have not been explored. Here, I reconstruct a phylogeny of the family using eleven chloroplast genes and two nuclear regions using parsimony, maximum likelihood, and Bayesian analyses. Trees resulting from all analyses of data from different compartments (chloroplast, nuclear) and from the combined regions are in good agreement. Strelitziaceae was found to be monophyletic and sister to the Orchidantha species. In most trees, P. guyannense is sister to the remaining Strelitziaceae taxa, and in all trees, the Strelitzia species form a monophyletic clade. Most relationships within Strelitzia are well established, except for that of S. reginae and S. juncea, which requires further study. 


\section{INTRODUCTION}

The Strelitziaceae Hutch. is one of eight families in the order Zingiberales. It includes three genera and seven species: Ravenala Adans and Phenkospermum Endl., which are both monotypic, and five species of Strelitzia Aiton. (Coates Palgrave and Coates Palgrave 2002; Archer 2003; Simpson, M.G. 2006). Taxa in the family share an herbaceous habit, large petiolate leaves with transverse venation, and colorful, bracteate inflorescences with other members of the order, but can be differentiated by an arborescent growth form (lost in two species of Strelitzia), three free sepals, two fused petals that enclose five (or six in Ravenala) fertile stamens, a woody loculicidal capsule (Kress 1990) and seeds with brightly colored arils. Two of the genera, Strelitzia and Ravenala, are widely cultivated as ornamentals. Strelitzia reginae, the bird of paradise flower, is particularly well known for its showy inflorescence which resembles the head of a bird. Phenakospermum, Ravenala, and Strelitzia are distributed across French Guyana, Madagascar, and southern Africa, respectively. The family is estimated to have diverged from other Zingiberales 55- 49 million years ago, likely via dispersal events (Kress and Specht 2006).

Strelitziaceae was formally included in Musaceae sensu lato (Bentham and Hooker 1883), but was later recognized as a distinct family by Hutchinson (1934), who included Heliconia, Ravenala, Phenakospermum, and Strelitzia in his circumscription. A monophyletic Strelitziaceae without Heliconia was recognized by Nakai (1941), and this classification was supported by most subsequent authors (see Kress et al. 1990, for a review of taxonomic history of the Zingiberales). The monotypic nature of Ravenala madagascariensis Sonn. and Phenakospermum guyannense (L.C. Rich.) Endl. ex Miq. 
has been little disputed, with the exception of the temporary recognition of a second species of Phenakospermum, P. amazonicum (Mart.), now recognized as conspecific with P. guyannense after temporary classification as a distinct genus, Musidendron Nakai (Kress and Stone, 1993). In contrast, the classification of Strelitzia species has undergone multiple revisions, with five species currently recognized: Strelitzia reginae Banks ex Aiton, Strelitzia juncea Link, Strelitzia alba Skeels, Strelitzia nicolai Regel \& Koern and Strelitzia caudata R.A.Dyer (Coates Palgrave and Coates Palgrave 2002; Archer 2003; Simpson 2006). Strelitzia reginae and S. juncea differ from S. alba, S. caudata, and S. nicolai by a shrub-like growth form, orange (to yellow) sepals, and dark blue petals. In contrast, S. alba, S. caudata and S. nicolai have a tree-like habit reaching heights of up to $15 \mathrm{~m}$, white sepals, and blue (white in S. alba) petals (Coates Palgrave and Coates Palgrave 2002; Dyer, 1945; Goldblatt and Manning 2000; Moore and Hyypio1970).

Strelitzia nicolai can be differentiated from S. alba and S. caudata by a compound inflorescence (i.e., a tiered structure with multiple spathes), including up to five spathes (boat-like bracts) (Wright 1913; Dyer 1945; Coates Palgrave and Coates Palgrave 2002). In contrast, S. caudata and S. alba have simple inflorescences comprising a single spathe with a cincinnus of between six and ten flowers. Strelitzia caudata has a similar coloration of sepals and petals to that of S. nicolai (white and blue, respectively), while $S$. alba has completely white flowers (Dyer 1945; Coates Palgrave and Coates Palgrave 2002). Identification of species is sometimes supported by geographic location and habit. S. nicolai occurs in coastal dune vegetation of the Eastern Cape and KwaZulu-Natal in South Africa, and in Mozambique, S. caudata is the only montane species, occurring on 
steep rocky slopes in Mpumalanga and Limpopo provinces of South Africa, and in Swaziland and the eastern highlands of Zimbabwe, and S. alba has a limited distribution in the coastal forests near Knysna and Plettenberg Bay in the Western Cape province of South Africa (Wright 1913; Dyer 1945; Goldblatt and Manning 2000; Coates Palgrave and Coates Palgrave 2002).

Strelitzia reginae and S. juncea are difficult to distinguish; the principal morphological difference between the two is a variable lamina width and shape. The lamina of S. reginae is large and ovate (Wright 1913; Dyer 1975; Goldblatt and Manning 2000), while that of S. juncea is highly reduced, usually with just the midrib remaining (Dyer 1975). Geographic locale is therefore useful in distinguishing among the taxa. Strelitzia juncea has a very limited distribution in the Eastern Cape, and occurs in bushveld as opposed to the riverine and coastal bush habitat of S. reginae. Dyer (1975) suggested that $S$. juncea may have arisen from S. reginae.

Phylogenetic analyses place the Strelitziaceae as one of the more basal lineages in Zingiberales, along with the Lowiaceae, Musaceae, and Heliconiaceae (Kress 1990; Smith et al. 1993; Kress 1995; Stevenson and Loconte 1995; Chase et al. 2000; Kress 2001). Most studies strongly support the sister relationship of Strelitziaceae and Lowiaceae (Rudall et al. 1999; Chase et al. 2000; Soltis et al. 2000; Kress et al. 2001; Givnish 2006; Soltis 2007), with some support for Musaceae as sister to the rest of the order (Kress 1990; Kress, 1995; Chase et al. 2000; Kress et al. 2001). In contrast, Johansen (2005) positioned Lowiaceae as sister to all remaining Zingiberales taxa, but sampling outside of Orchidantha was sparse. Other intrafamilial relationships among the Strelitziaceae, Lowiaceae, Musaceae, and Heliconiaceae have not been well established. 
Relationships within the family Strelitziaceae are also unclear. Ravenala madagascariensis was found to be sister to the clade comprising S. nicolai and $P$. guyannense in the combined three gene ( $a t p B, r b c L, 18 \mathrm{~s}$ rDNA) analyses of Soltis et al. (2000), Soltis et al. (2007), and Chase (2000), and also in the combined three gene (atpB, $r b c L, 18 s$ rDNA) plus morphological dataset of Kress (2001). In contrast, Givnish et al. (2006) found S. nicolai to be sister to the clade comprising R. madagascariensis and $P$. guyannense based on analysis of the single gene data set of $n d h F$.

In the present study, I reconstruct the phylogeny of the Strelitziaceae using eleven chloroplast regions, rbcL, matK -5'trnK, psbA- matk , psbB-psbH, Ycf6-trnC, rpL16 intron, rpoB-trnC, trnS-trnfM ,trnY-trnE, rp132-trnL, rps16, and two nuclear regions, the nuclear ribosomal external transcribed spacer (ETS) and the 23rd intron of RNA polymerase beta subunit II (rpb2). I sample each of the seven species in the family as well as selected outgroups from within Musaceae, Heliconiaceae, and Lowiaceae. My objectives include the elucidation of relationships within the Strelitziaceae and comparison of phylogenetic signals between the nuclear and chloroplast regions, and the evaluation of current species delimitation in Strelitzia.

\section{METHODS}

Taxon Sampling: All seven currently recognized species of Strelitziaceae, S. reginae, S. nicolai, S. caudata, S. alba, and S. juncea, and four outgroup species, Orchidantha fimbriata, Orchidantha siamensis, Musa acuminata, and Heliconia pendula were represented in this study (see Table 5.1 for a list of species with accession numbers). Outgroup species were chosen from each of the four most basal families in the Zingiberales (Kress 2001). 


\section{Molecular Characters:}

Rapidly evolving intron and intergenic spacers were selected from chloroplast and nuclear genomes that have previously been shown to resolve species level phylogenies (Shaw 2005; Shaw 2007), and the rbcL coding region was included to help resolve phylogenetic relationships at higher taxonomic levels (Small 2004).

A single accession was sequenced for the chloroplast and nuclear regions of both ingroup and outgroup taxa. A second accession for all ingroup species was sampled for all nuclear regions, and for three chloroplast regions: matK -5 'trnK, rpS16, and the $r p L 16$ intron.

DNA Extraction and Manipulation:

cpDNA

DNA was extracted from silica dried or fresh tissue using the DNeasy Plant Mini Kit (Qiagen). Protocol for cpDNA polymerase chain reactions (PCR) followed (Green et al. in revision). Primers for the regions rbcL, matK -5'trnK, psbA- matk , psbB-psbH, Ycf6trnC, rpoB-trnC, trnS-trnfM ,trnY-trnE, and rpL16 were taken from Shaw (2005), rp132trnL from Shaw (2007), rps16 from Levin et al. (2004), and $r b c L$ from Kress and Erickson (2007). Polymerase chain reactions were carried out in $25 \mu 1$ volume using 21.4 $\mu 1$ of 1X PCR buffer from New England BioLabs: (Taq PCR Kit \# E5000S), $0.125 \mu 1$ each of forward and reverse primer at $100 \mathrm{mM}, 0.5 \mu 1 \mathrm{dNTP}$ at $10 \mathrm{mM}, 0.1 \mu 1 \mathrm{Taq}(5,000$ units $/ \mathrm{ml}$ ), $0.25 \mu 1 \mathrm{DNA}$ (diluted in 5 of 11 taxa in 1:3 volume, others at full concentration). For several of the taxa, a 2X Diamond Reaction Mix from Bioline was substituted for the buffer, dNTP, and Taq. Amplifications were performed in a BioRad MyCycler, according to the following protocol: One cycle of $3 \mathrm{~min}$. at $95^{\circ} \mathrm{C}, 10$ cycles 
beginning at $95^{\circ} \mathrm{C}$ for $45 \mathrm{sec}$, followed by a variation in temperature per cycle at a $1^{\circ} \mathrm{C}$ gradient beginning at $55^{\circ} \mathrm{C}$ and ending at $45^{\circ} \mathrm{C}$, then $72^{\circ} \mathrm{C}$ for $45 \mathrm{sec}$. Then 20 cycles of $95^{\circ} \mathrm{C}$ for $45 \mathrm{sec}, 50^{\circ} \mathrm{C}$ for $45 \mathrm{sec}$, and $72^{\circ} \mathrm{C}$ for $45 \mathrm{sec}$. Cycling was finished with a final extension time of $72^{\circ} \mathrm{C}$ for $5 \mathrm{~min}$. The PCR products were held at $4^{\circ} \mathrm{C}$ for until they were checked for purity in a $1 \%$ agarose gel. The PCR products were purified using a MultiScreen $\mathrm{PCR}_{\mathrm{p} 96}$ Plate from Millipore. Cycle sequencing reactions were performed using Big Dye version 3.1 ABI (Applied Biosystems International) and sequenced on an ABI 3730 capillary sequencer. Sequencing of the $r b c L$ region followed Kress et al. (2009).

Continuous stretches of DNA, contigs, were assembled using the commercially available software Sequencher v. 4.1 (GeneCodes) and preliminary sequence alignments were performed using the Clustal W algorithm (Thompson et al. 1994) accessed via Geneious Pro 5.0.2 (Drummond et al. 2010). For chloroplast regions, manual adjustments were made using MacClade v. 4.08 (Maddison and Maddison 2005) or Geneious Pro 5.0.2 (Drummond et al. 2010). Evolutionary events were minimized (Zurawksi and Clegg 1987) and alignment of insertion-deletion (indel) events followed recommendations of Kelchner (2000). Areas of ambiguous alignment were excluded from analyses.

\section{Nuclear}

Nuclear DNA was extracted from silica-dried leaf material using a modified sodium dodecyl sulfate (SDS) extraction protocol (Edwards et al. 1991; Konieczny and Ausubel 1993). Previously published primers and protocols were used for PCR amplification in both cases (Baldwin and Markos 1998; Kay et al. 2005; Sass and Specht 2010). Phylogenetic Analyses: 
Maximum parsimony (MP) and maximum likelihood (ML) analyses were performed on the combined chloroplast regions, the combined nuclear regions, and the combined chloroplast and nuclear regions. For Bayesian analyses, the data matrix was partitioned according to three partitioning schemes: (1) unpartitioned, (2) a separate partition for each sequenced gene, and (3) separate partitions for markers within each compartment (chloroplast, nuclear) when relevant. All analyses (MP, ML, and Bayesian) were performed on two datasets, one which included all taxa, and one which excluded taxa which were incompletely sequenced for the chloroplast region (i.e., the second accession of each Strelitziaceae species). Tree topologies and support values from the analyses of the two datasets were compared to evaluate the effects of the missing data. Gaps were treated as missing data. In unambiguously aligned regions, parsimonyinformative gap characters were scored according to the simple indel coding method of Simmons \& Ochoterena (2000) and added as binary characters to the end of the matrix. All regions were analyzed both with and without indels. The ML analyses were only performed on datasets with indels excluded.

MP and ML analyses were conducted with PAUP* (Swofford 2003). Parsimony analyses of individual and combined datasets were performed with characters equally weighted and unordered. Branch and bound searches were performed using the furthest addition sequence. Topological support was evaluated by performing the bootstrap analysis (Felsenstein 1985). A heuristic search strategy was used to analyze 1000 bootstrap replicates, each with 10 random addition replicates. To measure the fit of characters to the trees, the consistency index (Kluge and Farris 1969) and the retention index (Farris 1989) were calculated using PAUP*. 
For ML analyses, models were chosen for the chloroplast data $(\mathrm{GTR}+\mathrm{I}+\mathrm{G})$, the nuclear data $(\mathrm{HKY}+\mathrm{G})$, and the combined chloroplast and nuclear data $(\mathrm{GTR}+\mathrm{I}+\mathrm{G})$ on the basis of the Akaike Information Criteria (AIC) criteria of ModelTest v. 3.7 (Posada and Crandall, 1998). Models identical to those suggested under the AIC were identified under hierarchical likelihood ration test (hLRT) of Modeltest for the nuclear and the combined chloroplast-nuclear datasets, but for the chloroplast region, the model $(\mathrm{TVM}+\mathrm{G})$ was identified. Chloroplast data were analyzed under both suggested models. Heuristic searches with a random order of sequence addition and tree bisection and reconnection (TBR) branch-swapping were repeated 100 times. Bootstrap tests were performed using 100 replicates, each with 10 random addition sequence addition replicates.

Strict consensus trees were computed for MP and ML analyses. All MP and ML trees were rooted for output using Musa acuminata. Congruence of data from the chloroplast and nucleus was assessed by the comparison of MP and ML consensus tree topologies and bootstrap values. In addition, strict consensus trees were computed within each partition (chloroplast, nuclear, and combined nuclear and chloroplast) across analysis types (MP, ML, and Bayesian).

For Bayesian analyses, model selection for each partition was performed using MrModeltest v2 (Nylander 2004). The coded indels were included as a separate data partition, under a modified F81 model (Ronquist and Huelsenbeck 2003). Bayesian inference of phylogeny was performed on the data matrix under each partitioning scheme, with and without indels, using MrBayes v3.2.1 (Huelsenbeck and Ronquist 2001). In each analysis, two analyses of 10 million generations sampled every 1,000 
generations were run to completion. In all cases, the two parallel analyses converged (average standard deviation of split frequencies $<0.005$ ). The first using $10 \%$ of the trees were discarded as burnin and a 50\% majority rule tree was constructed from the remaining trees.

\section{RESULTS}

The inclusion of a second accession, albeit incompletely sequenced, did not appear to negatively affect the outcome of the study in any way. The Strelitzia clade in the parsimony consensus tree of the chloroplast region was slightly less resolved when incomplete taxa were included than when they were excluded. However, ML and Bayesian consensus trees were dichotomously resolved and placement of taxa was constant, regardless of whether incomplete taxa were included. Support values for all trees were comparable (trees not shown). Thus, in this paper we present only the results of analyses which include all taxa.

Chloroplast data from each region was assumed to undergo similar evolutionary histories, therefore these regions were combined. Nuclear regions (ETS, rpb2) were also combined based on the comparison of tree topologies and MP and ML bootstrap values from consensus trees for each region, which differed only where bootstrap support was less then $70 \%$. Comparison of tree topologies and MP and ML bootstrap values from consensus trees for each data compartment (combined chloroplast, combined nuclear) showed differences only where bootstrap support was less then $70 \%$, therefore data from these regions were also combined. 
Bayesian analyses of data under all partitioning schemes produced trees with identical topologies and comparable support values. Thus, only the results of the unpartitioned analyses are presented here.

\section{Chloroplast DNA}

The length of the tree for the eleven combined chloroplast regions was $6738 \mathrm{bp}$, with 623 variable characters and 355 parsimony informative characters. A total of 53 informative and unambiguous indels were coded as binary characters. A single accession was sequenced for all eleven regions, and a second accession sequenced for three regions, matK -5'trnK, rpS16, and the rpL16 intron. Thus, the remaining seven regions of the second accession were coded as missing data. It was not possible to sequence the second accession of $R$. madagascariensis and $S$. alba for the rpL2 intron, thus these regions were also coded as missing data. Total missing data was 30.8\% (25.3\% due to the incomplete taxa).

Information regarding individual chloroplast regions is presented in Table 5.2. For the combined chloroplast region, there was a total of 132 equally most parsimonious trees $($ steps $=730 \mathrm{CI}=0.8973, \mathrm{RI}=0.8654)$. For $\mathrm{ML}$ analyses, the $\mathrm{TVM}+\mathrm{G}$ model and the GTR $+\mathrm{I}+\mathrm{G}$ yielded five most likely ML trees which were identical under each model with -log-likelihood $(-\mathrm{Ln})=13333.702$.

The outgroups $M$. acuminata and $H$. pendula are sister taxa. Orchidantha species form a well supported clade which is sister to the Strelitziaceae (maximum parsimony bootstrap support $(\mathrm{MPBS})=100$, maximum likelihood bootstrap support $(\mathrm{MLBS})=100$, posterior probability $(\mathrm{PP})=1.0)$, a monophyletic group $(\mathrm{MPBS}=100, \mathrm{MLBS}=100, \mathrm{PP}=$ 1.0). Placement of $R$. madagascariensis and P. guyannense differ among the three 
analyses. They are unresolved in the parsimony consensus trees, but are sister to each other in a clade which is sister to the Strelitzia clade in the Bayesian consensus tree ( $\mathrm{PP}=$ .92) (Fig. 5.1). In the ML consensus tree, $P$. guyannense is sister to remaining Strelitziaceae taxa (MLBS=100) (Fig. 2). Strelitzia species form a monophyletic clade in all analyses $(\mathrm{MPBS}=95, \mathrm{MLBS}=100, \mathrm{PP}=0.99)$, but differ in the degree of species resolution. In the parsimony analyses, the Strelitzia clade is unresolved at the base. Both accessions of S. reginae and S. juncea are ungrouped, as is S. nicolai, and S. caudata forms a polytomous clade with $S$. alba $(\mathrm{MPBS}=72)$ (tree not shown). In the ML consensus tree, $S$. alba accessions group together in a clade with $S$. caudata (MLBS=97.8) which is sister to a dichotomous clade containing the remaining Strelitzia taxa $(\mathrm{MLBS}=100)$. This clade consists of $S$. nicolai in one clade, and the poorly resolved accessions of $S$. reginae and $S$. juncea in the other. In the Bayesian consensus tree, $S$. nicolai is sister to the remaining Strelitzia species $(\mathrm{PP}=.99)$, which are split into two clades, one with $S$. alba paraphyletic with respect to $S$. caudata, and one clade containing S. reginae and S. juncea. Strelitzia juncea is paraphyletic with respect to $S$. reginae.

In the parsimony analyses, no changes in tree topology occurred when indels were included. In the Bayesian analyses including indels, P. guyannense is sister to other Strelitziaceae taxa, and $R$. madagascariensis is sister to a poorly resolved Strelitzia clade (trees not shown).

Nuclear

It was not possible to unambiguously align sequence information for rpb2 outgroup species (M. acuminata, H. pendula, O. fimbriata, and O. siamensis), thus this data was excluded from analyses. Missing data was 21\% (16.3\% due to missing rpb2 
sequence for outgroup taxa). A total of 23 informative and unambiguous indels were coded as binary characters. Information regarding individual regions is shown in Table 5.2. Two most parsimonious trees were found (tree length $=535, \mathrm{CI}=0.8953, \mathrm{RI}=$ 0.8519), and a single most likely tree was found ( $-\mathrm{Ln}=4918.81777)$.

Outgroup relationships in all analyses are similar to those described in the chloroplast trees. In the parsimony and Bayesian consensus trees, $P$. guyannense is sister to all other Strelitziaceae taxa $(\mathrm{MPBS}=97, \mathrm{PP}=0.84)$, and $R$. madagascariensis is sister to the Strelitzia clade $(\mathrm{MPBS}=75, \mathrm{PP}=0.76$ ). Strelitzia nicolai is sister to remaining Strelitzia species $(\mathrm{MPBS}=97, \mathrm{PP}=0.88)$, which is split into two clades $(\mathrm{MPBS}=98, \mathrm{PP}$ $=0.96)$ (Fig. 5.2). One clade contains $S$. alba and S. caudata, and one contains S. reginae and $S$. juncea. In the ML and Bayesian consensus trees, S. juncea is nested within a paraphyletic $S$. reginae $(\mathrm{MLBS}=67, \mathrm{PP}=.99)$, while in the parsimony consensus tree, the S. reginae accessions are unresolved. Outside of the clade containing $S$. reginae and $S$. juncea, the nuclear ML consensus tree is poorly resolved and is thus not further discussed. When indels were included in the data matrix, no changes in tree topology occurred in either parsimony or Bayesian analyses.

Combined Chloroplast and Nuclear

A total of 76 informative and unambiguous indels were coded as binary characters. Missing data was 29\%. Two most parsimonious trees were found (steps = $1266, \mathrm{CI}=.8957, \mathrm{RI}=0.8588)$, and a single most likely tree was found $(-\mathrm{Ln}=$ 18773.771).

Topologies of the combined nuclear-chloroplast consensus trees (parsimony, ML, and Bayesian) are identical to each other, with one exception (Fig. 5.3). The two $S$. 
reginae accessions are paraphyletic in the trees produced via Bayesian and ML analyses, but have variable positions in the two most parsimonious trees. MP and Bayesian trees are identical to the corresponding parsimony and Bayesian trees produced from nuclear data. Overall, support values are comparable among consensus trees from each analysis, but are slightly lower in the most likely tree at the node which divides S. alba, S. caudata, S. reginae, and S. juncea into two separate clades. MLBS values are also slightly lower in the node which defines the relationship between S. reginae and S. juncea.

The relationship between P. guyannense and R. madagascariensis changes when indels are included in parsimony and Bayesian analyses. Phenakospermum guyannense is sister to R. madagascariensis in a clade which is sister to the Strelitzia clade when indels are included, whereas P. guyannense is sister to other Strelitziaceae taxa when indels are excluded. Positions of other taxa remain unchanged.

\section{DISCUSSION}

The inclusion of incomplete taxa in analyses has been shown to reduce phylogenetic accuracy under some circumstances (Huelsenbeck 1991; Wiens and Reeder, 1995; Lemmon et al., 2009). However, the inclusion of incomplete taxa in our study did not appear to create ambiguity in our datasets or result in low support values. This observation is supported by other studies which have shown that the presence of missing data does not necessarily lead to erroneous results (see Kearney 2002; Wiens 2006; Wiens 2008 for reviews). In the chloroplast trees, species relationships within Strelitzia are poorly resolved in the parsimony consensus tree. However, ML and Bayesian consensus trees are dichotomously resolved, with the exception of S. reginae and $S$. juncea. In the nuclear region, ML analysis yielded a consensus tree which lacked 
resolution at its base, but the parsimony and Bayesian consensus trees are dichotomously resolved for all taxa with good support values. Combined chloroplast-nuclear trees are also dichotomously resolved.

Trees resulting from all analyses of data from different compartments (chloroplast, nuclear) and from the combined regions are in good agreement. Thus, relationships discussed here are common to all trees, unless otherwise specified. Strelitziaceae was found to be monophyletic and sister to the Orchidantha species, a position which agrees with previous studies (Rudall et al. 1997; Chase et al. 2000; Soltis et al. 2000; Kress et al. 2001; Givnish 2006; Soltis 2007). In all trees, P. guyannense is sister to the remaining Strelitziaceae taxa, except in the parsimony and Bayesian consensus trees from the chloroplast region which either lacked resolution of the genera (MP), or yielded P. guyannense and R. madagascariensis as sister taxa in a clade which is sister to the Strelitzia species (Bayesian). The latter relationship appears in the chloroplast-nuclear trees when indels are included, but the placement of genera in all other trees remains constant. In contrast, most previous studies place $R$. madagascariensis as sister to a clade containing the remaining genera (Kress, 2001, Soltis et al., 2000, Soltis et al., 2007, and Chase, 2000). However, the single loci study of Givnish et al. (2006) also found S. nicolai to be sister to the remaining taxa.

In all analyses, the Strelitzia species form a monophyletic clade. Despite few morphological differences between S. nicolai, S. alba, and S. caudata, I found high molecular support for the resolution of these taxa. In most trees, S. nicolai is sister to a dichotomous clade containing the other Strelitzia species; S. alba and S. caudata are resolved as sister taxa in one of the two clades. The other clade consists of S. reginae and 
S. juncea, but relationships among these accessions vary among trees, and overall we did not find support for the classification of these taxa as distinct species. In the consensus chloroplast trees, accessions of S. reginae and S. juncea form a polytomy, while in the nuclear and chloroplast-nuclear consensus trees, S. reginae is paraphyletic with respect to S. juncea with moderate to high support. The addition of indels into the analyses did not alter the relationships between the taxa.

Given the debated taxonomic history of $S$. reginae and $S$. juncea, these ambiguous results are not surprising. Strelitzia juncea was first described by Link (1821), although S. parvifolia Aiton var. juncea Ker Gawl. was described and illustrated by Ker-Gawler earlier that same year (Wright 1913; Dyer 1975). It is not absolutely certain that these are the same plants (Dyer 1975). Considering that leaf blade shape is the principal distinguishing feature among the taxa, Moore and Hyypio (1970) proposed that S. juncea should be classified as a variant or cultivar of S. reginae. However, Van der Venter (1975) observed variable leaf blade shapes in plants grown from two distinct seed stocks in a controlled environment, and concluded that genetic differences govern leaf development. Based on these observations, as well as geographic information, he supported the classification of the taxon as a distinct species. This position was supported by Dyer (1975) and is currently accepted by most authors today.

This study is the first to examine the evolutionary relationships among all species within the Strelitziaceae. With the exception of S. reginae and S. juncea, relationships within the family are well supported. In light of the sparse morphological evidence supporting the taxonomic division of S. reginae and S. juncea, the paraphyletic or ambiguous relationships shown here in the molecular data, and the short branch lengths 
differentiating the species (Fig. 5.4), further investigations are needed. Population level studies which sample additional accessions, both within and among populations of both taxa will help to clarify these species boundaries. This information, combined with morphological data, will help to achieve a robust understanding of the evolutionary history of the family.

\section{ACKNOWLEDGMENTS}

Co-authors on this paper will include Glynis Cron, Madelaine Bartlett, John W. Kress, Chelsea Specht. M. Bartlett sequenced ETS, rpb2, and the second accession for three of the chloroplast regions, and did the Bayesian analyses. Special thanks to Justin Ramsey and Adam Green for their guidance and use of facilities at the University of Rochester, and to Dave Erickson for sequencing the $r b c L$ region. Also a special thanks to Tim Collins for overseeing this work.

\section{LITERATURE CITED}

Archer C. 2003. Strelitziaceae. p. 1106. In: Germishuizen, G. \& Meyer, N. L. (eds.). Plants of southern Africa: an annotated checklist. Strelitzia National Botanical Institute of South Africa, Kirstenbosch.

Baldwin, B.G. and S. Markos. 1998. Phylogenetic utility of the external transcribes spacer (ETS) of 18S-26S rDNA: congruence of ETS and ITS trees of Calycadenia (Compostae). Mol. Phyl. Evol. 10: 449-463.

Bentham, G. and J.D. Hooker. 1883. Genera Plantarum, Volume 3. L. Reeve and Co.; Williams and Norgate, London.

Chase, M. W., D.E. Soltis, P. S. Soltis, P. J. Rudall, M. F. Fay, W. H. Hahn, S. Sullivan, J. Joseph, M. Movray, P. J. Kores, T. J. Givnish, K. J. Sytsma, and J.C. Pires. 2000. Higher-level systematics of the monocotyledons: An assessment of current knowledge and a new classification. p. 3-16. In: K. I. Wilson and D. A. Morrison (eds.). Monocots: Systematics and evolution. CSIRO, Melbourne.

Coates Palgrave, K. and Coates Palgrave, M. 2002. Strelitziaceae. p. 118-9. In: L. Martin (ed.). Trees of southern Africa. Struik Publishers, Cape Town. 
Drummond A.J., B. Ashton, S. Buxton, M. Cheung, A. Cooper, J. Heled, M. Kearse, R. Moir, S. Stones-Havas, S. Sturrock, T. Thierer, and A. Wilson. 2010. Geneious v 5.1, http://www.geneious.com.

Dyer, R. A. 1945. The Flowering Plants of Africa. Pretoria, Van Schaik LTD.

Dyer, R. A. 1975. Notes on African plants: Strelitziaceae: The status of Strelitzia juncea. Bothalia 1: $519-520$.

Edwards, K., C. Johnstone, and C. Thompson. 1991. A simple and rapid method for the preparation of plant genomic DNA for PCR analysis. Nucleic Acids Research 19: 1349.

Farris, J. S. 1989. The retention index and the rescaled consistency index. Cladistics, 5:417-419.

Felsenstein, J. 1985. Confidence intervals on phylogenies: an approach using the bootstrap. Evolution 39:783-791.

Givnish, T.J., J.C. Pires, S.W. Graham, M.A. McPherson, L.M. Prince, T.B. Patterson, H.S. Rai, E.H. Roalson, T.M. Evans, W.J. Hahn, K.C. Millam, A.W. Meerow, M. Movray, P.J. Kores, H.E. O’Brien, J.C. Hall, W.J. Kress, and K.J. Systma. 2006. Phylogenetic relationships of monocots based on the highly informative plastid gene $n d h \mathrm{~F}$ : evidence for widespread concerted convergence. Aliso 22: 28-51.

Goldblatt, P. and J. Manning. 2000. Cape plants: A conspectus of the Cape flora of South Africa. National Botanical Institute, Pretoria.

Green, A.F, T.S. Ramsey, and J. Ramsey. Phylogeny and biogeography of ivies (Hedera spp., Araliaceae), a polyploid complex of woody vines. Sys. Bot., in revision.

Huelsenbeck, J.P. 1991. When are fossils better than extant taxa in phylogenetic analysis? Syst. Zool. 40(4):458-469.

Huelsenbeck, J.P. and F. Ronquist. 2001. MRBAYES: Bayesian inference of phylogenetic trees. Bioinformatics 17: 754-755.

Hutchinson, J. 1943. The families of flowering plants, Volume 2. Monocotyledons. Macmillan and Co., London.

Johansen, L.B. 2005. Phylogeny of Orchidantha (Lowiaceae) and the Zingiberales Based on Six DNA Regions. Sys. Bot. 30 (1):106-117.

Kay, K.M., P.A. Reeves, R.G. Olmstead, and D.W. Schemske. 2005. Rapid speciation and the evolution of hummingbird pollination in neotropical Costus subgenus Costus 
(Costaceae): evidence from nrDNA ITS and ETS sequences. Amer. J. Bot. 92: 18991910.

Kearney, M. 2002. Fragmentary taxa, missing data, and ambiguity: mistaken assumptions and conclusions. Syst. Biol. 51(2):369-381.

Kelchner, S.A. 2000. The evolution of non-coding chloroplast DNA and its application in plant systematics. Ann. MO. Bot. Gar. 87(4): 482-498.

Kluge, A. G. and J. S. Farris. 1969. Quantitative phyletics and the evolution of Anurans. Sys. Zool. 18: 1-32.

Konieczny, A. and F.M. Ausubel. 1993. A procedure for mapping Arabidopsis mutations using co-dominant ecotype-specific PCR-based markers. Plant J. 4: 403-410.

Kress, J.W. 1990. The phylogeny of the Zingiberales. Ann. MO Bot. Gar. 77(4): 698721.

Kress, J.W. and D. Stone, 1993. Morphology and floral biology of Phenakospermum (Strelitziaceae), an arborescent herb of the neotropics. Biotropica 25(3): 290-300.

Kress, J.W. 1995. Phylogeny of the Zingiberanae: morphology and molecules. p. 443460In P.J. Rudall, P.J. Cribbs, D.F. Cutler, and C.J. Humphries (eds.). Monocotyledons: systematics and evolution. Royal Botanic Gardens, Kew.

Kress, J.W. and C. D. Specht. 2006. The evolutionary and biogeographic origin and diversification of the tropical monocot order Zingiberales. Aliso 22: 621-632.

Kress, J.W., L.M., Prince, W.J., Hahn, and E. Zimmer. 2001. Unraveling the evolutionary radiation of the families of the Zingiberales using morphological and molecular evidence. Sys. Biol. 50(6): 926-944.

Kress, W.J., F.A. Jones, N.G. Swenson, R. Perez, O. Sanjur, and E. Bermingham. 2009. Plant DNA barcodes and a community phylogeny of a tropical forest dynamics plot in Panama. Proc. Nat. Acad. Sci. 106(44): 18627-18632.

Kress, W.J. and D.L. Erickson. 2007. A two-locus global DNA barcode for land plants: the coding rbcL gene complements the non-coding trnH-psbA spacer region. PLoS ONE 2(6): e508.

Levin, R.A., W.L. Wagner, P.C. Hoch, W.J. Hahn, A. Rodriguez, D.A. Baum, L. Katinas, Z.A. Zimmer, and K.J. Sytsma. 2004. Paraphyly in the tribe Onagreae: insights into phylogenetic relationships of Onagraceae based on nuclear and chloroplast sequence data. Sys. Bot. 29(1): 147-164. 
Lemmon, A.R., J.M. Brown, K. Stangler-Hall, and E. Moriarty-Lemmon. 2009. The effect of ambiguous data on phylogenetic estimates obtained by maximum likelihood and Bayesian inference. Syst. Biol. 58(1):130-145.

Maddison, D. R. and W. P. Maddison. 2005. MacClade: analysis of phylogeny and character evolution, version 4.08. Sunderland : Sinauer Associates.

Moore, H.E. and P. A. Hyypio. 1970. Some comments on Strelitzia (Strelitziaceae). Baileya 17: 64-74.

Nakai, T. 1941. Notulae ad plantas orientales (XVI). Japanese Journal of Botany 17: 189-203.

Nylander, J. A. A. 2004. MrModeltest v2. Program distributed by the author. Evolutionary Biology Centre, Uppsala University.

Posada, D. and K. A. Crandall. 1998. Modeltest: testing the model of DNA substitution. Bioinformatics 14: 817-818.

Ronquist, F. and J.P. Huelsenbeck. 2003. MrBayes 3: Bayesian phylogenetic inference under mixed models. Bioinformatics 19: 1572-1574.

Rudall, P.J., D.W. Stevenson, and H.P. Linder. 1999. Structure and systematics of Hanguana, a monocotyledon of uncertain affinity. Austr. Sys. Bot.12: 311-330.

Sass, C. and C.D. Specht. 2010. Phylogenetic estimation of the core Bromelioids with an emphasis on the genus Aechmea (Bromeliaceae). Mol. Phyl. Evol. 55: 559-571.

Simmons, M. P. and H. Ochoterena. 2000. Gaps as characters in sequence-based phylogenetic analyses. Sys. Biol. 49: 369-381.

Simpson, M.G. 2006. Plant Systematics. Elsevier, San Diego, CA.

Small, R.L., R.C. Cronn, and J.F. Wendel. 2004. L.A.S. Johnson Review No. 2: use of nuclear genes for phylogeny reconstruction in plants. Austr. Sys. Bot. 17: 145-170.

Smith, J. F., W. J. Kress, and E. A. Zimmer. 1993. Phylogenetic Analysis of the Zingiberales Based on rbcL Sequences. Ann. MO Bot. Gar. 80(3): 620-630.

Soltis, D. E., P.S. Soltis, M.W. Chase, M.E. Mort, D.C. Albach, M. Zanis, V. Savoleinen, W.H. Hahn, S.B. Hoot, M.F. Fay, M. Axtell, S.M. Swensen, L.M. Prince, W.J. Kress, K.C. Nixon, and J.S. Farris. 2000. Angiosperm phylogeny inferred from 18S rDNA, $r b c L$, and $a t p B$ sequences. Bot. J. Linn. Soc. 133: 381-461. 
Soltis, D.E., M.A. Gitzendanner, and P. S. Soltis. 2007. A 567-taxon data set for angiosperms: the challenges posed by Bayesian analyses of large datasets. Int. J. Plant Sci. 168(2): 137-157.

Stevenson, D. W. and H. Loconte. 1995. Cladistic analysis of monocot families. p. 543578. In: P. Rudall, P. J. Cribb, D. F. Cutler, and C. J. Humphries (eds.). Monocotyledons: Systematics and evolution Royal Botanic Gardens, Kew, U.K.

Swofford, D.L. 2003. PAUP*. Phylogenetic analysis using parsimony (*and other methods), version $4.0 \mathrm{~b} 10$.

Thompson, J. D., D. G. Higgins, and T. J. Gibson. 1994. CLUSTAL W: improving the sensitivity of progressive multiple sequence alignment through sequence weighting, position specific gap penalties and weight matrix choice. Nucl. Acids Res. 22: 46734680.

Van der Venter, H.A., J.G.C. Small, and P.J. Robbertse. 1975. Notes on the distribution and comparative leaf morphology of the acaulescent species of Strelitzia Ait. J. S. Afr. Bot. 41(1): 1-16.

Wiens, J.J., and T.W. Reeder. 1995. Combining data sets with different numbers of taxa for phylogenetic analysis. Systematic Biology 44(4) 548-558.

Wiens, J.J. 2006. Missing data and the design of phylogenetic analyses. Journal of Biomed. Inform. 39: 34-42

Wiens, J.J., and D.S. Moen. 2008. Missing data and the accuracy of Bayesian phylogenetics. J. Sys. Evol. 46 (3): 307-314.

Wright, C. H. 1913. Strelitzia Aiton. p. 316 - 319. In: W.T. Thiselton-Dyer (ed.). Flora capensis. Volume 5: 3. Lovell, Reeve and Co. LTD, London.

Zurawski, G. and M. T. Clegg. 1987. Evolution of higher-plant chloroplast DNAencoded genes: Implications for structure function and phylogenetic studies. Ann. Rev. Plant Phys. 38: 391-418. 
Table 5.1. Species sampled and taxonomic affiliations.

Species
Musa acuminata
Heliconia pendula
Orchidantha fimbriata
Orchidantha siamensis
Ravenala madagascariensis
Phenakospermum guyannense
Strelitzia nicolai
Strelitzia reginae
Strelitzia juncea
Strelitzia alba
Strelitzia caudata

Species

Musa acuminata

Orchidantha fimbriata

Orchidantha siamensis

Ravenala madagascariensis

Phenakospermum guyannense

Strelitzia reginae

Strelitzia juncea

Strelitzia caudata

$\begin{array}{cc}\text { Accession Number } & \text { Source } \\ 02075 & \text { Smithsonian } \\ 94650 & \text { Smithsonian } \\ 2003-1178 \mathrm{~A} & \text { Fairchild } \\ 94843 & \text { Smithsonian } \\ \text { P.1395 H } & \text { Fairchild } \\ 1994-768 & \text { Smithsonian } \\ 77117 \mathrm{~A} & \text { Fairchild } \\ 74529 \mathrm{~A} & \text { Fairchild } \\ 2002-0688-\mathrm{A} & \text { Fairchild } \\ \text { K19A } & \text { Chetty } \\ \text { K01A } & \text { Chetty }\end{array}$

Table 5.2. Data on individual regions. ${ }^{*}=$ parsimony informative characters.

\begin{tabular}{|c|c|c|c|c|c|c|}
\hline locus & $\begin{array}{l}\text { accessions } \\
\text { sequenced }\end{array}$ & compartment & $\begin{array}{l}\text { length } \\
\text { (bp) }\end{array}$ & var. sites & $\%$ var. & $\mathrm{PICs}^{*}$ \\
\hline $\begin{array}{l}\text { matK -5'trnK } \\
\text { intron }\end{array}$ & 2 & chloroplast & 767 & 79 & $10.30 \%$ & 45 \\
\hline matK-psbA & 1 & chloroplast & 844 & 73 & $8.65 \%$ & 45 \\
\hline rps16 intron & 2 & chloroplast & 708 & 70 & $9.89 \%$ & 38 \\
\hline$p s b B-p s b H$ & 1 & chloroplast & 560 & 30 & $5.36 \%$ & 19 \\
\hline rp132-trnL & 1 & chloroplast & 1045 & 148 & $14.16 \%$ & 83 \\
\hline rpL16 intron & 2 & chloroplast & 662 & 75 & $11.33 \%$ & 47 \\
\hline rpoB-trnC & 1 & chloroplast & 604 & 53 & $8.77 \%$ & 23 \\
\hline $\operatorname{trn} C-y c f$ & 1 & chloroplast & 670 & 52 & $7.76 \%$ & 27 \\
\hline trnS-trnfM & 1 & chloroplast & 184 & 10 & $5.43 \%$ & 7 \\
\hline $\operatorname{trn} Y$-trnE & 1 & chloroplast & 157 & 7 & $4.46 \%$ & 4 \\
\hline$r b c L$ & 1 & chloroplast & 537 & 26 & $4.84 \%$ & 17 \\
\hline ETS & 2 & nuclear & 574 & 307 & $53.48 \%$ & 141 \\
\hline rpb2 & 2 & nuclear & 1294 & 87 & $6.72 \%$ & 55 \\
\hline
\end{tabular}




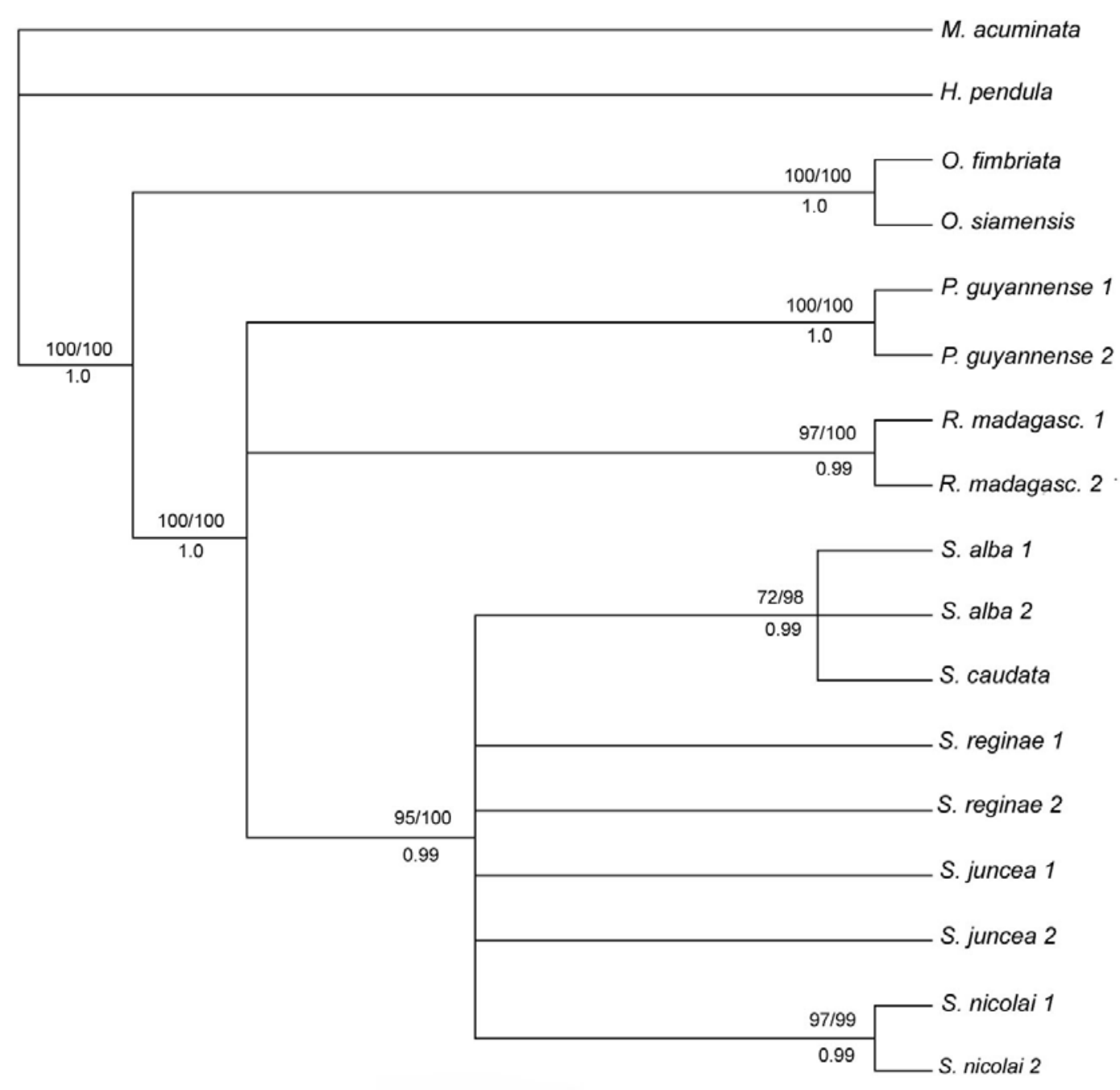

Figure 5.1. Strict consensus tree of all analysis types constructed using eleven chloroplast regions. Support values overlaid on nodes: MPBS (above branch, left), MLBS (above branch, right), and PP (below branch). 


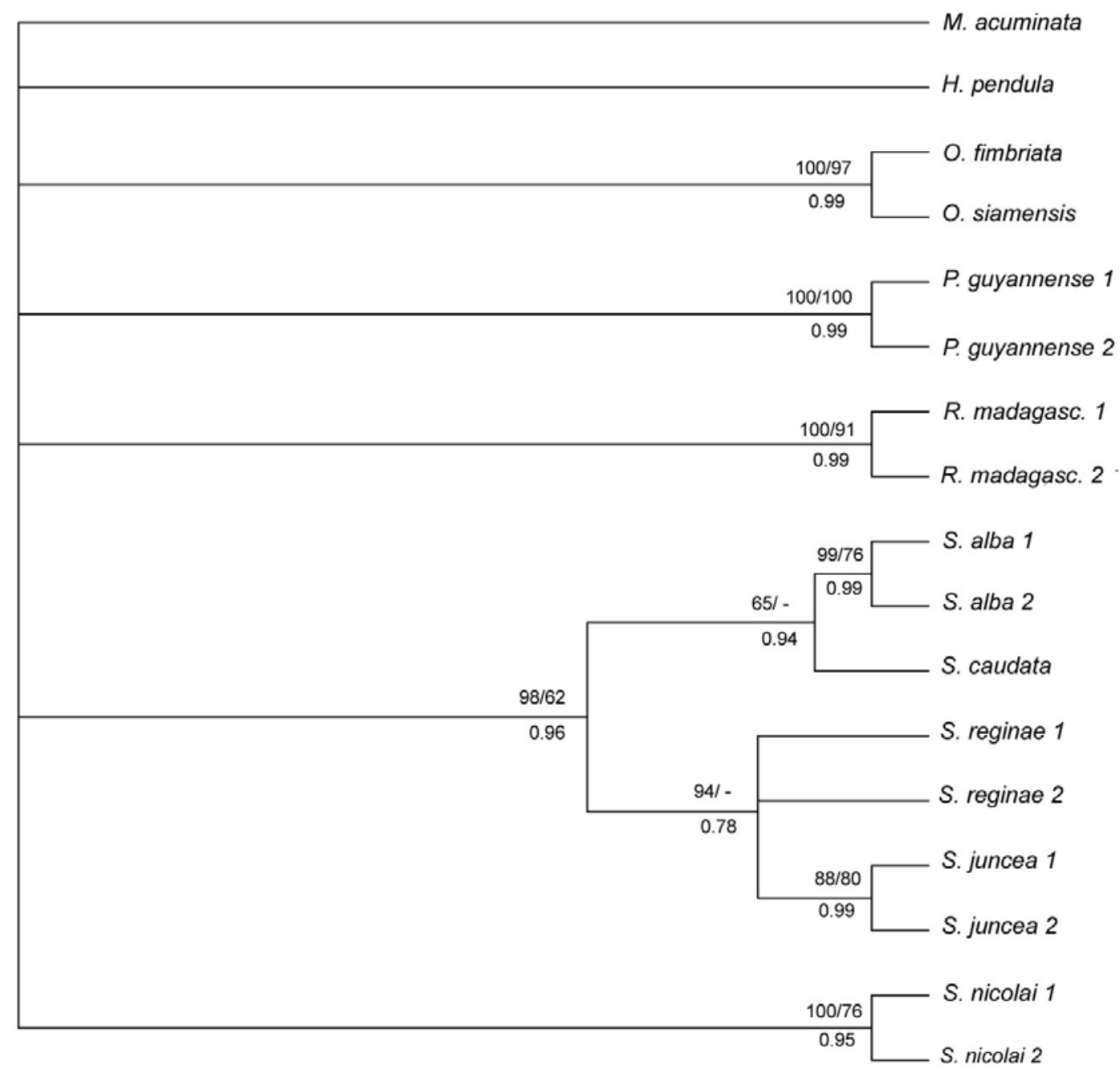

Figure 5.2. Strict consensus tree of all analysis types constructed using ETS and rpb2. Support values overlaid on nodes: MPBS (above branch, left), MLBS (above branch, right), and PP (below branch). "-“ indicates node not present. 


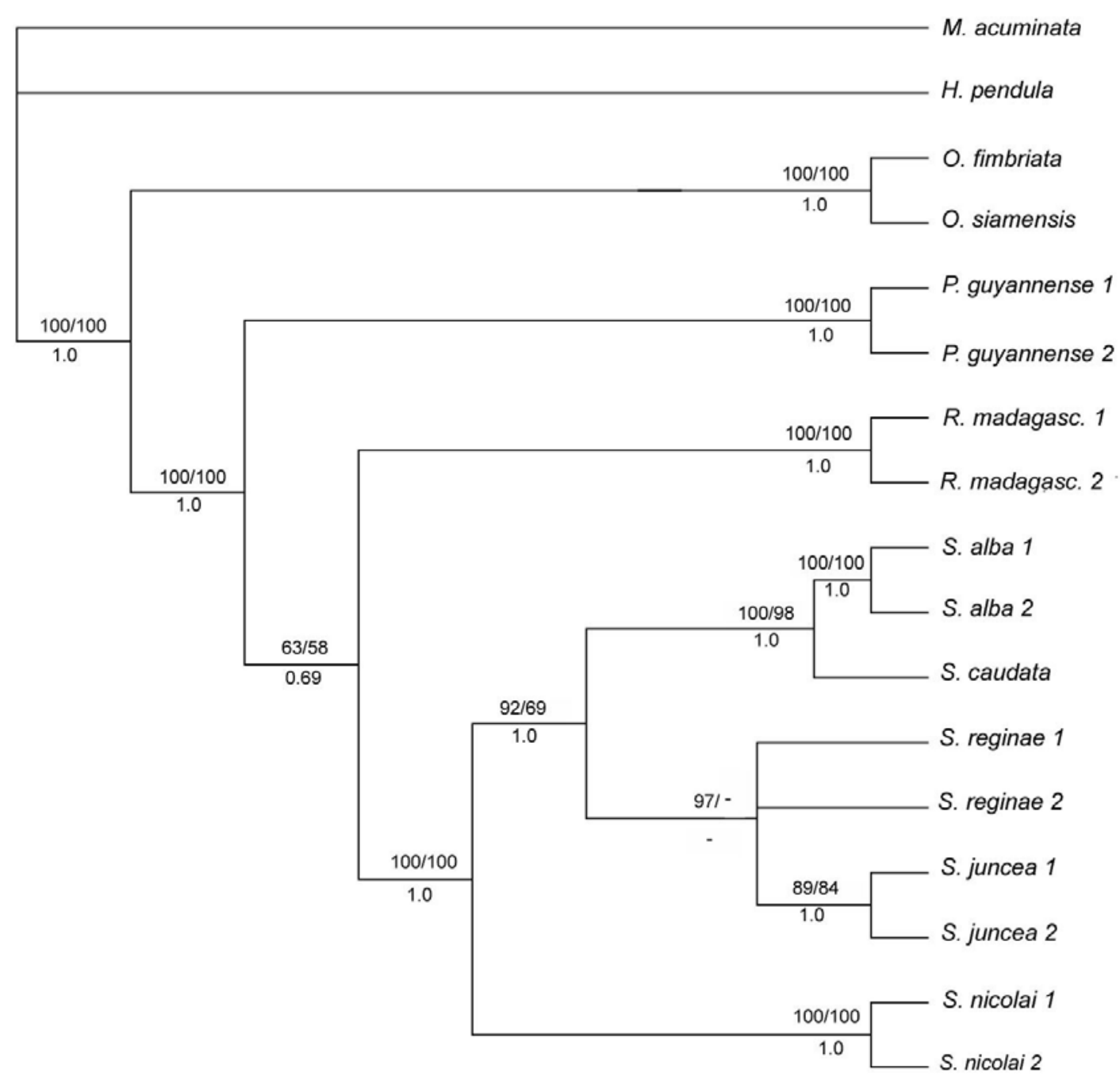

Figure 5.3. Strict consensus tree of all analysis types using combined nuclear and chloroplast regions. Support values overlaid on nodes: MPBS (above branch, left), MLBS (above branch, right), and PP (below branch). "-“ indicates node not present. 
M. acuminata

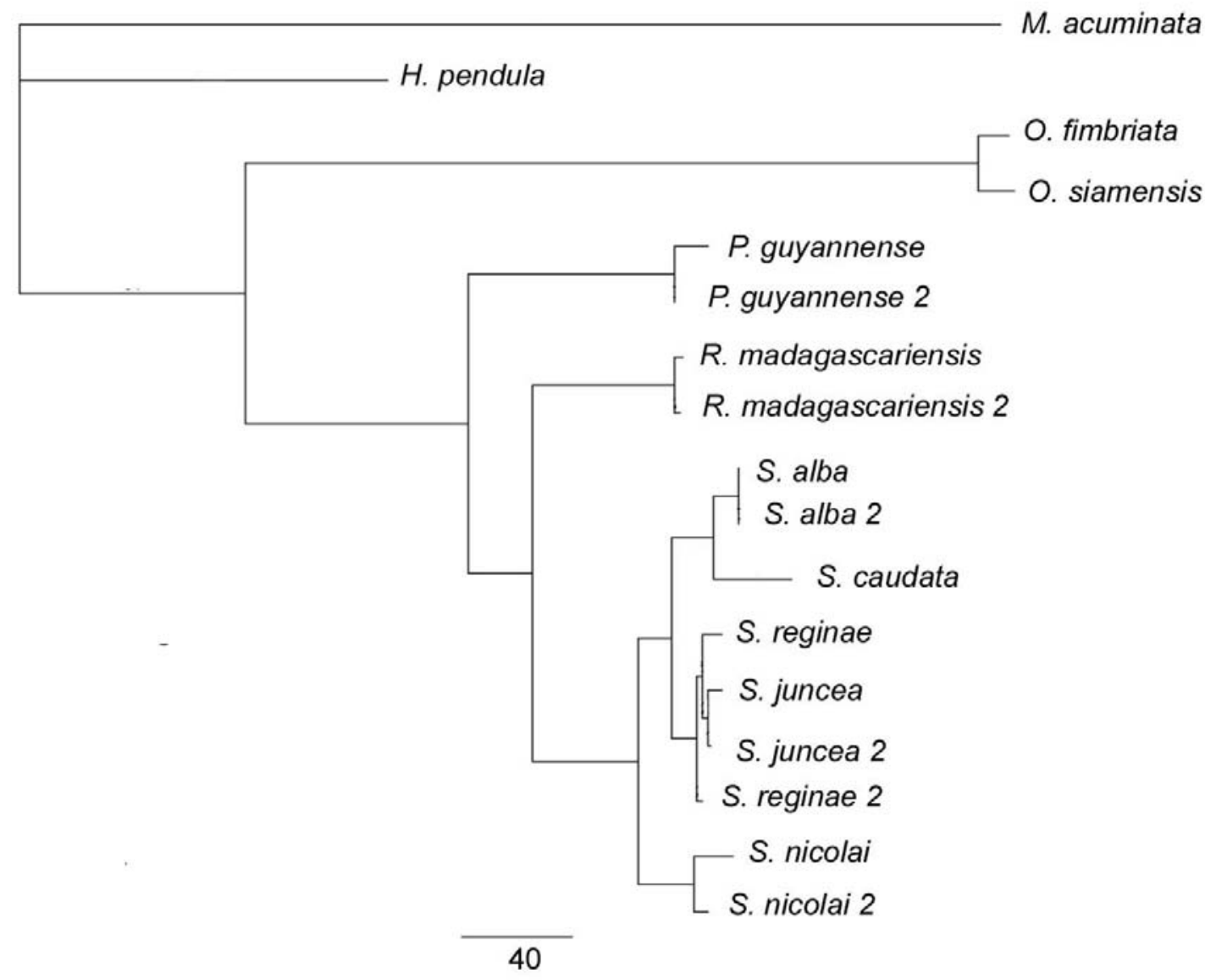

Figure 5.4. One of the two most parsimonious trees resulting from the analysis of the combined nuclear and chloroplast regions. 


\section{SUMMARY}

Although tetrapyrroles are ubiquitous in plants and include vital molecules such as chlorophyll, heme, and phytochromobilin, the presence of bilirubin- IX $\alpha$ in Strelitzia nicolai was the first example of this compound in a plant (Pirone et al., 2009).

Remarkably, the pigment was also present in a diverse sampling of angiosperm species, from the monocot orders Zingiberales and Arecales to the more derived eudicot Myrtales. In most species sampled, bilirubin was present in low levels detectable only by mass spectrometry (Chapter 3). However, in the family Strelitziaceae, pigment concentrations were high in the orange arils of Phenakospermum guyannense, Strelitzia nicolai, and S. reginae, and thus contribute to color. Although bilirubin concentrations in Ravenala madagascariensis were high enough to be detected via high performance liquid chromatography with UV detection (HPLC/UV), the arils of this species are blue, and thus bilirubin does not make a significant contribution to color, at least not one which is observable by the human eye. Our preliminary analyses indicate an unusual blue protein is responsible for the vibrant blue aril color in this species (Pirone, unpublished observations).

Investigation of phylogenetic relationships within the Strelitziaceae indicates that Phenakospermum guyannense is sister to a clade containing $R$. madagascariensis and the Strelitzia species. However, when indels were included in the combined chloroplastnuclear analyses, $R$. madagascariensis and P. guyannense are sister taxa in a clade which is, in turn, sister to the Strelitzia clade. In neither case is the accumulation of bilirubin to produce color a synapomorphy. 


\section{FUTURE STUDIES}

The unexpected discovery of bilirubin in plants provides a basis for additional research in diverse fields. Of high priority will be the determination of the biochemical pathway by which bilirubin- IX $\alpha$ is produced in plants. In animals, biliverdin-IX $\alpha$ is reduced by biliverdin-IX $\alpha$ reductase (BR) to form bilirubin-IX $\alpha$ (Maines and Trakshel, 1993). Conversely, in plants, biliverdin-IX $\alpha$ is converted to a structural isomer of bilirubin, 3Zphytochromobilin, the precursor of the phytochrome chromophore (Tanaka and Tanaka, 2007), by phytochromobilin synthase (Terry et al., 1995; Kohchi et al., 2001). In cyanobacteria and some algae, biliverdin-IX $\alpha$ is reduced by the bilin reductases, to form the phycobilin chromophores (Beale, 1993; Frankenburg et al., 2001). A BR enzyme was identified and cloned in the cyanobacterium Synechocystis (Schluchter and Glazer, 1997), and BR enzymes have also been found in a variety of other bacteria. Whether bilirubin IX- $\alpha$ in plants is formed via a BR enzyme or some other means remains to be determined.

It is also of great interest to establish the botanical function of bilirubin. As a novel source of plant color, bilirubin likely attracts pollinators and dispersers when present in high concentrations. Aril color is preserved for decades under mild conditions; we observed brilliantly colored arils in herbarium sheets up to 45 years old (HUH, Sturrock \#93, 1963; and Natal \#50,000, 1976). Thus, persistence of aril color may contribute to a prolonged period of dispersal. Bilirubin may also provide other benefits to the avian dispersers. Perhaps they use its antioxidant properties (Stocker, 1987), or they may sequester it as feather color. Within the plant, bilirubin may also function as a potent lipid soluble antioxidant, or serve other functions which are unknown 
at this time. Cellular and molecular studies which explore the possible physiological role(s) of bilirubin in plants will be useful.

Further sampling of bilirubin-IX $\alpha$ in plants will be necessary to gain a more complete view of its phylogenetic distribution, and determine whether its role in color production is limited to the Strelitziaceae. The research presented here focused on sampling within the Zingiberales, and included some representatives from the Arecales, Pandanales, Laurales, and Myrtales. Future sampling should include additional members of these and related orders, as well as basal angiosperm taxa from the Magnoliid clade, and derived representatives from the Asterid clade. To determine whether bilirubin-IX $\alpha$ is unique to flowering plants, sampling should also include ferns and gymnosperms (Cycadales, Gingkoales, Pinales, and Gnetales). Dense sampling of species within selected clades will elucidate fine scale phylogenetic patterns of bilirubin production. In addition to fruits and flowers, stems, leaves, and roots should also be sampled. Like many secondary compounds, it is likely that bilirubin production varies with time, developmental stage, or environment. Thus, species should be sampled under diverse conditions to accurately assess the presence or absence of bilirubin within a species. Observations of bilirubin under different conditions may also elucidate production trends which could provide clues regarding its function.

Further sampling should include species which were previously analyzed for pigment (carotenoid or flavonoid) content, as bilirubin-IX $\alpha$ may have been present but undetected due to its unique biochemical properties. Bilirubin is insoluble or minutely soluble in solvents routinely used for the extractions of carotenoids and flavonoids (acetone and hexane, and alcohols, respectively) (Goodwin and Britton, 1998; Harborne 
1998) and thus may have remained in plant tissues after extraction. Also, routine chromatographic procedures may have been insufficient to detect bilirubin. I observed the retention of bilirubin in both C-18 and silica columns under various solvent regimes which would have otherwise eluted molecules with a wide range of polarities.

Furthermore, the chromatographic peaks or bands corresponding to bilirubin may have been obscured by those of other plant pigments (personal observation). Bilirubin-IX $\alpha$ decomposes in heat, light, and change in $\mathrm{pH}$ (Lightner, 1982); therefore degradation may also occur during handling and chromatography and further preclude its detection.

The unique biochemical and chromatographic properties of bilirubin-IX $\alpha$ are likely attributable, at least in part, to conformational changes in the molecule. BilirubinIX $\alpha$ is a linear tetrapyrrole, but under most conditions folds in on itself to create a "ridgetile" conformation. Specifically, two sets of intramolecular hydrogen bonding occur, each involving a carboxylic acid, a pyrrole-imino hydrogen, and a terminal lactam system (Bonnett et al., 1978). This conformation renders the molecule more nonpolar than its linear form and thus interacts differently with its environment.

Future analyses which follow protocols designed specifically for the detection of bilirubin-IX $\alpha$ will result in the successful acquisition of data and lead to a more complete understanding of the evolutionary history of this unusual molecule in plants.

\section{LITERATURE CITED}

Beale, S. I. 1993. Biosynthesis of phycobilins. Chem. Rev. 93: 785-802.

Bonnett, R., J.E. Davies, M.B. Hursthouse, and G.M. Sheldrick. 1978. The structure of bilirubin. Proc. Roy. Soc. B 202: 249-268. 
Frankenberg, N., K. Mukougawa, T. Kohchi, and J. C. Lagarias. 2001. Functional Genomic analysis of the HY2 Family of ferredoxin-dependent bilin reductases from oxygenic photosynthetic organisms. Plant Cell 13, 965-978.

Goodwin, T. and G. Britton. 1988. Distribution and analysis of carotenoids. p. 61-127 In: T.W. Goodwin (ed.) Plant Pigments. Academic Press, San Diego, CA.

Harborne, J.B. 1988. The flavonoids: recent advances. p. 299-345 In: T.W. Goodwin (ed.) Plant Pigments. Academic Press, San Diego, CA.

Kohchi, T., K. Mukougawa, N. Frankenberg, M. Masuda, A. Yokota, and J.C. Lagarias. 2001.The Arabidopsis HY2 gene encodes phytochromobilin synthase, a ferredoxindependent biliverdin reductase. Plant Cell 13: 425-436.

Lightner, D. A. 1982. Structure, photochemistry and organic chemistry of bilirubin. p. 75-123. In: Heirwegh, K. P. M. \& Brown, S. B. (eds). Bilirubin. vol. 1, Chemistry. CRC Press, Boca Raton, FL.

Maines, M.D. and G.M.Trakshel. 1993. Purification and characterization of human biliverdin reductase. Arch. Biochem. Biophys. 300: 320-326.

Pirone, C. L., J.M.E. Quirke, H. Priestap, and D.W. Lee. 2009. Animal pigment bilirubin discovered in plants. J. Am. Chem. Soc. 131: 2830.

Schluchter, W.M. and A.N. Glazer. 1997. Characterization of cyanobacterial biliverdin reductase. J. Biol. Chem. 272: 13562-13569.

Stocker, R., Y. Yamamoto, A. F. McDonagh, A. N. Glazer, and B.N. Ames. 1987. Bilirubin is an antioxidant of possible physiologic importance. Science 235: 1043-1046.

Tanaka R. and A. Tanaka. 2007. Tetrapyrrole biosynthesis in higher plants. Ann. Rev. Plant Biol. 58: 321-346.

Terry, M. J., M.T. McDowell, and C. Lagarias. 1995. (3Z)- and (3E)-Phytochromobilin are intermediates in the biosynthesis of the phytochrome chromophore. J. Biol. Chem. 270: 11111-11119. 
VITA

\section{CARY LUNSFORD PIRONE}

September 9, 1978

1997- 2000

2000

2002

2004, 2008-9
Born, Baltimore, Maryland

Research Assistant

University of Maryland

College Park, Maryland

B.S., Biology, High Honors

University of Maryland

College Park, Maryland

Research Assistant

Botanical Gardens

Rio de Janeiro, Brazil

Teaching Assistant

Florida International University

Miami, Florida

\section{PUBLICATIONS AND PRESENTATIONS}

Pirone C., Quirke J.M., Johnson, J.V., Priestap H.A., and D.W. Lee. 2010. The Animal Pigment Bilirubin identified in Strelitzia reginae, the Bird of Paradise Flower. Hort. Sci. 45: $1411-1415$.

Pirone C., Quirke J.M., Priestap H.A., and D.W. Lee. 2009. Animal Pigment Bilirubin Discovered in Plants. J. Am. Chem. Soc. 131: 2830.

(Featured in Nature Research Highlights, C\&E News, Science News).

Pirone, C.L., Alexander, L.C., and W.O. Lamp. 2005. Patterns of Starch Accumulation in Alfalfa Subsequent to Potato Leafhopper (Homoptera: Cicadellidae) Injury. Environ. Ent. 34 (1): 199-204.

Pirone, C.L., Johnson, J.V., Quirke, M., Priestap, H. and D.W. Lee. 2010. An Amazing Story of Pigment Chemistry in the Strelitziaceae. Botanical Society of America Annual Meeting Providence, RI.

Pirone, C.L., Quirke, M., Priestap, H. and D.W. Lee. 2008. Animal Pigment Bilirubin in Plants. Botanical Society of America Annual Meeting, Vancouver, BC. 
Pirone, C.L., Kress, W.K., Kim, L., and D. W. Lee. 2007. Pigments in the Strelitziaceae Poster, Botanical Society of America Annual Meeting, Chicago, IL.

Pirone, C.L., Kress, W.K., Kim, L., and D. W. Lee. 2006. Aril Structure and Pigments in the Strelitziaceae. Botanical Society of America Annual Meeting. Washington, D.C.

Pirone, C.L., Kress, W.K., Kim, L., and D. W. Lee. 2006. A novel blue protein pigment complex in Ravenala madagascariensis (Strelitziaceae). Plant Biologists of South Florida, Fairchild Tropical Garden, FL. 